\title{
A review of the energy storage aspects of chemical elements for lithium-ion based batteries
}

\author{
Tariq Bashir ${ }^{1}$, Sara Adeeba Ismail ${ }^{1}$, Yuheng Song ${ }^{2}$, Rana Muhammad Irfan ${ }^{1}$, Shiqi Yang ${ }^{1}$, Shaowen Zhou ${ }^{1}$, \\ Jianqing Zhao' ${ }^{1}$, Lijun Gao'
}

${ }^{1}$ College of Energy, Soochow Institute for Energy and Materials Innovations, Soochow University, Suzhou 215006, Jiangsu, China.
${ }^{2}$ Materials and Nanosciences, University of Waterloo, Ontario N2L 3G1, Canada.

Correspondence to: Prof./Dr. Jianqing Zhao, College of Energy, Soochow Institute for Energy and Materials Innovations, Soochow University, 1 Shizi Street, Suzhou 215006, Jiangsu, China. E-mail: jqzhao@suda.edu.cn; Prof./Dr. Lijun Gao, College of Energy, Soochow Institute for Energy and Materials Innovations, Soochow University, 1 Shizi Street, Suzhou 215006, Jiangsu, China. E-mail: gaolijun@suda.edu.cn

How to cite this article: Bashir T, Ismail SA, Song Y, Irfan RM, Yang S, Zhou S, Zhao J, Gao L. A review of the energy storage aspects of chemical elements for lithium-ion based batteries. Energy Mater 2021;1:100019.

https://dx.doi.org/10.20517/energymater.2021.20

Received: 19 Oct 2021 First Decision: 24 Nov 2021 Revised: 13 Dec 2021 Accepted: 17 Dec 2021 Published: 31 Dec 2021

Academic Editors: Yuping Wu, Bin Wang Copy Editor: Xi-Jun Chen Production Editor: Xi-Jun Chen

\begin{abstract}
Energy storage devices such as batteries hold great importance for society, owing to their high energy density, environmental benignity and low cost. However, critical issues related to their performance and safety still need to be resolved. The periodic table of elements is pivotal to chemistry, physics, biology and engineering and represents a remarkable scientific breakthrough that sheds light on the fundamental laws of nature. Here, we provide an overview of the role of the most prominent elements, including s-block, p-block, transition and inner-transition metals, as electrode materials for lithium-ion battery systems regarding their perspective applications and fundamental properties. We also outline hybrid materials, such as MXenes, transition metal oxides, alloys and graphene oxide. Finally, the challenges and prospects of each element and their derivatives and hybrids for future battery systems are discussed, which may provide guidance towards green, low-cost, versatile and sustainable energy storage devices.
\end{abstract}

Keywords: Lithium-ion based batteries, specific capacity, cathode materials, anode materials 


\section{INTRODUCTION}

Energy storage is critical to our everyday lives and is one of the most important solutions for addressing the current energy crisis. It was announced by the general assembly of the United Nations that 2019 would be the international year of the periodic table to highlight its importance as one of the most influential discoveries in modern science. The nature and periodic behavior of microscale matter was extensively investigated and confirmed throughout the 19th and early 20th centuries. This activity led to insights into the predictable periodic behavior of the quantified atomic building blocks, as well as their chemical combinations to produce many stoichiometric molecular structures with many new properties. These efforts proceeded to the acceptance of Mendeleev's periodic table in 1867. Similar periodic behavior was observed at the subatomic level. An extension of this similar periodic paradigm to more complex hierarchical blocks beyond atoms (i.e., the nanoscale) has also been proposed ${ }^{[1]}$.

The increase in atomic number leads to an increase in atomic radius compression and ionization potential across the periods of the periodic table. Therefore, p-block elements (e.g., B, C and N) play a crucial role in forming strong covalent bonds with most of the strongly electronegative atoms, like $\mathrm{O}$ and $\mathrm{F}$. Electrons in the $p$ subshell form conjugated $\pi$-bonds, in addition to $\sigma$-bonds, and this ability leads to a large number of inorganic polymers. Therefore, $\mathrm{B}, \mathrm{C}$ and $\mathrm{N}$ can form a variety of one-dimensional (1D), two-dimensional $(2 \mathrm{D})$ and three-dimensional (3D) nanomaterials, including fullerenes, graphene and its $\mathrm{BN}$ analogs, nanodiamonds, MXenes and carbon nanotubes. This group is the largest and fastest-growing category of nanomaterials triggered by the nanotechnological revolution and the rapid rise of nanotechnological architecture. Oxygen is also one of the most active oxidants in the surrounding environment and plays a universal role in this group. Oxygen is pivotal to the synthesis of different transition metal oxides (TMOs) and their derived nanoparticles, which can be used as electrode materials in lithium-ion batteries (LIBs). Nanotechnological architectures are used to make supercapacitors, sensors, molecular electronics, fuel cells, batteries and advanced energy devices ${ }^{[2-7]}$.

To achieve high energy density, batteries should be based on cathode and anode active materials with large potential differences, light atomic or molecular weights and the ability to generate high voltages that result in the transformation of a large number of electrons for each active molecule. The highest known theoretical voltage $(6 \mathrm{~V})$ is for $\mathrm{Li} / \mathrm{F}_{2}$, which may be the limiting voltage that an electrochemical cell can reach. At present, the voltage of commercial LIBs has reached more than $4 \mathrm{~V}$ (i.e., Li- $\mathrm{LiMn}_{2} \mathrm{O}_{4}^{[8]}$ and Li- $\mathrm{LiCoO}_{2}$ batteries ${ }^{[9]}$ ), while the voltage of some LIBs under development (such as Li-LiNi $i_{0.5} \mathrm{Mn}_{1.5} \mathrm{O}_{4}$ batteries ${ }^{[10]}$ ) may exceed $5 \mathrm{~V}$. Therefore, increasing the voltage of a battery can be one of the measures to increase its energy density. The energy density of a battery material can be determined as follows:

$$
E D=\frac{n F E^{0}}{\sum M_{i}}
$$

where $E D$ represents the energy density, $n$ is the number of electrons transferred, $F$ is the Faraday constant, $E^{o}$ is the electromotive force and $\Sigma M_{i}$ represents the summation of the formula masses of the active substances.

In addition, most current battery systems are based on various transition metals and their oxides ${ }^{[11]}$; however, their energy density is very low due to their high mass. Therefore, electroactive materials composed of light elements and their derivatives, as well as hybrid materials, can be chosen to achieve greater energy density ${ }^{[12]}$. The properties of the coating materials may match the lithium energy in the 
electrolyte by providing different energy ranges for different lithium sites. Thus, changing the potential of the Li surface can enhance the adsorption of Li from the electrolyte. The nanosized particles of a material undoubtedly contribute to its high discharge rate capability and its rate performance is significantly better than similar ${ }^{[13]}$ or smaller-sized nanoparticles, as reported in the literature ${ }^{[14]}$, which shows that the rate capability can be improved by coating ${ }^{[15-17]}$.

Furthermore, Stevens et al. ${ }^{[18]}$ recently discovered that hard carbon intercalated with $\mathrm{Na}$ has a higher reactivity with non-aqueous electrolytes than $\mathrm{Li}_{\mathrm{x}} \mathrm{C}_{6}$, which has sparked new interest in the stability of electrolytes. The rate capacity can be masked by the limited electron transport across electrodes ${ }^{[1,20]}$. A large amount of carbon decreases the volumetric energy density of the electrode and therefore the highest rates (e.g., 200 and 400 C) can only be tested with a high amount of carbon to enhance the electronic conductivity of the active material. It should be noted that the volumetric energy density is more significant than the gravimetric energy density for many applications, particularly for portable electronic devices and vehicles. In this case, a similar procedure should be applied to balance the performance of the electrodes in asymmetric batteries. Volume capacitance and electrode volume can be used instead of weight capacitance and mass. Volumetric and gravimetric performances are linked by the density of the electrode and are mostly defined by the electrode design and porosity ${ }^{[1,22]}$. It is possible to specify structural characteristics, such as a fine distribution of pore straightness, pore connectivity, availability of redox-active sites and excellent balancing of ion and pore sizes, which are needed for optimum efficiency. A comparison of the energy density for various battery prototypes is presented in Figure 1a. LIBs have higher volumetric energy density than potassium ion batteries, sodium ion batteries, $\mathrm{Ni}-\mathrm{MH}, \mathrm{Ni}-\mathrm{Cd}$ and lead-acid batteries, as shown in Figure $1 b^{[21]}$.

2D materials, like MXenes ${ }^{[11]}$, graphene ${ }^{[23,24]}$, $\operatorname{carbides}^{[25]}$, sulfides (e.g., $\left.\mathrm{MoS}_{2}\right)^{[26]}$ and other dichalcogenides ${ }^{[27]}$, are promising for energy storage applications. The theoretical capacities of $\mathrm{Li}, \mathrm{Na}, \mathrm{Ca}$ and $\mathrm{K}$ calculated for $\mathrm{Ti}_{3} \mathrm{C}_{2} \mathrm{Tx}$ MXenes are 447.8, 351.8, 319.8 and $191.8 \mathrm{mAh} \mathrm{g}^{-1}$, respectively, which are far beyond that of graphite $^{[28]}$. Therefore, $2 \mathrm{D}$ materials are potentially excellent electrode materials for battery applications. An important factor for battery charge and discharge is the diffusion barrier, which allows the battery to discharge and charge at a specific rate. Researchers have calculated the diffusion barriers of $\mathrm{Li}, \mathrm{Na}, \mathrm{K}$ and $\mathrm{Ca}$ in $\mathrm{Ti}_{3} \mathrm{C}_{2}$ monolayers using the nudged elastic band method applied in the Vienna Ab initio Simulation Package to evaluate $2 \mathrm{D} \mathrm{Ti}_{3} \mathrm{C}_{2}$ as a promising high rate performance electrode material ${ }^{[2,30]}$.

In this review, we briefly discuss the types of LIBs, their mechanisms and the electrochemical properties of their electrode materials, such as specific capacity, rate performance, cycling performance and energy density, from the perspective of chemical elements. The mechanisms and long-term cycling stability of LIBs for s-, p-, d- and f-block elements, different transition metals and their oxides are studied in detail to provide appropriate treatment methods and creative remedial measures for energy storage devices with enhanced performance. We also discuss hybrid 2D materials (e.g., MXenes and graphene) and alloys for battery applications. Finally, this review provides insights into the challenges and future prospects of nextgeneration LIBs.

\section{TYPES OF LI-ION BATTERIES}

\section{Li-sulfur batteries}

Sulfur is a potential cathode material for future battery technologies, with an order of magnitude higher theoretical capacity $\left(1675 \mathrm{~mA} \mathrm{~h} \mathrm{~g}^{-1}\right)$ than existing transition metal oxides. It has a larger abundance in the Earth's crust than nickel and cobalt and is also low $\operatorname{cost}^{[31,32]}$. Figure 2 depicts the working principle diagram of a lithium-sulfur battery ${ }^{[33]}$. Despite these considerable benefits, sulfur cathodes face a number of 

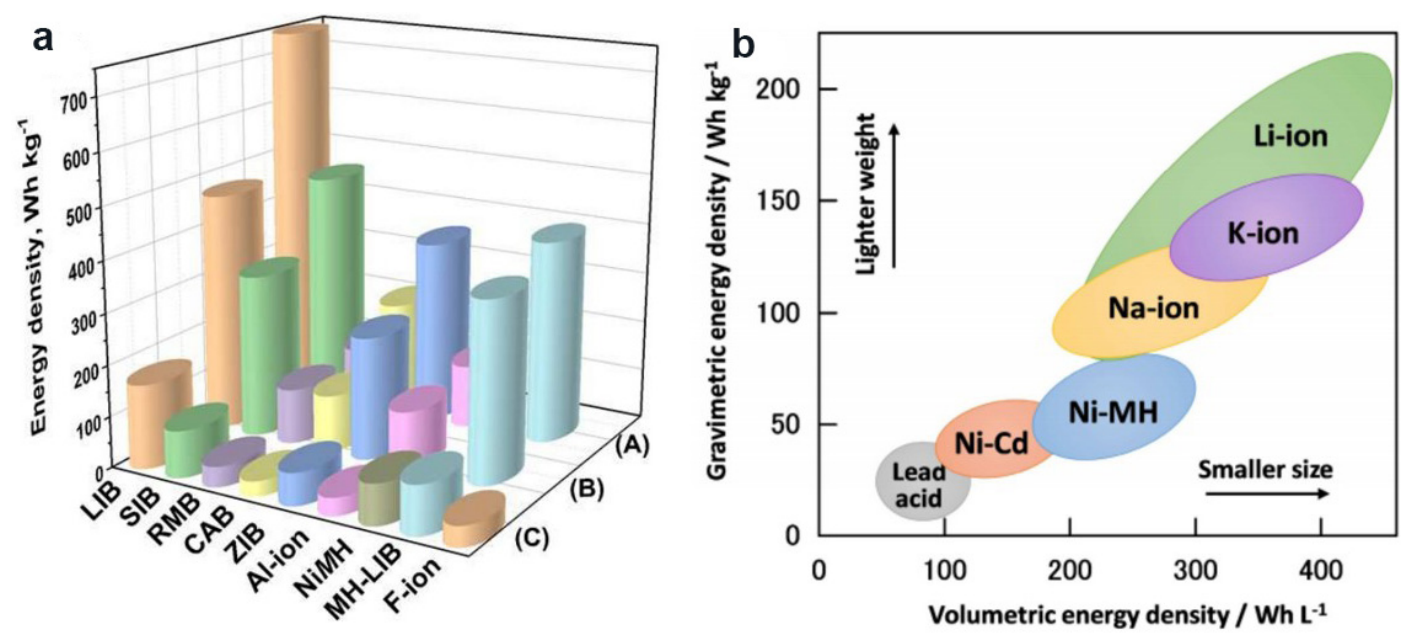

Figure 1. (a) Comparison of energy density for various battery prototypes. Average values are calculated using the available data, where (A) represents cathode, (B) represents both electrodes and (C) represents full cells (LIB normalized). (b) Volumetric and gravimetric energy densities of commercial batteries (LIBs, KIBs, SIBs, Ni-MH, Ni-Cd and lead-acid). Reproduced with permission from Ref. ${ }^{[21]}$ (Copyright 2020, Journal of Alloys and Compounds, Elsevier). LIBs: Lithium-ion batteries; KIBs: potassium ion batteries; SIBs: sodium ion batteries.

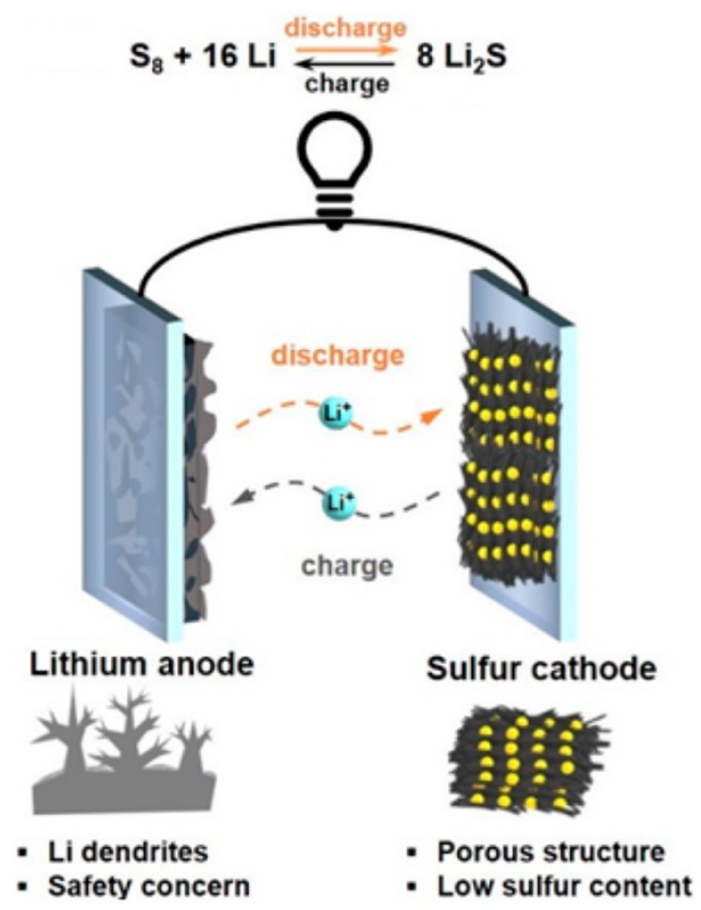

Figure 2. Schematic of the working principles of a Li-S battery. Reproduced with permission from Ref. ${ }^{[33]}$ (Copyright 2020, ACS Energy Letters).

technological challenges that limit their usage. They have a lower conductivity and electrochemical potential $v s$. $\mathrm{Li} / \mathrm{Li}^{+}$. The volume expansion rate of sulfur, like many other conversion electrodes, can reach up to $80 \%$, causing a drop off in the electrode conductivity, pulverization and cracking ${ }^{[34]}$. Furthermore, the evaporation temperature of sulfur-based cathodes is low, resulting in the loss of pure sulfur during vacuum electrode drying $^{[35]}$. Moreover, the intermediate reaction product produced during the charging/discharging process 
( $\mathrm{Li}_{2} \mathrm{~S}_{\mathrm{n}}$ polysulfides) can dissolve in the electrolyte, leading to capacity loss due to the shuttle effect ${ }^{[3,3,3]}$. The polysulfides dissolved in the electrolyte move back to the anode where they are converted to low-order polysulfides, which then migrate back to the cathode, causing reoxidation. Insoluble compounds, like $\mathrm{Li}_{2} \mathrm{~S}$ and $\mathrm{Li}_{2} \mathrm{~S}_{2}$, are produced via the shuttle effect ${ }^{[38]}$. Cañas et al. ${ }^{[39]}$ investigated this mechanism using ex-situ spectroscopic techniques and high-performance liquid chromatography and proposed complex steps for the discharge in a bis(trifluoromethanesulfonyl)imide and tetraethylene glycol dimethyl ether electrolyte system, as described in the below Equations (2-8):

$$
\mathrm{S}_{8(\mathrm{~s})} \leftrightarrow \mathrm{S}_{8(1)}
$$

(30\% initially dissolves)

$$
2 \mathrm{Li}+\mathrm{S}_{8(1)} \leftrightarrow \mathrm{S}_{8}^{2-}+2 \mathrm{Li}^{+}
$$

(70\% of $\mathrm{S}_{8}$ is consumed as the concentration in the solution decreases)

$$
\begin{gathered}
2 \mathrm{Li}+3 / 4 \mathrm{~S}_{8}^{2-} \leftrightarrow \mathrm{S}_{6}^{2-}+2 \mathrm{Li}^{+} \\
2 \mathrm{Li}+2 / 3 \mathrm{~S}_{6}^{2-} \leftrightarrow \mathrm{S}_{4}^{2-}+2 \mathrm{Li}^{+} \\
2 \mathrm{Li}+\mathrm{S}_{4}^{2-} \leftrightarrow 2 \mathrm{~S}_{2}^{2-}+2 \mathrm{Li}^{+} \\
2 \mathrm{Li}+1 / 2 \mathrm{~S}_{2}^{2-} \leftrightarrow 2 \mathrm{~S}^{2-}+2 \mathrm{Li}^{+} \\
2 \mathrm{Li}^{+}+\mathrm{S}^{2-} \leftrightarrow \mathrm{Li}_{2} \mathrm{~S}_{(\mathrm{s})}
\end{gathered}
$$

(at a $60 \%$ depth of discharge, solid $\mathrm{Li}_{2} \mathrm{~S}$ is observed)

The lithium anode is corroded by this polysulfide shuttle, which leads to self-discharge and low Coulombic efficiency ${ }^{[38]}$. Many studies have been conducted in an attempt to overcome these challenges facing Li-S batteries $^{[40]}$. According to Luo et al. ${ }^{[41]}$, oxygen stabilized sulfur in a carbon matrix of Li-S batteries has excellent reversible capacity and long cycling stability. The suppression of polysulfide intermediates caused by sulfur interception in the carbon matrix explains the increase in Li-S battery performance. Another study found that carbonized mesoporous wood fiber may be utilized as the primary material for intercalated sulfur, resulting in a Li-S battery with better cycling stability ${ }^{[41]}$.

\section{Li-air batteries}

The operating concept of a Li- $\mathrm{O}_{2}$ battery can be explained by the redox reaction between oxygen and $\mathrm{Li}$ metal. Abraham et al. ${ }^{[42]}$ used an organic electrolyte for the first time in 1996 for a lithium-air battery. The lithium-air battery has received significant interest as an alternative to LIBs because of its high theoretical energy density $\left(3500 \mathrm{Wh} \mathrm{kg}^{-1}\right)^{[43,44]}$. In $\mathrm{Li}_{-} \mathrm{O}_{2}$ batteries, the cathode is usually a carbon matrix containing a

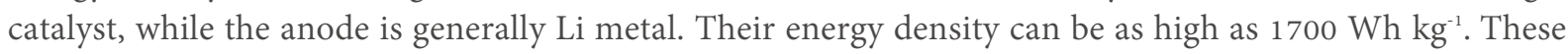


batteries can be classified into four distinct types based on the type of electrolyte used: (1) $\mathrm{Li}-\mathrm{O}_{2}$ water batteries; (2) $\mathrm{Li}-\mathrm{O}_{2}$ aprotic batteries; (3) $\mathrm{Li}-\mathrm{O}_{2}$ all-solid-state batteries; and (4) $\mathrm{Li}-\mathrm{O}_{2}$ hybrid batteries. The aprotic structure of $\mathrm{Li}-\mathrm{O}_{2}$ batteries has received particular attention, since it forms a barrier between the anode and the electrolyte, protecting the lithium metal from the redox interaction with the electrolyte during the charge/discharge process. The $\mathrm{Li}_{-} \mathrm{O}_{2}$ battery has the following redox reactions:

$$
\begin{aligned}
& 2 \mathrm{Li}^{+}+2 \mathrm{e}^{-}+\mathrm{O}_{2} \rightarrow \mathrm{Li}_{2} \mathrm{O}_{2} \\
& \mathrm{Li}_{2} \mathrm{O}_{2} \rightarrow 2 \mathrm{Li}^{+}+2 \mathrm{e}^{-}+\mathrm{O}_{2}
\end{aligned}
$$

$\mathrm{Li}$ is converted into $\mathrm{Li}_{2} \mathrm{O}_{2}$ during discharge. The electromotive force of the battery when configured with a lithium metal anode is $2.9 \mathrm{~V}$ with a high theoretical specific energy density of $3500 \mathrm{Wh} \mathrm{kg}^{-1[45,46]}$. In terms of formal capacity per mass and volume, $\mathrm{Li}_{2} \mathrm{O}_{2}$ is an excellent charge storage medium; however, it is a poor medium for the basic charge storage process. Unlike other $\mathrm{Li}^{+}$storage materials, $\mathrm{Li}^{+}$and $\mathrm{e}^{-}$do not need insertion and extraction through the bulk of $\mathrm{Li}_{2} \mathrm{O}_{2}$ because dissolution and growth occurs on the surface of $\mathrm{Li}_{2} \mathrm{O}_{2}$. This distinct property of $\mathrm{Li}_{2} \mathrm{O}_{2}$ results in significant cycling stability and rate capability. The slow charge transport in these batteries is due to the several orders of magnitude slower ion diffusivity compared to liquids, which results in extremely fast charging transfer ${ }^{[47]}$.

It is possible to synthesize high-power $\mathrm{Li}-\mathrm{O}_{2}$ batteries by bypassing $\mathrm{Li}_{2} \mathrm{O}_{2}$ for the transmission of ions and electrons across the phase, both of which are simple to execute, where only $\mathrm{Li}_{2} \mathrm{O}_{2}$ stores charge, while liquid electrolytes provide facile ion transportation. In contrast, electron transport through liquids is difficult. The second electron transfer can be carried out by the second electron disproportionation or reduction, whether the solution or surface pathway is dominant [Figure $3 \mathrm{~A}$ ]. $\mathrm{O}_{2} / \mathrm{Li}_{2} \mathrm{O}_{2}$ has a standard potential of $2.96 \mathrm{~V}, \mathrm{O}_{2} / \mathrm{O}_{2}-$ has a standard potential of $\sim 2.65 \mathrm{~V}$ and $\mathrm{O}_{2}^{-} / \mathrm{Li}_{2} \mathrm{O}_{2}$ has a standard potential of $\sim 3.3 \mathrm{~V}^{[48]}$. The other is a redox mediator, which is reduced or oxidized and then goes through the electrolyte to oxidize $\mathrm{Li}_{2} \mathrm{O}_{2}$ or reduce $\mathrm{O}_{2}$ in order to restore itself, as shown in Figure 3B. Furthermore, the cost of lithium-oxygen batteries is reduced compared to LIBs due to the simplicity of the active material composites. Aqueous or non-aqueous electrolytes can be used in lithium-air batteries.

The production of $\mathrm{LiOH}$ in aqueous conditions can help avoid air cathode obstruction and protect it from over voltage during discharge. However, because $\mathrm{LiOH}$ cannot be entirely dissolved during charging, it precipitates, resulting in inefficient cycling and lower energy density ${ }^{[32,45}$. To avoid direct contact between $\mathrm{H}_{2} \mathrm{O}$ and the surface of lithium metal, aqueous batteries require a surface protective barrier or a $\mathrm{Li}$ superionic conductive layer (LISICON glass with the composition $\left.\mathrm{Li}_{(1+x+y)} \mathrm{Al}_{\mathrm{x}} \mathrm{Ti}_{2-\mathrm{x}} \mathrm{Siy}_{(3-\mathrm{y})} \mathrm{O}_{12}\right)^{[32]}$. However, the duration of these surface coating treatments is inadequate for preventing lithium dendrite formation ${ }^{[45]}$. To overcome this problem, not only must the breakdown rate of $\mathrm{Li}_{2} \mathrm{O}_{2}$ be enhanced, but also the side reactions of lithium metal must be reduced. Furthermore, using ambient air in the presence of $\mathrm{H}_{2} \mathrm{O}$ vapor, $\mathrm{N}_{2}$ and $\mathrm{CO}_{2}$ may result in a variety of side reactions, as well as poor cycling ${ }^{[32]}$. Although organic electrolyte research has been conducted for several years on current LIB technology, the electrolytes of LIBs cannot be utilized directly in lithium-oxygen batteries due to electrode stability issues. The aprotic electrolyte of a lithiumoxygen battery must be able to stably withstand the active redox process, resulting in reducing oxygen species. To increase the rate of mass transfer towards the cathode, high $\mathrm{O}_{2}$ diffusivity and solubility are required, as well as a high boiling point and low volatility to reduce cathode solvent evaporation ${ }^{[49]}$. Initially, carbonate-based liquid electrolytes, including dimethyl carbonate, vinyl carbonate (EC) and propylene carbonate, were commonly employed in $\mathrm{Li}-\mathrm{O}_{2}$ batteries, although the cycling performance was clearly 
A

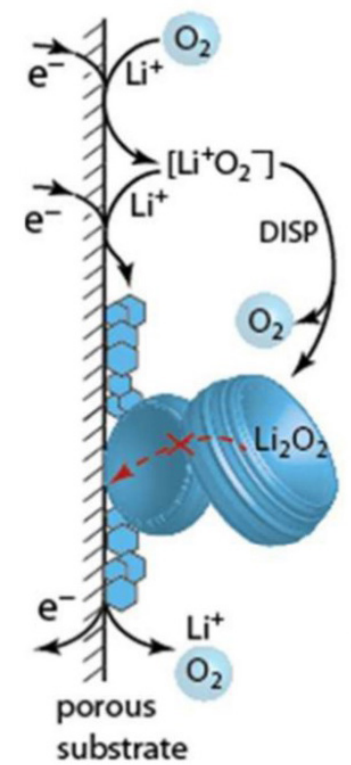

discharge

charge
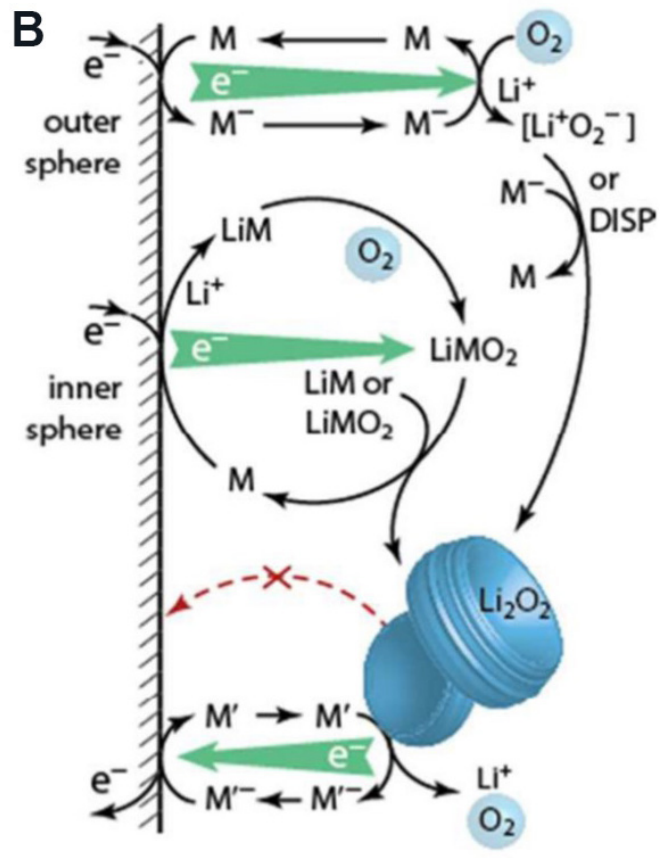

Figure 3. (A) Schematic diagram of reactions in a $\mathrm{Li}_{-} \mathrm{O}_{2}$ cathode $\left(\mathrm{O}_{2}+2 \mathrm{Li}^{+}+2 \mathrm{e}^{-} \leftrightarrow \mathrm{Li}_{2} \mathrm{O}_{2}\right)$ during charge/discharge process in a typical electrolyte. $\mathrm{Li}_{2} \mathrm{O}_{2}$, an insulating and insoluble discharge product, develops on the surface of the conducting porous substrate and suppresses the electron transport. (B) The mediators $M$ and $M^{\prime}$ mediate electron/hole transport. In an inner sphere process, the reduction mediator $\mathrm{M}$ can transfer electrons to $\mathrm{O}_{2}$ via an $\mathrm{O}_{2}$-binding transition state or in an outer sphere process via an $\mathrm{O}_{2}$-binding transition state. Reproduced with permission from Ref. ${ }^{[48]}$ (Copyright 2017, Royal Society of Chemistry).

inadequate ${ }^{[50,51]}$. In Li- $\mathrm{O}_{2}$ batteries, sulfur-based solvents, such as ether-based electrolytes, sulfolane and dimethyl sulfoxide (DMSO), are also commonly employed. DMSO has low acidity, a high boiling point $\left(189^{\circ} \mathrm{C}\right)$ and a high oxidation potential $(4.8 \mathrm{~V})^{[52]}$. Lithium-air batteries with ether electrolytes and DMSO are thought to be extremely reversible in performance.

\section{Organic electrode batteries}

Organic materials have been proposed as electrodes for LIBs in recent decades, although they have received less attention than metal-based electrodes ${ }^{[53]}$. Organic electrode batteries benefit from good sustainability, eco-friendly features, flexibility in materials design, lightweight elements (e.g., C, H, N and O) and abundant resources $^{[53,54]}$. In the last two decades, many studies have been carried out for various types of organic materials, carbonyl compounds and organic free radicals (or free radical polymers), particularly organic sulfur and imino groups $(\mathrm{C}=\mathrm{N})^{[55]}$. Because of their strong redox potential and activity and abundance, carbonyl compounds have received significant interest. When carbonyl group conjugation is added, the redox activity with reversible electron transfer can be expanded to a multiple electron reaction, resulting in the synthesis of multivalent anions. Liang et al. ${ }^{[54]}$ described the use of quinone compounds as battery cathodes for secondary batteries in 1972. Another organic material, chloroaniline, showed a capacity retention rate of $95 \%$ at $0.5 \mathrm{C}$ over 50 cycles $^{[56]}$.

Nevertheless, organic electrode batteries have a number of drawbacks, including solubility in the electrolyte, low energy density, poor conductivity and slow reaction kinetics ${ }^{[53,54,57]}$. Adjusting the electrode level, adding conductive materials (such as carbon) and modifying the structure with conductive materials (such as graphene, carbon nanotubes and nanofibers and super-P) are all typical strategies for overcoming these 
issues. Luo et al. ${ }^{[55]}$ demonstrated that azo $(\mathrm{N}=\mathrm{N})$ functional groups can be used as alternate organic electrode materials (OEMs) for addressing these issues. More than two functional groups are required for imino or carbonyl groups, whereas azo electrodes only require one functional group, thereby simplifying the chemical structure. Azo-based batteries offer high rate performance and strong cycling stability ${ }^{[55]}$. Another approach that can potentially overcome the fundamental issues of organic electrodes in LIBs is utilizing self-assembled organic nanowires using $\mathrm{C}_{5} \mathrm{Na}_{2} \mathrm{O}_{5}$ (croconic acid disodium salt) ${ }^{[5,58]}$. Two benzodipteridine derivatives, $\mathrm{BF}-\mathrm{H}_{2}$ and $\mathrm{BF}-\mathrm{Me}_{2}$, were reported as high-capacity electrodes for LIBs by Cariello et al. ${ }^{[59]}$. These portions enable each molecule to bind numerous lithium ions and maintain low solubility in the supporting electrolyte, which is often an exclusion issue for organic electrodes. As indicated in Figure 4A-D, BF- $\mathrm{H}_{2}$ and BF- $\mathrm{Me}_{2}$ have Coulombic efficiencies of $\sim 100 \%$ and $\sim 96 \%$, respectively, over 100 cycles at a $0.1 \mathrm{C}$ rate. Different reaction processes involve a variety of structural approaches. Carbonyl molecules have a number of challenges, one of which is their high solubility in organic electrolytes, which can be reduced by salt formation.

In OEMs, two or more carboxylic acid groups are linked to conjugated structures (i.e., benzene rings). The two $-\mathrm{C}=\mathrm{O}$ in the lithium terephthalate carboxyl group react reversibly with two $\mathrm{Li}^{+}$and two $\mathrm{e}^{-}$during the lithiation and delithiation process [Figure 5A]. The air-stabilized lithium cathode material, which is based on the main chain of 1,4-benzenedisulfonate, contains two sulfonate groups, which improves the reaction potential to $3.25 \mathrm{~V}$ and maintains a reversible capacity of $100 \mathrm{mAh} \mathrm{g}^{-1}$ over 50 cycles at $\mathrm{C} / 20$ [Figure $\left.5 \mathrm{~B}\right]^{[60,61]}$. The anthracene-based organic disulfide cathode material can reversibly react with six $\mathrm{Li}^{+}$and six $\mathrm{e}^{-}$, resulting in the regeneration and dissociation of disulfide bonds. However, its low conductivity and high solubility are still challenging [Figure $5 \mathrm{C}$ ]. The electrochemically active center in the OEMs of LIBs was found to be the azo group ${ }^{[62]}$. The double bond in the azo group of aromatic azo compounds is transformed to a single bond in the process of lithiation and then converted back to a double bond in the delithiation process. Each $\mathrm{N}$ atom reacts with one $\mathrm{Li}^{+}$and one $\mathrm{e}^{-}$in the lithiation and delithiation reaction [Figure 5D].

In the imine group $(\mathrm{C}=\mathrm{N})$, there is a reversible electrochemical reaction between $\mathrm{Li}^{+}$and nitrogen atoms. Peng et al. ${ }^{[63]}$ reported that $\pi$-conjugated heteroaromatic quinoxaline molecules (3Q) represent an example of an imine-based organic cathode material. The reaction can be divided into two steps, as shown in Figure 5E. One $\mathrm{Li}^{+}$reacts with two $\mathrm{N}$ atoms in the imine group in the first step. In the second step, each $\mathrm{Li}^{+}$ further reacts with two $\mathrm{N}$ atoms, resulting in a N-Li-N structure. In $3 \mathrm{Q}$, each of the six imine groups reacts with six $\mathrm{e}^{-}$and six $\mathrm{Li}^{+}$to yield a reversible capacity of $395 \mathrm{mAh} \mathrm{g}^{-1}$ over 10000 cycles. The super-lithiation reaction is based on the conjugated hydrocarbon, such as in polyacetylene, where the carbon-carbon bond in the unsaturated hydrocarbons is converted to a saturated carbon-carbon bond during discharge ${ }^{[64]}$. During the discharge process, the unsaturated carbon bond in the OEMs is transferred to a saturated carbon bond and each carbon atom receives one $\mathrm{e}^{-}$and one $\mathrm{Li}^{+}$. The reaction process of the unsaturated carbonbased organic anodes and carbonyl is shown in Figure 5F. The carbonyl group in naphthalenetetracarboxylic dianhydride first reacts with $\mathrm{Li}^{+}$and $\mathrm{e}^{-}$and then the unsaturated carbon-carbon bond combines with $\mathrm{Li}^{+}$and $\mathrm{e}^{-}$at a low reaction potential, resulting in an ultra-high capacity of $1000 \mathrm{mAh} \mathrm{g}^{-1}$.

\section{Solid-state batteries}

In the development of solid-state batteries, the solid electrolyte is a critical component. Thin-film solid electrolytes and solid polymer electrolytes are the two main types of solid electrolytes. Inorganic solid electrolytes, such as garnets (e.g., $\left.\mathrm{Li}_{7} \mathrm{La}_{3} \mathrm{Zr}_{2} \mathrm{O}_{12}\right)^{[65]}$, NASICONs [e.g., $\operatorname{LiZr}_{2}\left(\mathrm{PO}_{4}\right)_{3}, \mathrm{LiGe}_{2}\left(\mathrm{PO}_{4}\right)_{3}$ and $\mathrm{LiTi}_{2}\left(\mathrm{PO}_{4}\right)_{3}$ ], sulfides (e.g., $\mathrm{Li}_{2} \mathrm{~S}-\mathrm{SiS}_{2}$ and $\mathrm{Li}_{2} \mathrm{~S}-\mathrm{P}_{2} \mathrm{~S}_{5}$ based ${ }^{[66]}$ and perovskites $\left(\mathrm{Li}_{3 \mathrm{X}} \mathrm{La}_{2 / 3-\mathrm{x}} \mathrm{TiO}_{3}\right)^{[67,68]}$, are the most widely studied inorganic solid electrolytes. Oxide materials, such as NASICONs, garnets and perovskites, have drawn much interest, since they provide many benefits for all-solid-state batteries, such as mechanical 
A
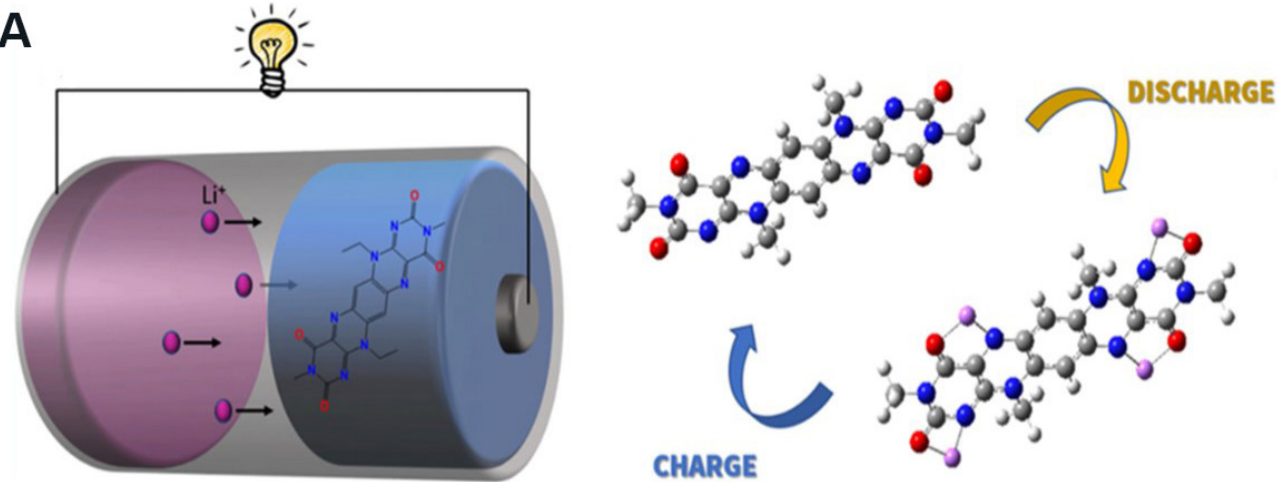

B
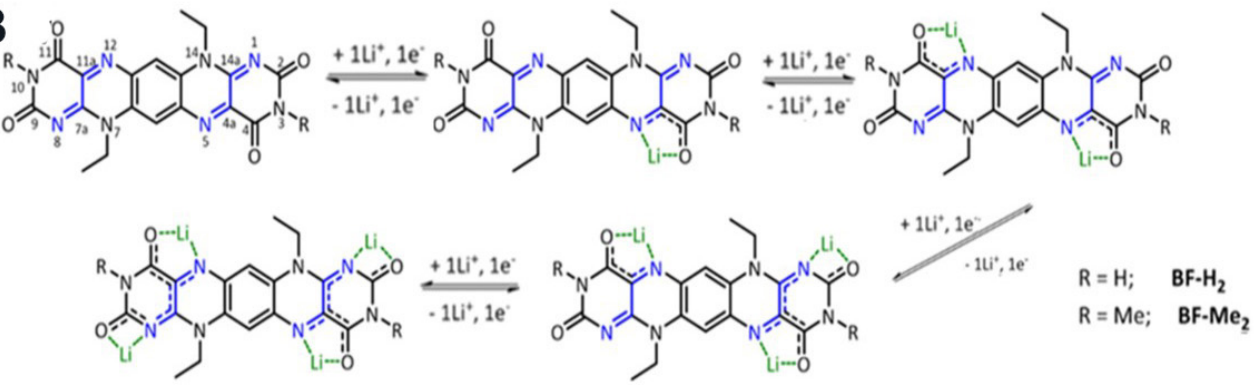

C

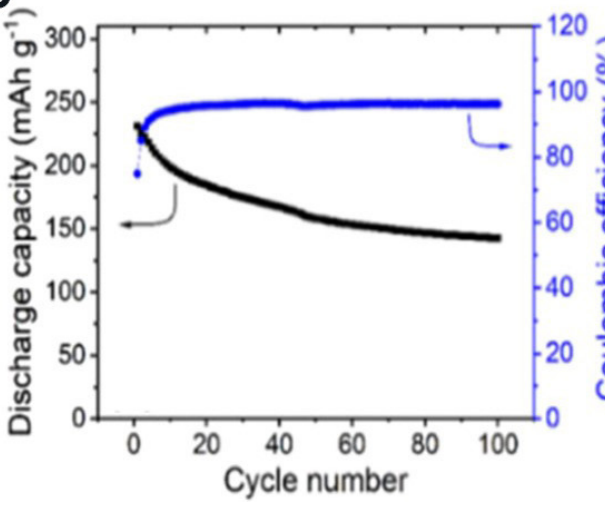

D

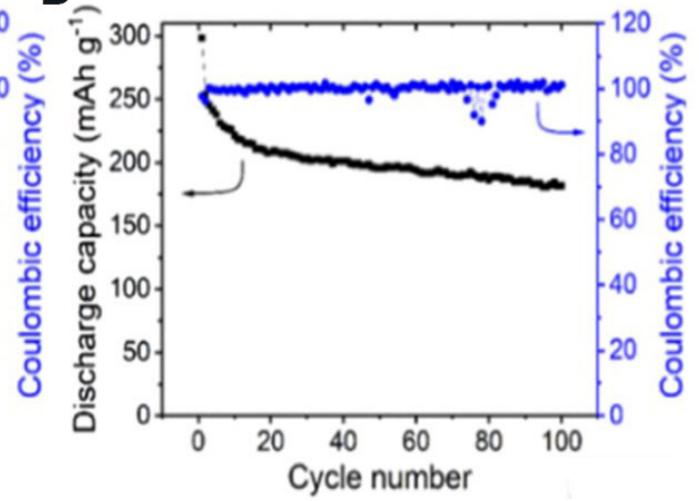

Figure 4. (A) Schematic illustration of organic electrode. (B) Potential reaction procedure and structure of benzo-dipteridine derivatives $\mathrm{BF}-\mathrm{H}_{2}$ and $\mathrm{BF}-\mathrm{Me}_{2}$ with lithium. Cycling and Coulombic efficiency of (C) BF-Me $\mathrm{Me}_{2}$ and (D) BF- $\mathrm{H}_{2}$ at a $0.1 \mathrm{C}$ rate in an ether-based electrolyte. Reproduced with permission from Ref. ${ }^{[59]}$ (Copyright 2020, American Chemical Society).

characteristics, chemical stability, conductivity $\left(10^{-4}\right.$ to $\left.10^{-3} \mathrm{~S} \mathrm{~cm}^{-1}\right)$ and safety. In contrast, sulfide solid electrolyte have high conductivity $\left(10^{-2} \mathrm{~S} \mathrm{~cm}^{-1}\right)$, low grain boundary resistance, excellent flexibility and high mechanical characteristics ${ }^{[69]}$. However, sulfide solid electrolytes are limited by their high reactivity with metal oxides and their instability when exposed to moisture, which can result in $\mathrm{H}_{2} \mathrm{~S}$ gas evolution ${ }^{[6,70]}$.

Another potential solid electrolyte type for solid-state batteries is the solid polymer electrolyte. Poly(methyl methacrylate $)^{[71]}$, polyethylene oxide (PEO $)^{[72]}$, poly(acrylonitrile $)^{[73]}$ and polyvinylidene fluoride ${ }^{[71,74]}$ are commonly used as polymer host materials in composite polymer electrolytes. However, these materials have considerable drawbacks, such as reduced electrode compatibility and oxidation stability. Therefore, improving the conductivity of solid electrolytes over a long period remains a major challenge and there still remains the question of whether amorphous or crystalline structures boost ionic conductivity. With lithium metal, polymers have the benefits of high stability, low shear modulus and superior flexibility, but they also 
A LiO

B<smiles>COS(=O)(=O)C1=CC(=O)C(C(=O)O)=CC1=O</smiles>

C

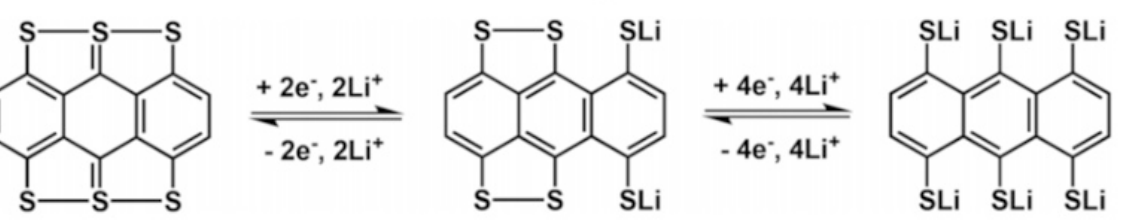

\section{D}

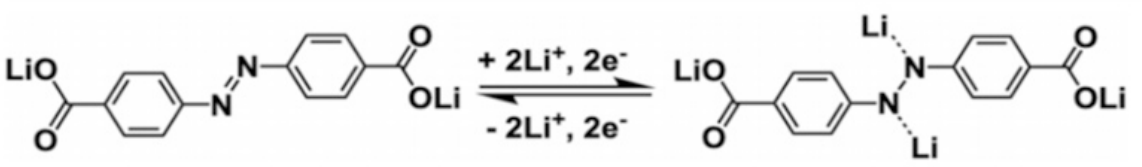

E

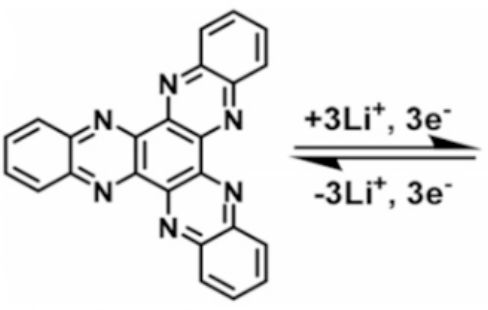

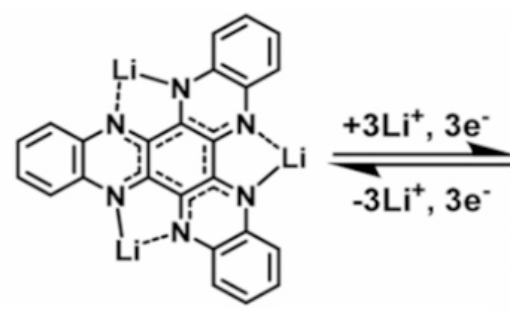

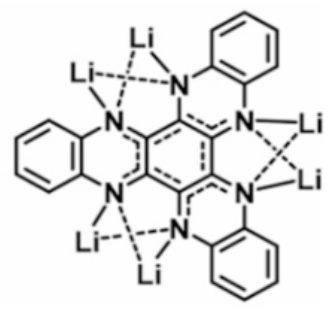

$\mathbf{F}$

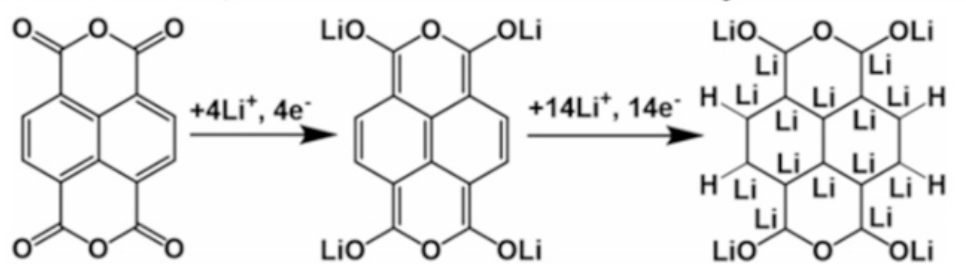

Figure 5. Reaction mechanisms of (A) a carboxylate-based organic anode, (B) an air stable quinone-based organic cathode, (C) an organodisulfide cathode material based on anthracene, (D) an azo compound, azobenzene-4,4'-dicarboxylic acid lithium salt, (E) lithiated structures of $\pi$-conjugated quinoxaline-based heteroaromatic molecules ( $3 Q$ ) during the discharge process and (F) a carbonyland unsaturated carbon-carbon group-based organic anode with carbon-carbon bonds in naphthalenetetracarboxylic dianhydride. Reproduced with permission from Ref. ${ }^{[61]}$ (Copyright 2020, American Chemical Society).

have low oxidation chemical potential, ionic conductivity and thermal stability. The practical use of solid polymer electrolytes is significantly hampered by these issues.

Thin-film solid electrolytes have also piqued interest, owing to their greater flexibility in design applications and high energy density compared to standard LIBs. In the early 1980 s, a $\mathrm{Li} / \mathrm{Li}_{3.6} \mathrm{Si}_{0.6} \mathrm{P}_{0.4} \mathrm{O}_{4} / \mathrm{TiS}_{2}$ composite was the first thin-film solid electrolyte to be used for secondary LIBs ${ }^{[75]}$. There are a variety of thin-film deposition techniques, including chemical vapor deposition ${ }^{[76]}$, radio frequency sputtering ${ }^{[77]}$, pulsed-laser deposition $^{[78]}$ and atomic layer deposition ${ }^{[79]}$. The lithium phosphorus nitrogen oxide glass (LiPON) battery is one of the most studied thin-film batteries. Bates et al ${ }^{[80]}$ first reported its use in 1992 and a team from Oak Ridge National Laboratory (ORNL, USA) then investigated it further. The stability window of LiPON compared to a Li metal electrode is reported to be between 0 and $5.5 \mathrm{~V}^{[81]}$. The thermal stability and hardness of LiPON have further advantages ${ }^{[82]}$. As a result, the thin-film LiPON battery $\left(\mathrm{LiNi}_{0.5} \mathrm{Mn}_{1.5} \mathrm{O}_{4}\right.$ 
/LiPON/Li) shows a cycle life of 10000 cycles, a $90 \%$ capacity retention rate and a voltage of up to $5 \mathrm{~V}^{[83]}$. Although LiPON has recently become a common solid electrolyte for all-solid-state thin-film batteries, its low conductivity in comparison to oxide materials must be overcome to build high-capacity thin-film batteries. Solid-state LIB chemistries operated with solid electrolytes and their performance metrics (i.e., power density, cycle life, energy density and other relevant parameters) at the current stage of development are summarized in Table 1.

Ion transport in solids is a complicated process that is influenced by a variety of parameters and is still in the early stages of development at the moment. Liquids have a distinct wetting effect compared to inorganic solids ${ }^{[88]}$. When in contact with solid electrodes, they disintegrate quickly and generate undesired phases, which obstruct ion transport and lower the total ionic conductivity ${ }^{[89]}$. It is anticipated that it will become possible to alter key parameters and eliminate related issues during the manufacturing process in order to obtain appropriate products in future years.

\section{$\mathrm{Li}-\mathrm{CO}_{2}$ batteries}

Lithium-carbon dioxide batteries have gained significant interest from the battery industry in recent years. This battery system can store energy by removing carbon dioxide from the atmosphere. Takechi et al. ${ }^{[0]}$ reported that a novel form of gas battery, $\mathrm{Li} / \mathrm{CO}_{2}-\mathrm{O}_{2}$, has a high irreversible discharge capacity, which is three times that of a lithium-air battery. Lim et al.$^{[91]}$ later developed a reversible $\mathrm{Li} / \mathrm{CO}_{2}-\mathrm{O}_{2}$ battery utilizing DMSO, which resulted in the reversible production of $\mathrm{Li}_{2} \mathrm{CO}_{3}$. In response to the earlier $\mathrm{O}_{2}$ and $\mathrm{CO}_{2}$ mixed gas battery, $\mathrm{Xu}$ et al. ${ }^{[92]}$ developed a main $\mathrm{Li}-\mathrm{CO}_{2}$ battery that achieves charging capacity by employing pure $\mathrm{CO}_{2}$ gas as the working electrode. Liu et al. ${ }^{[93]}$ demonstrated a $100 \%$ reversible $\mathrm{Li}-\mathrm{CO}_{2}$ battery by utilizing $\mathrm{LiCF}_{3} \mathrm{SO}_{3}(1: 4 \mathrm{~mol})$ as an electrolyte a year later. The following electrochemical reaction can be used to increase the charging capacity of lithium-carbon dioxide batteries. In $\mathrm{Li}_{-} \mathrm{CO}_{2}$ batteries, there is a disproportion process based on the ultimate discharge products of $\mathrm{C}$ and $\mathrm{Li}_{2} \mathrm{CO}_{3}$. Equations (11-15) show that $\mathrm{CO}_{2}$ undergoes a single electron reduction to $\mathrm{C}_{2} \mathrm{O}_{4}^{2-}$ (Equation 12), resulting in an open circuit potential of $3 \mathrm{~V}$. The intermediate, $\mathrm{C}_{2} \mathrm{O}_{4}^{2-}$, is further disproportioned (Equations 14 and 15) to synthesize stable crystalline $\mathrm{Li}_{2} \mathrm{CO}_{3}{ }^{[94,95]}$ :

$$
\begin{gathered}
3 \mathrm{CO}_{2}+4 \mathrm{Li}^{+}+4 \mathrm{e}^{-} \rightarrow 2 \mathrm{Li}_{2} \mathrm{CO}_{3}+\mathrm{C}\left(2.8 \mathrm{~V} v s . \mathrm{Li} / \mathrm{Li}^{+}\right) \\
2 \mathrm{CO}_{2}+2 \mathrm{e}^{-} \rightarrow \mathrm{C}_{2} \mathrm{O}_{4}^{2-} \\
\mathrm{O}_{4}^{2-} \rightarrow \mathrm{CO}_{2}^{2-}+\mathrm{CO}_{2} \\
\mathrm{CO}_{2}^{2-}+\mathrm{C}_{2} \mathrm{O}_{4}^{2-} \rightarrow 2 \mathrm{CO}_{3}^{2-} \\
2 \mathrm{Li}^{+}+\mathrm{CO}_{3}^{2-} \rightarrow 2 \mathrm{Li}_{2} \mathrm{CO}_{3}
\end{gathered}
$$

The main component in determining the reversibility of the application of these batteries is $\mathrm{Li}_{2} \mathrm{CO}_{3}$. Although $\mathrm{Li}_{2} \mathrm{CO}_{3}$ is an insulator, its oxidation requires a large overpotential while charging. Qiao et al. ${ }^{[96]}$ employed ruthenium as a cathode catalyst in a recent study to successfully minimize the excessive overpotential and increase the reversibility of lithium-carbon dioxide batteries. $\mathrm{Li}-\mathrm{CO}_{2}$ batteries are undoubtedly an attractive technology as they can simultaneously help to address both energy and 
Table 1. Summary of performance metrics of various solid-electrolyte battery systems

\begin{tabular}{|c|c|c|c|c|c|c|}
\hline Battery system & Solid electrolyte & Energy density $\left(\mathrm{Wh} \mathrm{kg}^{-1}\right)$ & Power density $\left(\mathrm{mW} \mathrm{cm}{ }^{-2}\right)$ & Cycle life (number of cycles) & Cell voltage (V) & Refs. \\
\hline \multirow[t]{4}{*}{ All-solid-state LIBs } & Oxide (NASICON, LISICON and garnet) & $300-600$ & 10-50 (temperature dependent) & 300 & $3.5-5.0$ & {$[84,85]$} \\
\hline & Sulfide $\left(\mathrm{Li}_{2} \mathrm{~S}-\mathrm{P}_{2} \mathrm{~S}_{5}-\mathrm{MS}_{x}\right)$ & & 10-60 (temperature dependent) & 1000 & $4.5-5.0$ & {$[86]$} \\
\hline & Thin-film LiPON & & 5-50 (cathode dependent) & 10000 & $3.0-4.0$ & [83] \\
\hline & Polymer (PEO) & & 10-100 (elevated temperatures) & 400 & 3.3-3.7 & [87] \\
\hline
\end{tabular}

LIBs: Lithium-ion batteries; LiPON: lithium phosphorus nitrogen oxide glass; PEO: polyethylene oxide

environmental issues. However, in practice, the major issues to be addressed for their widespread application are excessive overpotential and low Coulombic efficiency.

\section{PERIODIC CLASSIFICATION OF ELEMENTS FOR LIBS}

\section{S-block elements}

Hydrogen is one of the most abundant chemical substance in the universe, accounting for $\sim 75 \%$ of all baryonic matter. On this basis, studies have shown that storing renewable energy in the form of hydrogen through an electrolytic process is considered the most promising option. Hydrogen storage offers several benefits and hydrogen and fuel cells have the potential to contribute to future sustainable development in terms of energy demand and environmental sustainability ${ }^{[9]}$. For decades, hydrogen fuel cells have been investigated as clean alternatives to internal combustion engines. In the past decade, a widespread search for alternative fuels has resulted from a lack of safe and effective hydrogen supply and storage. Among the different anodic fuels studied, borohydride has been reported to a good choice due to its rapid anodic kinetics, high energy density, high stability and easy storage, transport, usage and disposal. It is also free of hazards and pollutant emissions. The eight-electron oxidation process of borohydride results in high-density energy storage. According to the complete oxidation reaction of the eight electrons, the theoretical specific capacity of $\mathrm{NaBH}_{4}$-based anodes is up to $5700 \mathrm{mAh} \mathrm{g}^{-1}$. The equilibrium voltage of a $\mathrm{NaBH}_{4} / \mathrm{O}_{2}$ fuel cell with an oxygen cathode was $1.64 \mathrm{~V}$ and its energy density was $9.3 \mathrm{kWh} \mathrm{kg}^{-1}$, while a gaseous ammonia fuel cell gave $5.5 \mathrm{kWh} \mathrm{Kg}^{-1}$ and a pure methanol fuel cell gave $6.2 \mathrm{kWh} \mathrm{kg}^{-1[12]}$.

Lithium has attracted attention because of its high voltage capacity and energy density. LIBs are widely used in portable devices, wearable electronics and electric vehicles due to their small size and superior performance ${ }^{[98]}$. Graphite is the most prevalent anode material used in LIBs ${ }^{[99]}$. Unfortunately, the Li storage capacity of graphite $\left(372 \mathrm{mAh} \mathrm{g}^{-1}\right)$ is limited and further higher capacity materials are therefore needed for modern appliances. Ideal anode materials have high adsorption capacity and easily diffusion of $\mathrm{Li}^{+}$on their surface. Single-walled carbon nanotubes can adsorb lithium internally and comparatively show a high reversible capacity $\left(500 \mathrm{mAh} \mathrm{g}^{-1}\right)^{[100]}$. Furthermore, chemical etching and ball milling techniques offer the potential to synthesize Li ${ }_{2.7} \mathrm{C}_{6} \mathrm{CNT}$, which give higher Li capacity (1000 $\mathrm{mAh} \mathrm{g}^{-1}$ ). High mechanical strength, electrical conductivity, surface area and thermal conductivity and wide electrochemical applications make graphene a potential alternative anode material for LIBs ${ }^{[101]}$. Unfortunately, graphene still has some problems as an anode 
material. Regardless of the concentration of $\mathrm{Li}^{+}$on graphene, lithium atoms can form clusters and dendrites, which may reduce the battery charge and discharge capacity ${ }^{[102]}$. The adsorption energy of $\mathrm{Li}^{+}$on graphene is weaker than that of $\mathrm{Li}-\mathrm{Li}$, which is the prominent reason for the synthesis of $\mathrm{Li}$ clusters.

To solve this problem, the adsorption energy of $\mathrm{Li}^{+}$on graphene must be higher than their cohesive energy. The most studied dopants for graphene are $\mathrm{N}$ and $\mathrm{B}$, adjacent to the $\mathrm{C}$ atom in the periodic table. In graphene, $\mathrm{N}$ is electron doped (n-type) and $\mathrm{B}$ is hole doped (p-type). These dopants can change the electronic structure of graphene by increasing $(\mathrm{N})$ or decreasing $(\mathrm{B})$ the Fermi levels in the valence and conduction bands. There is a wealth of information regarding the nitrogen substitution concentration of graphene and its applications in oxygen reduction reactions and fuel cell materials ${ }^{[103]}$. Lowering the mobility of the counter anions bis(trifluoromethanesulfonyl)imide with the help of amine-functionalized boron nitride nanosheets can improve $\mathrm{Li}^{+}$transport in ionic gels. Boron nitride nanosheets (BNNS) exhibit acidic properties and interact with bases. The activation of BNNS with amine functional groups increases $\mathrm{Li}^{+}$mobility and anion migration, thus improving the ionic conductivity ${ }^{[104,105]}$. Reportedly, the formation energy of $\mathrm{N}$-substituted graphene changes with the $\mathrm{N}$ doping concentration, indicating the maximum possible content of $\mathrm{N}$ in graphene.

The formation of B dopants in graphene can interfere with cluster formation. Therefore, B-doped graphene can be considered as an excellent long-term material for battery applications. Reportedly, B-doped graphene delivers a very high reversible capacity $\left(1549 \mathrm{mAh} \mathrm{g}^{-1}\right)$ at $50 \mathrm{~mA} \mathrm{~g}^{-1}$. Wang et al.$^{[106]}$ stated that the theoretical capacity of $\mathrm{Li}$ for $\mathrm{Li}_{6} \mathrm{BC}_{5}$ (B-doped graphene) was calculated using density functional theory (DFT), which was higher than $2271 \mathrm{mAh} \mathrm{g}^{-1}$. It was reported that $\mathrm{B}$-doped graphene is more efficient than $\mathrm{N}$-doped graphene in terms of Li adsorption. This is because B can transfer most of its valence charge to graphene, leaving graphene as a p-type dopant and Li as an electronic dopant for graphene. The high theoretical capacity of $\mathrm{B}$-doped graphene for $\mathrm{Li}^{+}$storage makes it one of the most attractive alternatives to graphite.

Some materials (e.g., Si and Sn with theoretical capacities of 4200 and $994 \mathrm{mAh} \mathrm{g}^{-1}$, respectively) are capable of storing multiple $\mathrm{Li}^{+}$on a single atom through an alloying reaction, thus delivering high energy. However, these alloying reactions show a rapid capacity decay as they are primarily associated with large volume changes during cycling ${ }^{[107]}$. Several methods have been proposed to solve the problem of large volume changes. One method involves making electrodes based on nanostructures, such as nanotubes, nanowires, nanoparticles or porous nanostructures ${ }^{[57,108]}$. Another method is to dope inactive elements to reduce the volume changes. The third method involves the preparation of nanocomposites containing an inert matrix and an active substance. In nanocomposites, an inert matrix is used as a mechanical buffer for various active substances, which results in better cycling performance than the pristine material ${ }^{[109]}$.

The electrode material determines the electrochemical performance of LIBs. $\mathrm{LiMn}_{1-\mathrm{x}} \mathrm{M}_{\mathrm{x}} \mathrm{O}_{2}, \mathrm{LiMn}_{2-\mathrm{x}} \mathrm{M}_{\mathrm{x}} \mathrm{O}_{4}$, $\mathrm{LiCoO}_{2}$ and $\mathrm{LiMPO}_{4}(\mathrm{M}=\mathrm{Ni}$, Co or Fe $)$ are all lithium metal oxides with high positive redox potentials and are commonly used as LIB cathodes. At high current rates of 1-10 C, they can deliver capacities of 100-200 $\mathrm{mAh} \mathrm{g}^{-1}$. LIB anodes are usually made of low-cost carbonaceous materials with a storage capacity of less than $372 \mathrm{mAh} \mathrm{g}^{-1}$. Large-scale applications place a premium on lithium safety. Well-known LIB anode materials, such as $\mathrm{Si}, \mathrm{Sn}, \mathrm{Al}$ and their alloys have very high capacities (1000-4000 $\left.\mathrm{mAh} \mathrm{g}^{-1}\right)$. However, their capacities are prone to fading rapidly even at low current rates (0.05-0.20 C), meaning their actual performance is far below that expected due to their rapid volume expansion (>300\%) during cycling. This causes the electrode to disintegrate and shatter, thereby losing electrical contact between adjacent particles $^{[110]}$. 
Due to their high capacity, rich abundance and safety, metal oxides are considered as promising nextgeneration anode materials for LIBs. Metal oxides form a $\mathrm{Li}_{2} \mathrm{O}$ buffer matrix or crystalline structure (such as $\mathrm{TiO}_{2}$ ) when compared to $\mathrm{Al}, \mathrm{Sn}$ and $\mathrm{Si}$ electrodes. This facilitates the insertion of $\mathrm{Li}^{+}$in the electrochemical reaction and significantly extends the $\mathrm{Li}^{+}$cycle life. Many metal oxides can be used as anodes at high rates of 0.5 to $1 \mathrm{C}$ by their redox reaction with $\mathrm{Li}$ and have a high capacity of 500-800 $\mathrm{mAh} \mathrm{g}^{-1}$. In addition, the charge/discharge process for $\mathrm{TiO}_{2}$ electrodes may be faster despite their low storage capacity (100-170 $\left.\mathrm{mAh} \mathrm{g}^{-1}\right)$ at different rates ${ }^{[111,112]}$. Low charge/ion conductivity and long-term cycling stability are currently limiting the use of metal oxides as anodes in LIBs. Preparing a hollow-structured material with a short diffusion path and a large surface area is one of the most efficient methods to solve this problem. Metal oxides have large surface areas, which provide more space to store more Li ions. Furthermore, there is a large contact area between the electrolyte and electrode, resulting in higher $\mathrm{Li}^{+}$flux passing through the interface. The transparent thin shell provides a very simplified pathway for the diffusion of $\mathrm{Li}^{+}$and electrons, thereby increasing the rate capacity ${ }^{[113]}$. The hollow interior provides additional free space, reduces structural distortions and accommodates large volume changes due to repeated $\mathrm{Li}^{+}$ion insertion/extraction processes, thereby improving the cycling stability. Due to the significant reduction of electrode pulverization and polarization, the excellent electrochemical properties of hollow metal oxide structures are highly anticipated ${ }^{[114]}$.

In $\mathrm{Li}_{2} \mathrm{O}_{2}$ batteries, the morphologies of the byproducts of $\mathrm{Li}_{2} \mathrm{O}_{2}$ have been well documented. At low current density, toroid-shaped nuclei are formed, while at high current density, stratified growth occurs ${ }^{[115]}$. $\mathrm{Li}_{2} \mathrm{~S}$ is also a promising cathode material that is being developed for use in emerging energy storage fields. $\mathrm{Li}_{2} \mathrm{~S}$ and $\mathrm{S}$ cathodes require effective encapsulation to reduce the dissolution of lithium polysulfide $\left(\mathrm{Li}_{2} \mathrm{Sn}\right)$ in the electrolyte. The $\mathrm{Li}_{2} \mathrm{~S}$ cathode is coated with a $2 \mathrm{D}$ layered transition metal disulfide, which has high conductivity and strong binding to $\mathrm{Li}_{2} \mathrm{~S} / \mathrm{Li}_{2} \mathrm{~S}_{\mathrm{n}}$. In particular, titanium disulfide $\left(\mathrm{Ti}_{2} \mathrm{~S}\right)$ is used as the packaging material and demonstrates a high specific capacity of $503 \mathrm{mAh} \mathrm{g}^{-1}$ at $4 \mathrm{C}$ and a high area capacity of $3.0 \mathrm{mAh} \mathrm{cm}$ at high mass loading (5.3-25.3 $\left.\mathrm{mg}_{\mathrm{LizS}} \mathrm{cm}^{-2}\right)$. This opens up new possibilities by using transition metal disulfides instead of conventional carbon-based materials to effectively enhance the capacity of electrode materials ${ }^{[16]}$. The anode of a Li-ion batteries is made of lithium compounds that are reversibly inserted by $\mathrm{Li}^{+}$, while the cathode is made of carbon or graphite, which holds the $\mathrm{Li}^{+}$in a solid state. Nonaqueous electrolytes, such as propylene carbonate, and a suitable lithium solution are used to avoid the violent reaction of $\mathrm{Li}$ with water. The separator is a microporous plastic film that can be coated with ceramic particles to improve the safety of the battery.

The safety of $\mathrm{Li}^{+}$cells should be carefully considered. Thermal runaway is a crucial problem facing LIBs; therefore, selected materials, battery design, organic electrolyte and charging systems should be carefully identified to minimize the risk. A schematic diagram for the thermal runaway of different materials is given in Figure $6^{[17]}$. Battery safety systems with thermal sensors, voltage and current measurements and fuses are used for safe operation ${ }^{[118]}$. The following are the main criteria to improve LIBs.

\section{Energy capacity}

The energy accumulated in LIBs corresponds to the amount of $\mathrm{Li}^{+}$ions that can be neutralized and absorbed in the battery electrodes during the charge/discharge phase. The effectiveness of $\mathrm{Li}^{+}$neutralization and the way they can be reversibly evacuated and absorbed or desorbed should be considered. Compounds with low Li binding energy should be used for all battery parts. For example, in the case of cathode materials, $\mathrm{LiFePO}_{4}, \mathrm{LiCoO}_{2}$, $\mathrm{Li}$ in graphite electrodes and some aprotic polymer electrolytes represent ideal candidates $^{[119]}$. The following Equation (16) is used to determine the storage capacity of LIBs: 


$$
\mathrm{C}=\frac{(n F)}{M} \times \frac{1000}{3600}
$$

where $n$ shows the number of charges $\left(\mathrm{Li}^{+}\right), F$ is the Faraday constant, $M$ is the molar mass of the electrode material and to convert from Coulombs to $\mathrm{mAh}, 1000 / 3600$ is used ${ }^{[120]}$.

\section{Power and loading time}

The cathode materials must be capable of repeatedly accepting and releasing $\mathrm{Li}^{+}$at high current rates. This depends on the $\mathrm{Li}^{+}$flux and how fast they can move in the electrolyte and can absorb on the electrode surface. The latter aspect requires a low work function, where incoming $\mathrm{Li}^{+}$ions can be neutralized more easily, and high surface mobility and mass diffusion, by which the neutralized Li atoms can be released.

\section{Number of cycles and $\mathrm{Li}^{+}$loss}

The reduction in the number of charge/discharge cycles is mainly because of chemical modification of the electrode and electrolyte surfaces. However, this also depends on the release of $\mathrm{Li}^{+}$with different mechanisms that affect the reversibility of $\mathrm{Li}^{+}$neutralization and absorption, which should be avoided or limited. Some of the stable compounds with impurities and degraded electrolyte compounds may recombine with $\mathrm{Li}^{+}$; therefore, electrolytes should be selected appropriately. The neutralized $\mathrm{Li}^{+}$may diffuse further into the body of the electrode material and may recombine into a larger low-diffusivity compound or rearrange into a solid Li cluster, meaning that specific methods must be adopted. These strategies limit the overall diffusion of $\mathrm{Li}$ atoms with an appropriate stable diffusion barrier and hinder the formation of $\mathrm{Li}$ clusters in the electrode bulk material. The synthesis of a passivation layer on the electrode surface and any rearrangement of atoms, which is beneficial to dielectric materials, should also be avoided. This particularly affects the electrical conductivity of electrode materials containing graphene ${ }^{[119]}$.

It has been reported that a simple and effective method of synthesizing Li anodes is by rationally designing $3 \mathrm{D}$ current collectors with optimized surface and skeleton characteristics from a metal foam wrapped in porous carbon nanostructures with $\mathrm{N}$-doped carbon nanosheets (designated as $\mathrm{M} / \mathrm{NPCN}, \mathrm{M}=\mathrm{Cu}$ or $\mathrm{Ni}$ ). This potentially enables the placement of a large amount of $\mathrm{Li}$ and ensures uniform nucleation/growth of $\mathrm{Li}$ [Figure 7A]. The synthesized M/NPCN can enhance the stability of the Li anode and the cycle life of high sulfur loading in lithium-sulfur anodes. Figure $7 \mathrm{~B}$ and $\mathrm{C}$ show that NPCN has a highly porous surface area. A Li/Cu foil|C/S cell showed a capacity of $129 \mathrm{mAh} \mathrm{g}^{-1}$ with an $84.9 \% \mathrm{CE}$ after 92 cycles (capacity retention of $16.6 \%$ ), while a $\mathrm{Li} / \mathrm{Cu}$ foam $\mid \mathrm{C} / \mathrm{S}$ cell gave a capacity of $280 \mathrm{mAh} \mathrm{g}^{-1}$ with a $95.0 \% \mathrm{CE}$ of over 300 cycles (34.2\% capacity retention) [Figure $7 \mathrm{D}$ ]. A Li/Cu/NPCN|C/S cell gave a high capacity $\left(816 \mathrm{mAh} \mathrm{g}^{-1}\right)$ and very stable CE ( 99.9\%) after 300 cycles, as shown in Figure 7D. Therefore, the prominent reason for the poor cycling stability of the $\mathrm{Li} / \mathrm{Cu}$ foil $\mid \mathrm{C} / \mathrm{S}$ and $\mathrm{Li} / \mathrm{Cu}$ foam $\mid \mathrm{C} / \mathrm{S}$ is the instability of the anode, which shows that the $\mathrm{Li}$ anode limits the practical application of the sulfur in the cathodes. In order to observe the $\mathrm{Li}$ anode intuitively, the battery cell was disassembled after the cycling test. Many Li dendrites were found, which are also known as "dead Li", as noted in both $\mathrm{Li}$ foil and $\mathrm{Li} / \mathrm{Cu}$ anodes. In contrast, the surface of $\mathrm{Li} / \mathrm{Cu} / \mathrm{NPCN}$ was smooth without clear Li dendrites ${ }^{[121]}$.

Graphene becomes an electron-deficient system when doped with Be. DFT simulations were used to model the adsorption of $\mathrm{Li}^{+}$on Be-doped graphene. The adsorption energy of $\mathrm{Li}^{+}$on $\mathrm{Be}$-doped graphene can be increased to $-2.53 \mathrm{eV} / \mathrm{Li}$, which is 2.24 times that of $\mathrm{Li}$ on undoped graphene ${ }^{[122]}$. $\mathrm{Li}^{+}$can be stored on the hexagon centered and also on the nearest hexagon of graphene, which can easily interact with $12 \mathrm{Li}^{+}$for single vacancies of $\mathrm{Be}$ on the hexagon and provide $16 \mathrm{Li}^{+}$for vacancies around each $\mathrm{Be}$ center hexagon of graphene. This shows that graphene can be doped with a small amount of dopant to store more $\mathrm{Li}^{+}$, thereby 


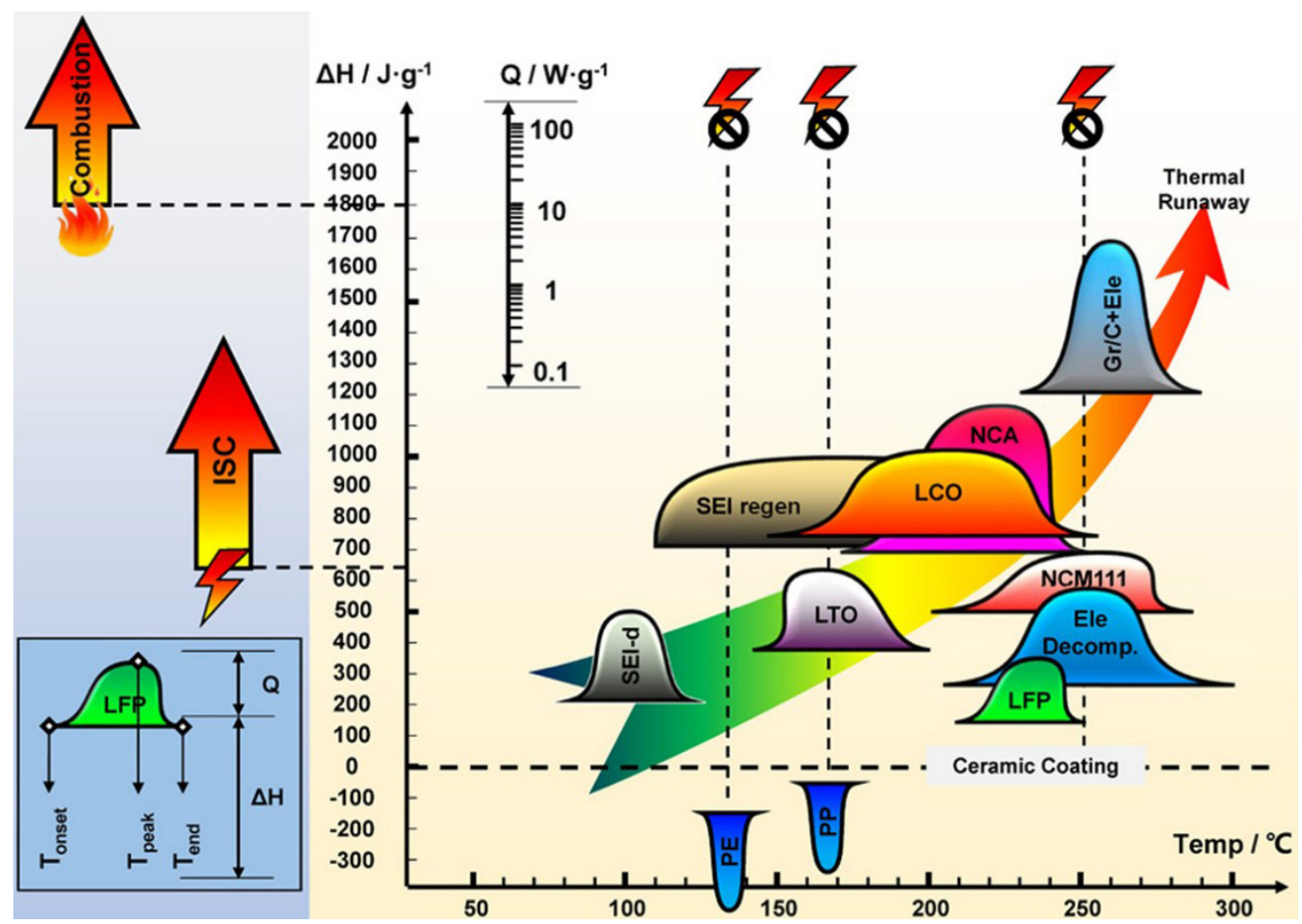

Figure 6. Energy release diagram for a LIB with an NCM/graphite electrode used to analyze the thermal runaway mechanism. Reproduced with permission from Ref. ${ }^{[117]}$ (Copyright 2015, Energy Storage Materials, Elsevier). LIB: Lithium-ion battery; SEI: solid electrolyte interface; LTO: $\mathrm{Li}_{4} \mathrm{Ti}_{5} \mathrm{O}_{12} ; \mathrm{LCO}$ : $\mathrm{LiCoO}_{2}$; LFP: lithium Iron Phosphate $\left(\mathrm{LiFePO}_{4} / \mathrm{C}\right)$; ISC: internal short circuit; NCA: lithium nickel-cobalt-aluminum oxide $\left.\left(\mathrm{Li}^{2} \mathrm{Ni}_{x} \mathrm{Co}_{y} \mathrm{Al}_{z}\right] \mathrm{O}_{2}\right)$; PE: polyethylene; PP: polypropylene.

retaining the extraordinary properties of graphene to a large extent and increasing its Li storage capacity up to $2303.2 \mathrm{mAh} \mathrm{g}^{-1}$. This is because $\mathrm{Be}$ doping produces $\mathrm{Li}_{8} \mathrm{BeC}_{7}$ with a reasonable adsorption energy of $-1.47 \mathrm{eV} / \mathrm{Li}$. The reported capacity value is 6.19 times that of graphite. This surprising result represents a breakthrough for using Be-doped graphene as a LIB anode material ${ }^{[120]}$. It is important to consider the capacity of Be-doped graphene and bare graphene compared with other anode materials. The theoretical specific capacities of $\mathrm{Li}_{16} \mathrm{BeC}_{48}, \mathrm{Li}_{12} \mathrm{BeC}_{48}$ and $\mathrm{Li}_{12} \mathrm{BeC}_{49}$ were found to be 73.355, 549.266 and $538.226 \mathrm{mAh} \mathrm{g}^{-1}$, respectively, which are greater than that of $\mathrm{Li}_{6.84} \mathrm{~B}_{2} \mathrm{C}_{70}\left(212.6 \mathrm{mAh} \mathrm{g}^{-1}\right)$. These specific capacity values are also higher than those of phosphorus $\left(433 \mathrm{mAh} \mathrm{g}^{-1}\right)$, graphite $\left(372 \mathrm{mAh} \mathrm{g}^{-1}\right), \mathrm{Ti}_{3} \mathrm{C}_{2}$ $\left(320 \mathrm{mAh} \mathrm{g}^{-1}\right)$ and even $\mathrm{Mo}_{2} \mathrm{C}\left(526 \mathrm{mAh} \mathrm{g}^{-1}\right)$.

When six $\mathrm{Li}^{+}$(three up and three down) are adsorbed in this system, $\mathrm{Li}_{6} \mathrm{BeC}_{7}$ is formed. The measured adsorption energy is $-1.59 \mathrm{eV} / \mathrm{Li}$, which is slightly lower than that of $\mathrm{Li}_{6} \mathrm{BeC}_{49}(-1.68 \mathrm{eV} / \mathrm{Li})$. Curiously, the theoretical lithium capacity calculated by $\mathrm{Li}_{6} \mathrm{BeC}_{7}$ is very high $\left(1727.47 \mathrm{mAh} \mathrm{g}^{-1}\right)$. The calculated adsorption energy $\left(\mathrm{Li}_{8} \mathrm{BeC}_{7}\right)$ of a given eight $\mathrm{Li}^{+}$is as high as $-1.475 \mathrm{eV} / \mathrm{Li}$, with a theoretical efficiency of 2303.29 $\mathrm{mAh} \mathrm{g}^{-1}$. This storage capacity is far more than the experimental $\left(1549 \mathrm{mAh} \mathrm{g}^{-1}\right)$ and theoretical capacity (2271 $\left.\mathrm{mAh} \mathrm{g}^{-1}\right)$ of B-doped graphene used as an anode material for LIBs. The following formula can be used to calculate the lithium potential $\left(V_{L i}\right)$ of an anode material for LIBs:

$$
V_{L i}=-\frac{E_{\text {tot }}-E_{\text {shheet }}-n E_{L i}}{n z F}
$$



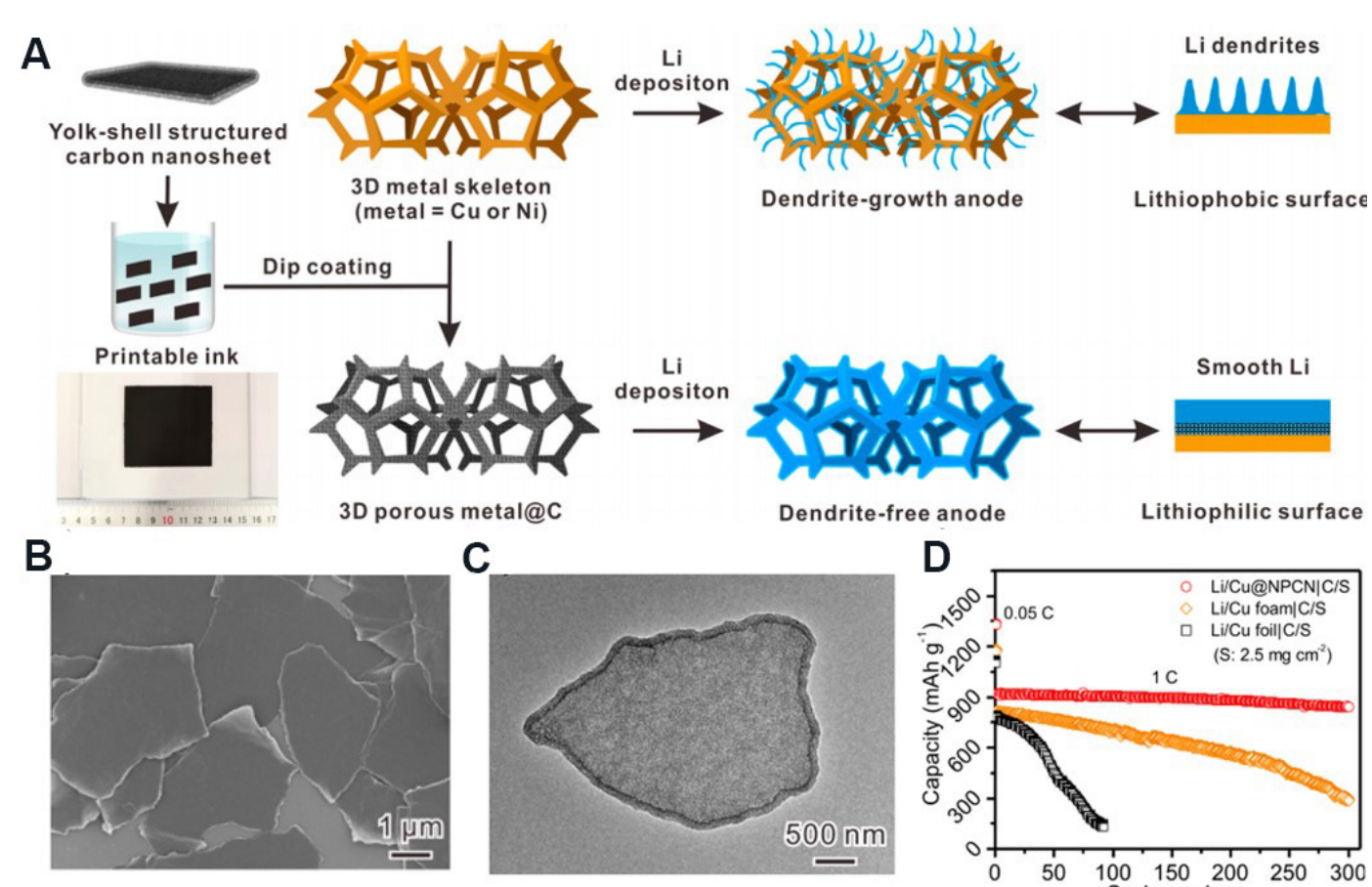
$\mathrm{K}_{2} \mathrm{FeO}_{4}$ is completely stable over 500 cycles. The synthetic route is introduced, which can produce 80-100 $\mathrm{g}$ of $96.5 \%-99.5 \%$ pure $\mathrm{K}_{2} \mathrm{FeO}_{4}$ and $\mathrm{BaFeO}_{4}$. These synthetic products have been proven to give high energy discharge in various AAA alkaline batteries. Super-iron alkaline AAA batteries like $\mathrm{BaFeO}_{4}$ can provide more than 0.8 Wh of electricity during $2.8 \Omega$ of discharge, which is more than $200 \%$ of the capacity of traditional alkaline batteries. The studied barium super-iron battery configuration gives a greater capacity than the studied configuration of potassium super-iron alkaline batteries ${ }^{[124]}$.

Adding witherite $\left(\mathrm{BaPbO}_{3}\right)$ to the anode of lead-acid batteries can increase the efficiency and current acceptance of deep discharge batteries. At room temperature, the half-life of $\mathrm{BaPbO}_{3}$ in the battery acid determined from the decomposition rate constant is $\sim 4$ years. However, the rate of decomposition of $\mathrm{BaPbO}_{3}$ increases with increasing temperature, applied potential and acid concentration. It is estimated that the threshold of $\mathrm{BaSO}_{4}$ content detriment to the cycle life of a lead-acid battery is $\sim 0.3 \%$. With $1 \% \mathrm{BaPbO}_{3}$, an appreciable improvement of the formation can be attained. At this level, the decomposition of $\mathrm{BaPbO}_{3}$ into $\mathrm{BaSO}_{4}$ is not detrimental to the life of the battery ${ }^{[125]}$. Mn-doped $\mathrm{BaPbO}_{3}$ showed improved rate and capacity compared to typical $\mathrm{MnO}_{3}$, with a first cycle capacity of $\sim 360 \mathrm{mAh} \mathrm{g}^{-1}$, as well as better recharge capacity even after a deep discharge. Further investigation is required to determine the load storage mechanism and its specific crystalline and amorphous phases synthesized during the process. The high capacity performance of $\mathrm{Mn} / \mathrm{BaPbO}_{3}$ suggests that these materials may be potential electrode materials ${ }^{[126]}$. The high impedance characteristics and power discharge performance of cathodes of $\mathrm{K}_{2} \mathrm{FeO}_{4}$ and $\mathrm{BaFeO}_{4}$ in dry alkaline $\mathrm{Zn}$ cells show that ferrate materials are bonded to maximize the surface area of the cathode and they can offer superior performance over electrolytic $\mathrm{MnO}_{2}$ at running voltages of $>1.6 \mathrm{~V}$ and currents of up to $100 \mathrm{~mA} \mathrm{~g}^{-1}$ of the active material ${ }^{[124]}$.

\section{P-block elements}

The anode performance of B-doped graphite was studied by electrochemical measurements. In the galvanostatic measurements, a discharge capacity of $\sim 315 \mathrm{mAh} \mathrm{g}^{-1}$ was achieved for B-doped pitch cokederived graphite. Due to the graphitization of B, the discharge capacity of B-doped graphite was enhanced compared to $\mathrm{B}$-free graphite ${ }^{[127]}$. It is reported that the doping of $\mathrm{B}$ with boric acid, boron oxide and boron carbide enhances the discharge capacity and Coulombic efficiency. It is also noted that the B-doped mesophase pitch-based carbon fiber exhibits a prominent phenomenon of B doping in carbon, which is effective for battery performance. Co-B and Fe-B alloy powders affect the electrochemical performance when used in aqueous alkaline solutions as anodic materials. The discharge capacities of Co-B and Fe- $\mathrm{B}$ electrodes were 1100 and $1200 \mathrm{mAh} \mathrm{g}^{-1}$ at a high rate of $100 \mathrm{~mA} \mathrm{~g}^{-1}$, respectively, which are much higher than that of $\mathrm{Zn}\left(820 \mathrm{mAh} \mathrm{g}^{-1}\right)$. The activated $\mathrm{B}$ maintains the electrode potential in the negative range, thereby preventing passivation of the transition metal ${ }^{[128,129]}$.

Carbon remains a highly promising material for electrochemical devices. $\mathrm{Li}^{+}$can easily disperse between the hexagonal graphite planes of the cathode in lithium-metal/graphite batteries ( $\mathrm{LiCoO}_{2}$ batteries), where the anode content is made of graphite as opposed to the previously cited design. In the case of $\mathrm{LiFePO}_{4}$ batteries, black carbon is used as a cathode material to improve its porosity for ionic conductivity and reversible $\mathrm{Li}^{+}$absorption. The graphene-plated anode of LIBs improves the energy storage capacity and charging speed of the battery, although it does not provide the desired results in other areas. Furthermore, most results have been obtained on a semi-empirical basis, so further research into higher performance and reliability is needed. For example, dendritic growth may cause short circuit, attract unwanted compounds of basic electrochemical elements or may redeposit and cover the surface of the electrode, eventually resulting in electrical and material leakage, and the release of combustible compounds, which may be the result of manufacturing failures. Graphite is the utmost common material used for LIBs. However, its limited Li storage capacity (372 $\mathrm{mAh} \mathrm{g}^{-1}$ ) restricts LIB performance. 
A suitable anode material is one with high adsorption capacity for $\mathrm{Li}^{+}$and facile diffusion on the anode material. Carbon nanotubes (CNTs) have the potential to adsorb Li, either internally or externally. Therefore, experimentally studied single-walled CNTs have been found to be better than graphite and give a reversible capacity of $500 \mathrm{mAh} \mathrm{g}^{-1}$. In addition, ball milling techniques and chemical etching offer the possibility of synthesizing $\mathrm{Li}_{2.7} \mathrm{C}_{6} \mathrm{CNTs}$, which show even higher Li capacities of up to $1000 \mathrm{mAh} \mathrm{g}^{-1}$. Graphene is a potential and alternative material for LIBs anode due to its special properties, such as a large surface area, high mechanical strength, high thermal and electrical conductivity ${ }^{[121]}$. In 2015, multilayer $\mathrm{Ti}_{3} \mathrm{C}_{2}$ / carbon nanofiber (CNF) particles were used as LIB anode materials and their electrochemical performance was successfully improved by growing conductive "CNF bridges" within each $\mathrm{Ti}_{3} \mathrm{C}_{2} \mathrm{~T}_{\mathrm{x}}$ flake. The rate performance of the $\mathrm{Ti}_{3} \mathrm{C}_{2} / \mathrm{CNF}$ s was improved, while their specific capacity was still maintained at $320 \mathrm{mAh} \mathrm{g}^{-1}$ over 295 cycles at $1 \mathrm{C}$. More notably, the capacity of the $\mathrm{Ti}_{3} \mathrm{C}_{2} / \mathrm{CNF}$ hybrid at a super-high rate of $100 \mathrm{C}$ is only slightly lower than that of pure $\mathrm{Ti}_{3} \mathrm{C}_{2} \mathrm{~T}_{\mathrm{x}}$ particles at $1 \mathrm{C}$. It was also reported that a delaminated $\mathrm{Nb}_{2} \mathrm{CT}_{\mathrm{x}} / \mathrm{CNT}$ composite, when used as an anode material, shows an excellent capacity of $400 \mathrm{mAh} \mathrm{g}^{-1}$ at $0.5 \mathrm{C}^{[130]}$. However, the maximum specific capacity for carbon cathodes to date is $\sim 120 \mathrm{mAh} \mathrm{g}^{-1}$ for graphene nanoribbons directly developed on extremely porous 3D graphene structures. Despite their high performance, most reported graphene and graphite-based cathodes exhibit low Coulombic performance at low rates ${ }^{[131]}$.

Graphene was discovered more than a decade ago. Carbon materials with $\mathrm{sp}^{2}$ bonding have a variety of structure forms with different dimensions, including $0 \mathrm{D}, 1 \mathrm{D}, 2 \mathrm{D}$ and $3 \mathrm{D}$ structures, fullerenes, nanotubes, graphene and graphite. Graphene is composed of a single honeycomb lattice with covalently bonded carbon atoms and fully conjugated $\pi$ electrons, giving it excellent electronic, mechanical, thermal and chemical properties. It is a semiconductor and can withstand a high current density exceeding $109 \mathrm{~A} \mathrm{~cm}^{-2}$. Graphene is also an excellent energy storage material due to its high surface area $\left(2630 \mathrm{~m}^{2} \mathrm{~g}^{-1}\right)$ and is conductive and easy to functionalize with other molecules. Graphene family include double- and few- (three to nine) layer graphene and graphene resembling large polyaromatic molecule called graphene nanoribbon (single-, double-, few- or multilayer; multilayer graphene nanoribbons are also called stacked graphite nanofibers or graphene nanofibers ${ }^{[132]}$. Graphene oxide, represented as a monolayer of graphite oxide, is the most important chemically-derived form of graphite and is typically synthesized by its exfoliation, long-time stirring of graphite oxide/water mixtures or simple sonication ${ }^{[130]}$.

In recent decades, the insertion of lithium ions in the graphite lattice has been studied in detail for electrochemical energy storage applications. Graphite carbon forms the structure of $\mathrm{LiC}_{6}$ and as a result has a low $\mathrm{Li}^{+}$storage capacity of only $372 \mathrm{mAh} \mathrm{g}^{-1}$. Single graphene sheets can store $\mathrm{Li}$ on either side to form $\mathrm{LiC}_{3}$ with a capacity limit of $744 \mathrm{mAh} \mathrm{g}^{-1}$. Graphite-based electrode materials suffer from the large size of lateral graphite and long Li-ion diffusion paths into the material. In order to enhance the diffusion of $\mathrm{Li}^{+}$ into the interlayer space of the substrate and to increase the reversibility, a solution that decreases the lateral dimensions ( $\mathrm{x}$-y axes) is used. Stacked graphene nanofibers represent such a solution and have a length of several micrometers and lateral dimensions of tens of nanometers. Graphite shows high electrochemical performance because of its high surface area, edge-like structure and interlayer spacing, although its base planes only have space at the ends of nanofibers. These nanosized lateral dimensions provide a better energy storage capacity of more than $461 \mathrm{mAh} \mathrm{g}^{-1}$. Nanosized stacked graphene nanofibers have high energy storage capacity. Additionally, electrodes made of graphene sheets have been used to boost the basic potential of LIBs, resulting in a capacity of $540 \mathrm{mAh} \mathrm{g}^{-1}$. However, to prevent graphene nanosheets from restacking, CNTs were used as spacers and the reported storage capacity for LIBs was enhanced to 730-784 $\mathrm{mAh} \mathrm{g}^{-1[133]}$. 
In other work, Li and graphene were used as anode and cathode materials, respectively, and the observed discharge capacity was $582 \mathrm{mAh} \mathrm{g}^{-1}$. The high discharge capacity of this anode is due to the nanoholes in the sheets of graphene. This is a significant discovery for the further development of $\mathrm{Li}^{+}$graphene-based batteries because graphene nanoholes can be used to support the passage of selective ions. However, due to the comparatively strong bonds formed with defects during the charge process, the discharge of $\mathrm{Li}$ necessitates high voltages and, as a result, a large voltage hysteresis. Tangled graphene has a high reversible capacity of 794-1054 $\mathrm{mAh} \mathrm{g}^{-1}$. These high volumes are very similar to the $\mathrm{Li}_{2}$ covalent model. Although graphene batteries initially had poor performance, current devices show outstanding cycling performance (90\%-95\%). It is noteworthy that studies have shown that the solid electrolyte interface between graphene with a high specific surface area and electrolyte morphology has a high capacity of reversibility ${ }^{[134]}$.

With the aim of synthesizing metal/graphene nanocomposites, DFT and volumetric experiments proved that the capacity of LIB composites of Sn/graphene show an improvement in storage capacity of the cathode material and can store up to $994 \mathrm{mAh} \mathrm{g}^{-1}$. $\mathrm{Li}^{+}$interacts with $\mathrm{Sn}$ to form $\mathrm{Li}_{4.4} \mathrm{Sn}$ but pure $\mathrm{Sn}$ can induce accumulation and clustering of Sn nanoparticles; therefore, repeated cycles may cause a loss in capacity of such electrode materials. Graphene plays a double role in supporting $\mathrm{Sn}$ atoms for the adsorption of $\mathrm{Li}^{+}$and avoiding their aggregation. For Sn/graphene nanocomposites, a capacity of up to $795 \mathrm{mAh} \mathrm{g}^{-1}$ has been observed. Another option is to use metal oxides (especially transition metal oxides) as components of graphene nanocomposites. To separate their adjacent flakes, $\mathrm{Co}_{3} \mathrm{O}_{4}$ nanoparticles $(10-30 \mathrm{~nm}) \mathrm{can}$ be homogeneously dispersed on graphene sheets. Over 30 cycles, the recycling efficiency of the material was $98 \%$ and the capacity was maintained at $935 \mathrm{mAh} \mathrm{g}^{-1}$. $\mathrm{TiO}_{2}$ nanoparticle/graphene nanocomposites were constructed similarly with a recycling efficiency of over $98 \%^{[135]}$. Si and graphene nanosized composites have an average Coulombic efficiency of $93 \%$ and a high capacity of $1168 \mathrm{mAh} \mathrm{g}^{-1}$ over 30 cycles. Graphene can also act as a conductive source for batteries with olivine-based $\mathrm{LiFePO}_{4}$, with minimal capacity fade even after several hundreds of cycles $^{[136]}$. Graphene sheets with a single-fold layer material have the highest capacity of $1175 \mathrm{mAh} \mathrm{g}^{-1}$, while threefold and fivefold layer materials have capacities of 1007 and $842 \mathrm{mAh} \mathrm{g}^{-1}$, respectively. It is evident from these capacity values that graphene sheets with high edge sites, increased defects and reduced size are very beneficial for Li storage.

The performance of LIBs can be efficiently increased by heteroatomic doping, which effectually increase the surface chemical properties and electronic band structure. For example, B- or N-doped graphene has a very high reversible capacity of over $1040 \mathrm{mAh} \mathrm{g}^{-1}$ at a very low rate of $50 \mathrm{~mA} \mathrm{~g}^{-1[133]}$. More significantly, it has a high rate and superb long-term cycling capabilities and can charge and discharge easily in a short period of $1 \mathrm{~h}$ to tens of seconds. Heteroatomic defects, disordered surface morphologies and the unique 2D structure of the material increase the inter-sheet distance and electrical conductivity, which are helpful for increasing the absorption of $\mathrm{Li}^{+}$at the surface and providing high $\mathrm{Li}^{+}$diffusion. Doped materials generally outperform pristine carbonaceous materials. Porous graphene has rich porosity and an extraordinary specific surface area (SSA), which are advantageous for the faster diffusion of electrolytes and the transportation of electrons in energy storage. For instance, well-ordered mesoporous graphene sheets with a large pore volume $\left(1.8 \mathrm{~cm}^{3} \mathrm{~g}^{-1}\right)$ and high SSA $\left(1000 \mathrm{~m}^{2} \mathrm{~g}^{-1}\right)$ have a capacity of $520 \mathrm{mAh} \mathrm{g}^{-1}$ at $300 \mathrm{~mA} \mathrm{~g} \mathrm{~g}^{-1}$ over 400 cycles. However, their practical use in LIBs is limited because of the resulting significant irreparable capacity ${ }^{[137]}$. A quasi-1D form of graphene, graphene nanoribbons (GNRs), has rich edges, which are advantageous for $\mathrm{Li}^{+}$ storage. A low capacity ( $250 \mathrm{mAh} \mathrm{g}^{-1}$ ) over 50 cycles was delivered by pure GNRs. Taking advantage of $\mathrm{N}$ doping and the edge effect, $\mathrm{N}$-doped GNRs have a stable capacity of $714 \mathrm{mAh} \mathrm{g}^{-1}$ after 100 cycles at $3 \mathrm{~A} \mathrm{~g} \mathrm{~g}^{-1}$. An N-doped GNR-based 3D aerogel structure exhibited an improved $\mathrm{Li}^{+}$storage capacity and consequently gave $910 \mathrm{mAh} \mathrm{g}^{-1}$ at $0.5 \mathrm{~A} \mathrm{~g}^{-1[133,138]}$. 
Nanomaterials, such as Si and Ge, have short ion diffusion pathways, which are appropriate for the insertion of $\mathrm{Li}^{+}$, enhance the energy efficiency and cycling performance and minimize the internal strain for LIBs. Si, Ge and their alloys are used as elemental anodes and can provide high capacities but have greater volumetric expansion during charging. Therefore, for phase change cathodes, a complex 3D architecture should be used for better cycling and rate performance ${ }^{[139]}$. Si is an excellent anode material for LIBs because it has a low discharge potential, high theoretical capacity $\left(4200 \mathrm{mAh} \mathrm{g}^{-1}\right)$ and is ten times more efficient than graphite and much higher than various oxide and nitride materials. However, due to drastic volume changes $(>300 \%)$ upon extraction and insertion of $\mathrm{Li}^{+}$, its usage results in capacity fade and pulverization $^{[140]}$. Results illustrates that $\mathrm{Si}$ nanowires have better capacity than other types of Si. Even at a higher $1 \mathrm{C}$ rate, they give a capacity of $2100 \mathrm{mAh} \mathrm{g}^{-1}$, which is five times higher than that of graphite. Despite their improved performance, due to the interfacial phase of the solid electrolyte, Si nanowires anodes lose irreversible capacity through the initial cycling ${ }^{[139]}$. The performance of gold-plated porous $\mathrm{Si}$ is superior to that of non-gold-plated porous $\mathrm{Si}$, which has a discharge capacity of $500 \mathrm{mAh} \mathrm{g}^{-1}$ at the initial cycle but quickly decreases over the 10th cycle to only $76 \mathrm{mAh} \mathrm{g}^{-1}$.

The composition of the gold coating and internal pores shows excellent long-term cycling stability and high performance for LIB anodes ${ }^{[141]}$. The maximum possible specific capacity of Si $\left(3579 \mathrm{mAh}^{-1}\right)$ is much higher than the theoretical capacity of graphite $\left(372 \mathrm{mAh} \mathrm{g}^{-1}\right)$. Nevertheless, the increase in volume ( 300\%) of Si during cycling causes cracking of the Si electrode and results in short circuit and rapid capacity loss ${ }^{[142]}$. It is known that at low potentials, $\mathrm{Au}$ reacts with $\mathrm{Li}$ and has a capacity of $451 \mathrm{mAh} \mathrm{g}^{-1}$ for $\mathrm{Li}_{15} \mathrm{Au}_{4}$. Lee et al. ${ }^{[143]}$ observed that a $50 \mathrm{~nm}$ Au film causes an initial charge capacity of $47 \mathrm{mAh} \mathrm{g}^{-1}$ at $20 \mathrm{C}$; however, by increasing the number of cycles, the charge/discharge capacity decreases rapidly. The low discharge potential $\left(<0.5 \mathrm{~V}\right.$ compared to $\left.\mathrm{Li} / \mathrm{Li}^{+}\right)$and increased capacity of Si make it a good choice as a cathode material in high-energy LIBs. Despite their huge volume changes, Si and Si-based alloys are considered to be possible substitutes for graphite-based cathodes in current commercial LIBs ${ }^{[141]}$.

The electrochemical performance of a Si- $\mathrm{Cu}_{3} \mathrm{Si}-\mathrm{CNT} / \mathrm{G}$ electrode was shown to be good but it has not yet reached current commercial goals (a reversible capacity of $1000 \mathrm{mAh} \mathrm{g}^{-1}$, an $80 \%$ capacity retention over 100 cycles and a Coulombic efficiency of $>85 \%$ ). To enhance the performance of Si- $\mathrm{Cu}_{3} \mathrm{Si}-\mathrm{CNT} / \mathrm{G}$, a known pyrolytic carbon coating method has been used. A schematic of the three-step manufacturing process of Si$\mathrm{Cu}_{3} \mathrm{Si}-\mathrm{CNT} / \mathrm{G}-\mathrm{C}$ is given in Figure 8A. Under full discharge conditions (100\% SOC at $\left.0 \mathrm{~V}\right)$, the expansion of the $\mathrm{Si}-\mathrm{Cu}_{3} \mathrm{Si}-\mathrm{CNT} / \mathrm{G}$ and Si-Cu $\mathrm{Si}_{3} \mathrm{SNT} / \mathrm{G}-\mathrm{C}$ electrodes was $39.5 \%$ and $48.0 \%$, respectively, much lower than that of $\mathrm{Si}-\mathrm{Cu}_{3} \mathrm{Si}(110.3 \%)$ and bulk Si $(140.4 \%)$. When fully charged (0\% SOC at $2 \mathrm{~V}$ ), the expansion rates of the $\mathrm{Si}-\mathrm{Cu}_{3} \mathrm{Si}-\mathrm{CNT} / \mathrm{G}$ and $\mathrm{Si}-\mathrm{Cu}_{3} \mathrm{Si}-\mathrm{CNT} / \mathrm{G}-\mathrm{C}$ electrodes are $9.5 \%$ and $8.3 \%$, respectively. In Figure $8 \mathrm{~B}$, the cycling performance of $\mathrm{Si}-\mathrm{Cu}_{3} \mathrm{Si}-\mathrm{CNT} / \mathrm{G}-\mathrm{C}$, commercial graphite and bulk $\mathrm{Si}$ is compared at $200 \mathrm{~mA} \mathrm{~g}^{-1}$ in a voltage range of $0-2 \mathrm{~V}$. Due to the formation of $\mathrm{Li}_{3.75} \mathrm{Si}$, the volume of $\mathrm{Si}$ changes significantly, resulting in mechanical cracking and destruction, decreasing the ICE and fading the cycling performance and the stability of bulk Si. Si-Cu $\mathrm{Si}_{3} \mathrm{Si}$-CNT/G-C shows a high CE of over $99 \%$ and a stable cycling performance at 100 cycles, while the capacity retention rate was $94.9 \%$ and $88.0 \%$ of IRC after 50 and 100 cycles, respectively ${ }^{[143]}$. A uniform distribution of nanosized Li-active Si nanocrystals prevents agglomeration of Si nanocrystals during cycling and buffering effects on bulk Si nanocrystals of a multi-carbon matrix, providing excellent ICE, IRC and retention of capacity and volume changes.

Figure $8 \mathrm{C}$ shows the rate performance of commercial graphite and $\mathrm{Si}-\mathrm{Cu}_{3} \mathrm{Si}-\mathrm{CNT} / \mathrm{G}-\mathrm{C}$ at $1 \mathrm{C}$ and $1200 \mathrm{~mA} \mathrm{~g}^{-1}$. Figure $8 \mathrm{D}$ summarizes the capacity retention and ICE of $\mathrm{Si}, \mathrm{Si}-\mathrm{Cu}_{3} \mathrm{Si}$ (1st step), $\mathrm{Si}-\mathrm{Cu}_{3} \mathrm{Si}$ $\mathrm{CNT} / \mathrm{G}$ (2nd step) and $\mathrm{Si}-\mathrm{Cu}_{3} \mathrm{Si}-\mathrm{CNT} / \mathrm{G}-\mathrm{C}$ (3rd step). The CV peaks of $\mathrm{Si}-\mathrm{Cu}_{3} \mathrm{Si}-\mathrm{CNT} / \mathrm{G}-\mathrm{C}$ agree well with $\mathrm{Si}-\mathrm{Cu}_{3} \mathrm{Si}$, but by using a multi-carbon substrate, the $\mathrm{CV}$ peak is smoothed. In addition, $\mathrm{Si}-\mathrm{Cu}_{3} \mathrm{Si}$-CNT/G-C 

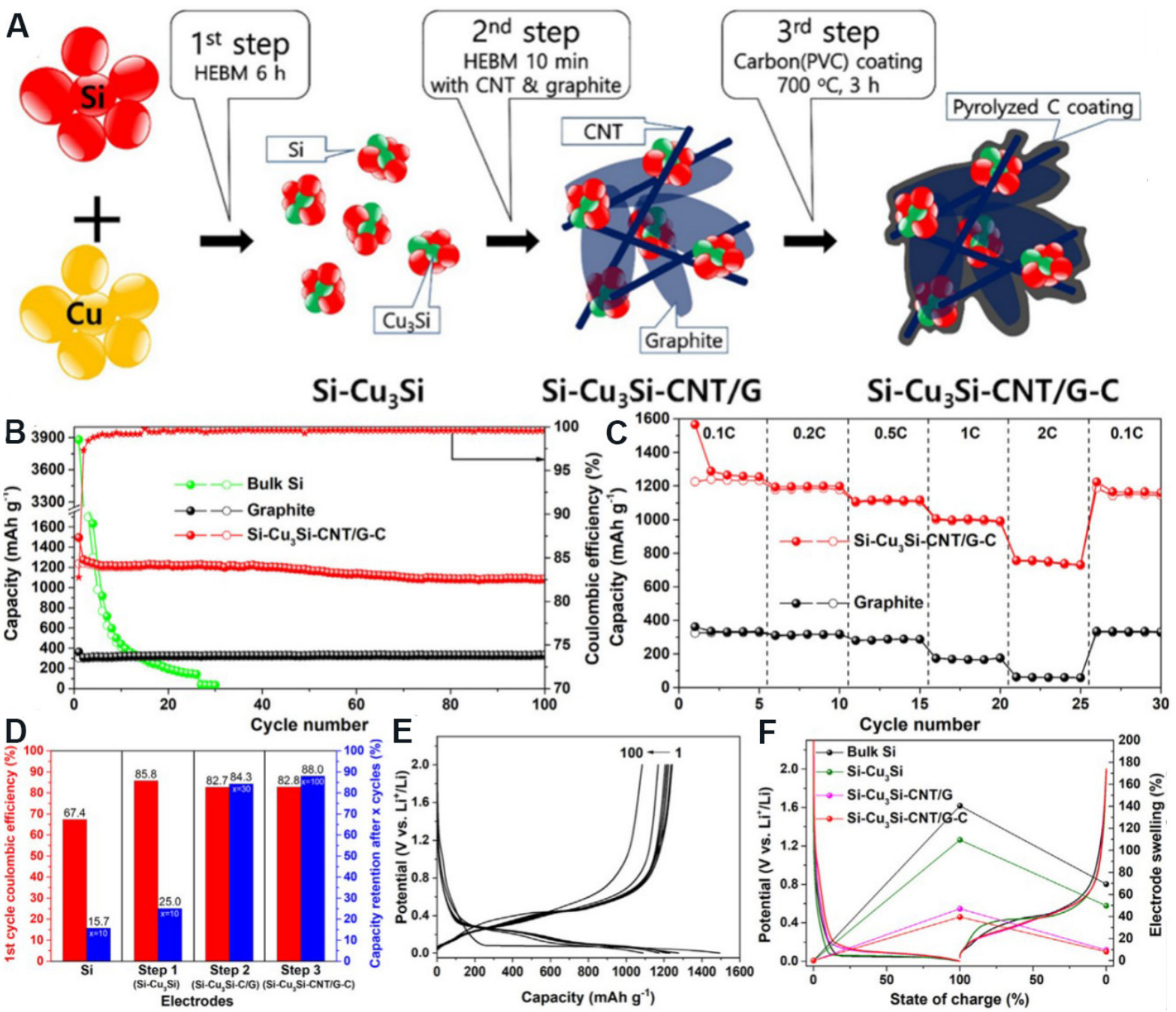

Figure 8. (A) Schematic representation of $\mathrm{Si}-\mathrm{Cu}_{3} \mathrm{Si}-\mathrm{CNT} / \mathrm{G}-\mathrm{C}$ synthesis. (B) Cycling behavior of graphite, bulk $\mathrm{Si}$ and $\mathrm{Si}-\mathrm{Cu}_{3} \mathrm{SiCNT} / \mathrm{G}-\mathrm{C}$. (C) Rate capabilities of graphite and $\mathrm{Si}-\mathrm{Cu}_{3} \mathrm{Si}-\mathrm{CNT} / \mathrm{G}-\mathrm{C}$. (D) ICE and capacity retention for bulk $\mathrm{Si}, \mathrm{Si}-\mathrm{Cu}_{3} \mathrm{Si}, \mathrm{Si}-\mathrm{Cu}_{3} \mathrm{Si}-\mathrm{CNT} / \mathrm{G}$ and $\mathrm{Si}-\mathrm{Cu}_{3}$ $\mathrm{Si}-\mathrm{CNT} / \mathrm{G}-\mathrm{C}$ electrodes. (E) Voltage profiles from 1st to 100th cycle for $\mathrm{Si}-\mathrm{Cu}_{3} \mathrm{Si}-\mathrm{CNT} / \mathrm{G}-\mathrm{C}$. (F) Changes to the thickness of bulk Si, Si$\mathrm{Cu}_{3} \mathrm{Si}, \mathrm{Si}-\mathrm{Cu}_{3} \mathrm{Si}-\mathrm{CNT} / \mathrm{G}$ and $\mathrm{Si}-\mathrm{Cu}_{3} \mathrm{Si}-\mathrm{CNT} / \mathrm{G}-\mathrm{C}$ electrodes according to the SOC. Reproduced with permission from Ref. ${ }^{[143]}$ (Copyright 2020, Chemical Engineering, Elsevier). CNT: Carbon nanotube; HEBM: heat treatment and ball milling; SOC: state of charge.

has better capacity retention [Figure $8 \mathrm{D}-\mathrm{F}$ ]. Figure $8 \mathrm{D}$ summarizes bulk $\mathrm{Si}, \mathrm{Si}-\mathrm{Cu}_{3} \mathrm{Si}$ (first preparatory stage), $\mathrm{Si}-\mathrm{Cu}_{3} \mathrm{Si}-\mathrm{CNT} / \mathrm{G}$ (second preparatory stage) and $\mathrm{Si}_{-} \mathrm{Cu}_{3} \mathrm{Si}-\mathrm{CNT} / \mathrm{G}-\mathrm{C}$ (third preparatory stage). After 100 cycles, the ICE of $\mathrm{Si}-\mathrm{Cu}_{3} \mathrm{Si}-\mathrm{CNT} / \mathrm{G}-\mathrm{C}$ is as high as $82.8 \%$, the value of IRC is $1237 \mathrm{mAh} \mathrm{g}^{-1}$ and the stable capacity retention rate is $88 \%$. All these electrochemical parameters (capacity retention, ICE and IRC) have reached a certain goal of commercialization for high capacity Si-based anodes for LIBs. Figure $8 \mathrm{~F}$ shows changes in thickness for the $\mathrm{Si}, \mathrm{Si}-\mathrm{Cu}_{3} \mathrm{Si}-\mathrm{CNT} / \mathrm{G}, \mathrm{Si}-\mathrm{Cu}_{3} \mathrm{Si}$ and $\mathrm{Si}-\mathrm{Cu}_{3} \mathrm{Si}-\mathrm{CNT} / \mathrm{G}-\mathrm{C}$ electrodes during the charge/discharge process ${ }^{[143]}$.

$\mathrm{SnO}_{2}$ is an excellent semiconductor with high acid/alkali resistance and stability. The capacity of a $\mathrm{SnSb}$ nanocomposite was almost twice that of a carbon-based cathode material ${ }^{[18]}$. $\mathrm{SnO}_{2}$ has a high theoretical capacity but its volume expansion and rapid capacity fade during cycling render it unsuitable for LIBs. It has been reported that rGO and fluorine-doped tin oxide nanocomposites (FTO) are ideal anode materials with high rate performance and good capacity and show better structural stability throughout the process of 
lithiation and delithiation. Through conductive FTO nanocrystals, a stable and thin solid electrolyte interfacial film can be formed, which has a discharge capacity of $1439 \mathrm{mAh} \mathrm{g}^{-1}$ after 200 cycles at $100 \mathrm{~mA} \mathrm{~g}^{-1[144]}$.

Plante invented the lead-acid battery in 1859 and it has been extensively used ever since. Lead-acid batteries are a simple technology with low production costs, but they have a limited number of charge/discharge cycles, charge slowly and cannot be completely discharged due to their low energy to weight and volume ratios. A passive layer of lead sulfate is synthesized through the charge/discharge process on the positive electrode surface:

$$
\mathrm{PbSO}_{4}+2 \mathrm{H}_{2} \mathrm{O} \rightarrow \mathrm{PbO}_{2}+4 \mathrm{H}^{+}+\mathrm{SO}_{4}{ }^{2-}+2 \mathrm{e}^{-}
$$

The lead sulfate layer, near the electrode surface, acts as a selective membrane for the diffusion of ions and can pass only ions, such as $\mathrm{H}^{+}$and $\mathrm{Pb}^{2+}$. The growth of lead dioxide $\left(\mathrm{PbO}_{2}\right)$ is determined by the flux of $\mathrm{Pb}^{2+}$ ions. $\mathrm{Pb}^{2+}$ ions move by surface diffusion, besides the surface of $\mathrm{PbSO}_{4}$ crystals to the $\mathrm{PbO}_{2}$ phase and oxidized there. The electrochemical properties of carbon-based electrode materials can be improved by the modification of their surface with non-carbon-based elements, such as B and N. The presence of noncarbon-based heteroatom functional groups on the carbon surface can increase $\mathrm{Li}^{+}$storage capacity, conductivity and reactivity. N-doped CNFs have an excellent rate capability and high capacity ( $943 \mathrm{mAh} \mathrm{g}^{-1}$ ) at $2 \mathrm{~A} \mathrm{~g}^{-1}$ over 600 cycles $^{[145]}$.

Despite their widespread usage in mobile and portable electronic devices as a result of their high specific capacity and power density, LIBs can be ignited, especially under extreme conditions, such as crushing, overheating and charging. In order to improve the thermal stability of LIBs, electrochemists have considered the development of nonflammable electrolytes. An effective approach is to add flame retardants directly into standard electrolytes. Phosphite and phosphate are used as flame retardants and show outstanding nonflammability. Among these additives, the compounds of phosphorous(III), such as trimethyl phosphite and tris(2,2,2-trifluoroethyl) phosphite, have more efficient nonflammability and can enhance the electrochemical performance of LIBs compared to subsequent phosphorous(V) compounds ${ }^{[146]}$.

For the protection of Li anodes, LiPON films represent excellent protective layers for Li secondary batteries. A LiPON layer may be adsorbed on a Li electrode surface using radio frequency sputtering as an amorphous phase. This layer has excellent characteristics as a lithium ionic conductor and electric insulator for protecting the electrode surface from electrolytic decay. Such films are also predicted to be outstanding passive layers to protect the anode surfaces of LIBs. The deposition of a LiPON layer synthesizes a stable solid electrolyte on the lithium anode surface, which effectively decreases the reaction between lithium and the electrolyte $\left(1: 1 \mathrm{w} / \mathrm{w} \mathrm{EC}+\mathrm{DEC}+1.0 \mathrm{M} \mathrm{LiPF}_{6}\right)$. Impedance measurements show that the LiPON layer is a fast ionic conductor compared to the film formed by electrolyte decay ${ }^{[147]}$. Triphenylphosphite is also used as a phosphorous additive for LIBs. It can improve the thermal stability of electrolytes (1 $\mathrm{M} \mathrm{LiPF}_{6} /$ ethylene carbonate, dimethyl carbonate and diethyl carbonate, 1:1:1 by weight) and provide overcharge safety for LIBs. Recently, it has been suggested that metal phosphides can be used as anode materials for LIBs. Zhao et al. ${ }^{[148]}$ prepared a $\mathrm{CuP}_{2} / \mathrm{C}$ composite material with a capacity of $430 \mathrm{mAh} \mathrm{g}^{-1}$ after 30 cycles at $150 \mathrm{~mA} \mathrm{~g}^{-1}$. Li et al. ${ }^{[149]}$ reported yolk-shell $\mathrm{Sn}_{4} \mathrm{P}_{3} / \mathrm{C}$ nanospheres with an excellent capacity of $790 \mathrm{mAh} \mathrm{g}^{-1}$ at $100 \mathrm{~mA} \mathrm{~g}^{-1}$. 
In LIBs, arsenic (As) is the most promising anode material substitute for graphite. A theoretical and experimental approach was used to investigate the electrochemical performance of As/carbon nanocomposite materials for LIBs. The LIBs provided good cycling performance with a promising capacity of $1306 \mathrm{mAh} \mathrm{g}^{-1}$ (over 100 cycles), which is higher than that of $\mathrm{Li}_{3} \mathrm{As}\left(1072 \mathrm{mAh} \mathrm{g}^{-1}\right)^{[150]}$.

Microsized antimony $(\mathrm{Sb})$ can be successfully applied as an electrode material for LIBs and provides a high capacity of $600 \mathrm{mAh} \mathrm{g}^{-1}$ over 160 cycles and a CE of $99 \%$. It delivers $310 \mathrm{mAh} \mathrm{g}^{-1}$ of discharge capacity at a very high current rate of $30 \mathrm{C}$ for $\mathrm{LIBs}^{[151,152]}$. A SnSb/C nanocomposite material based on a $\mathrm{Na}$ alloy electrode can provide a very high capacity (544 $\mathrm{mAh} \mathrm{g}^{-1}$, about double that of intercalated carbon materials) and recyclability of $\mathrm{Na}^{+}$storage ( $80 \%$ capacity over 50 cycles) ${ }^{[153]}$. However, the poor rate capability and low capacity of existing anodes are major hindrances to future development. The homogenous coating of antimony sulfide (stibnite) on a graphene surface has also been reported, which provides a capacity of $730 \mathrm{mAh} \mathrm{g}^{-1}$ at $50 \mathrm{~mA} \mathrm{~g}^{-1}$. It also provides a model site for the anchoring of nanoparticles. A study has also shown that a battery made of a stibnite-graphene composite material does not contain $\mathrm{Na}$ metal and its energy density is $80 \mathrm{Wh} \mathrm{kg}^{-1}$. This energy density can be optimized over some $\mathrm{LIBs}^{[154]}$.

Bismuth is a promising anode material for LIBs and the theoretical capacity of bismuth oxide $\left(\mathrm{Bi}_{2} \mathrm{O}_{3}\right)$ is $690 \mathrm{mAh} \mathrm{g}^{-1}$. Surprisingly, little attention has been paid to $\mathrm{Bi}_{2} \mathrm{O}_{3}$. $\mathrm{Bi}_{2} \mathrm{O}_{3}$ nanoparticles with a particle size of $\sim 5 \mathrm{~nm}$ were uniformly dispersed on $\mathrm{rGO}$ sheets. The nanocomposite $\mathrm{Bi}_{2} \mathrm{O}_{3} / \mathrm{rGO}$ enhances cycling stability and electrochemical reversibility compared to agglomerated bare $\mathrm{Bi}_{2} \mathrm{O}_{3}$ nanoparticles. This $\mathrm{Bi}_{2} \mathrm{O}_{3} / \mathrm{rGO}$ anode material can provide an excellent rate capability of $270 \mathrm{mAh} \mathrm{g}^{-1}$ at a high current rate of $10 \mathrm{C}$ and an initial capacity of $900 \mathrm{mAh} \mathrm{g}^{-1}$ at $0.1 \mathrm{C}$ [Figure $9 \mathrm{~A}$ ]. Over 100 cycles at $1 \mathrm{C}$, the capacity of the $\mathrm{Bi}_{2} \mathrm{O}_{3} / \mathrm{rGO}$ anode material is maintained at $347.3 \mathrm{mAh} \mathrm{g}^{-1}$ and its capacity retention rate is $79 \%$ [Figure 9B]. The diffusion coefficient of $\mathrm{Li}^{+}$is $\sim 10^{-15}-10^{-16} \mathrm{~cm}^{2} \mathrm{~S}^{-1}$ during the lithiation/delithiation of $\mathrm{Bi}_{2} \mathrm{O}_{3} / \mathrm{rGO}$ nanocomposites ${ }^{[23]}$.

The specific initial charge/discharge capacity of bare $\mathrm{Bi}_{2} \mathrm{~S}_{3}$ is 598 and $921 \mathrm{mAh} \mathrm{g}^{-1}$, respectively. The charge/discharge capacity of a $\mathrm{Bi}_{2} \mathrm{~S}_{3} / \mathrm{rGO}$ composite at $100 \mathrm{~mA} \mathrm{~g}^{-1}$ is 685 and $1004 \mathrm{mAh} \mathrm{g}^{-1}$, which is $14.5 \%$ and $9.0 \%$ higher than that of $\mathrm{Bi}_{2} \mathrm{~S}_{3}$, respectively. The retention rate of the capacity of $\mathrm{Bi}_{2} \mathrm{~S}_{3}$ is only $0.4 \%$ $\left(4 \mathrm{mAh} \mathrm{g}^{-1}\right)$ after 50 cycles, far less than that of $\mathrm{Bi}_{2} \mathrm{~S}_{3} / \mathrm{rGO}\left[11.9 \%,\left(110 \mathrm{mAh} \mathrm{g}{ }^{-1}\right)\right]$. These results show that graphene not only increases the electrochemical activity of the whole electrode but also greatly improves the conductivity of $\mathrm{Bi}_{2} \mathrm{~S}_{3}$ during cycling ${ }^{[155]}$. The layered structure of $\mathrm{Bi}_{2} \mathrm{~S}_{3}$ also provides host sites for the insertion of $\mathrm{Na}$ ions. CNTs play a role in promoting the high conductivity network of electron transport in $\mathrm{Bi}_{2} \mathrm{~S}_{3} / \mathrm{CNT}$ nanocomposites. The results exhibit that $\mathrm{Bi}_{2} \mathrm{~S}_{3} / \mathrm{CNT}$ nanocomposites have a stable capacity in the range of 0.01-3.0 $\mathrm{V}\left(v s . \mathrm{Na} / \mathrm{Na}^{+}\right)$, particularly better than bare $\mathrm{Bi}_{2} \mathrm{~S}_{3}$ material $s^{[156]}$. Bismuth directly developed on nickel foam ( $\mathrm{p}-\mathrm{Bi}_{2} \mathrm{O}_{3} / \mathrm{Ni}$ ) has excellent electrochemical properties compared with $\mathrm{Bi}_{2} \mathrm{O}_{3}$ powder $\left(\mathrm{p}-\mathrm{Bi}_{2} \mathrm{O}_{3}\right)$ prepared by a polymer-assisted solution and commercial $\mathrm{Bi}_{2} \mathrm{O}_{3}\left(\mathrm{c}-\mathrm{Bi}_{2} \mathrm{O}_{3}\right)$. The capacity of $\mathrm{p}-\mathrm{Bi}_{2} \mathrm{O}_{3} / \mathrm{Ni}$ was maintained at $782 \mathrm{mAh} \mathrm{g}^{-1}$ over 40 cycles at $800 \mathrm{~mA} \mathrm{~g}^{-1[157]}$.

Of the chalcogens, $\mathrm{S}$ as a cathode material for lithium-sulfur batteries has been widely studied because of its low cost and high theoretical gravimetric energy density of $2570 \mathrm{Wh} \mathrm{kg}^{-1}$. By the one-electron transfer method, synthesizing $\mathrm{LiO}_{2}$ by absorbing oxygen on the surface of $\mathrm{Li}$ was proposed to reduce the oxygen content of $\mathrm{Li}$ and then one electron reduction to form $\mathrm{Li}_{2} \mathrm{O}_{2}$ (solid). It is also proposed that $\mathrm{LiO}_{2}$ can chemically decompose to $\mathrm{Li}_{2} \mathrm{O}_{2}$ and $\mathrm{O}_{2}$. Furthermore, $\mathrm{Li}_{2} \mathrm{O}_{2}$ is reduced to $\mathrm{LiO}_{2}$ in the discharge potential range of $\mathrm{Li}-\mathrm{O}_{2}$ batteries $(2.8-2.0 \mathrm{~V} \mathrm{Li})$. The specific capacities of $\mathrm{Li}$-air batteries are dominated due to the electrode porosity required for the storage of $\mathrm{Li}_{2} \mathrm{O}_{\mathrm{x}}$ and by the diffusion of oxygen through the pores of flooded electrolytes. Therefore, using electrolytes with high oxygen solubility and oxygen pressure enhances 

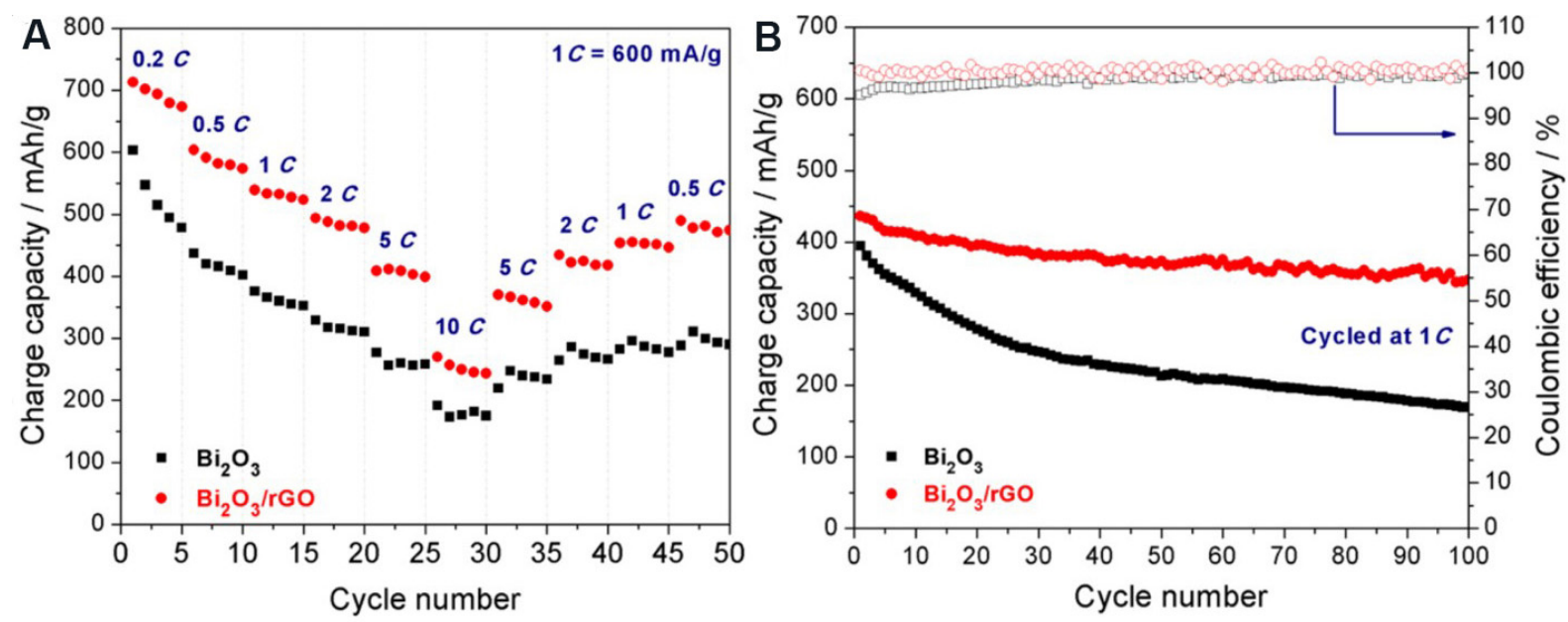

Figure 9. (A) Rate and (B) cycling performance of $\mathrm{Bi}_{2} \mathrm{O}_{3}$ and $\mathrm{Bi}_{2} \mathrm{O}_{3} / \mathrm{rGO}$ anode materials at 0.01-3.0 V vs. $\mathrm{Li} / \mathrm{Li}^{+}$. Reproduced with permission from Ref. ${ }^{[23]}$ (Copyright 2017, American Chemical Society).

the specific activity. Usually, the reported specific capacities for carbon-based Li-air cathodes are 2500-5000 $\mathrm{mAh} \mathrm{g}^{-1}$. Pt/C is a useful catalyst for the charging of $\mathrm{LiO}_{2}$ batteries and it provides one of the lowest charging voltages $\left(3.8 \mathrm{~V} \mathrm{Li} \text { at } 250 \mathrm{~mA} \mathrm{~g}^{-1}\right)^{[158]}$.

Li-S batteries are extremely promising for future two-electron reaction energy storage systems. Li-S has a capacity of $1675 \mathrm{mAh} \mathrm{g}^{-1}$, which is much greater than typical LIBs $\left(387 \mathrm{Wh} \mathrm{kg}^{-1}\right)$. Furthermore, elemental sulfur has other advantages, such as its abundance in nature and low environmental pollution and cost. However, there are many barriers to improving Li-S batteries, including the dissolution of polysulfides in the liquid electrolyte and reaction of intermediates with the Li anode in the electrolyte, leading to the migration of low-order polysulfides towards the cathode and the "shuttle effect". The slow decay of active S from the cathode into the electrolytic solution and onto the Li metal anode also results in "shuttle reactions", severe degradation of cycle life, low Coulombic efficiency, low utilization of the cathode, selfdischarge, poor conductivity of $\mathrm{S}$ and a large expansion in volume (80\%) from $\mathrm{S}$ to $\mathrm{Li}_{2} \mathrm{~S}$ after lithiation, resulting in rapid capacity decay and instability of the cathode.

Extensive research attempts have been devoted to resolving these challenges. Chen et al. ${ }^{[159]}$ successfully anchored S nanoparticles on the surface of multiwalled CNTs to improve the sulfur cycling performance. The capacities of the S/C nanocomposites were increased up to $1000 \mathrm{mAh} \mathrm{g}^{-1}$, depending on the content of S in the composite material. Ji et al. ${ }^{[160]}$ noted that mesoporous carbon/sulfur nanofillers had a specific capacity of up to $1300 \mathrm{mAh} \mathrm{g}^{-1}$. Carbon enhances the electrical contact between the carbon matrix and insulating sulfur particles and decreases the solubility of the polysulfides by anchoring the sulfur particles on some supports. However, the manufacturing procedure of these composite materials is complicated. Xiao et al. ${ }^{[161]}$ stated that $\mathrm{MoS}_{2}$ may reduce to $\mathrm{Li}_{2} \mathrm{~S}$ and $\mathrm{Mo}$ at $0.01 \mathrm{~V}\left(v s . \mathrm{Li}^{+} / \mathrm{Li}\right)$.

However, it has been experimentally clarified that the Li storage process of a fully discharged $\mathrm{MoS}_{2} / \mathrm{Li}$ cell estimates the feasibility of applying $\mathrm{Li}_{2} \mathrm{~S}$ as a cathode active material with carbonate-based electrolytes in $\mathrm{Li}$ $S$ batteries ${ }^{[162]}$. Therefore, Li-S batteries undergo rapid capacity decay and low Coulombic efficiency, thereby hindering the commercialization of $\mathrm{S}$ cathodes. The polar oxygen-containing functional groups in graphene oxide nanosheets are eliminated by microwave irradiation. $\mathrm{S}_{2} \mathrm{O}_{3}{ }^{2-}$ ions are reduced to nanostructures by $\mathrm{HCl}$ treatment after adding $\mathrm{Na}_{2} \mathrm{~S}_{2} \mathrm{O}_{3}$ into the suspension of irradiated GO. The mixture of GOF/nano-S is evenly 
dispersed in a VC-Na solution and heated for $3 \mathrm{~h}$ at $95^{\circ} \mathrm{C}$ to obtain the mixture of rGOF/nano-S, as given in Figure 10A. When the specific capacity of $\mathrm{rGOF} /$ nano-S hybrids $\left(\sim 886 \mathrm{mAh} \mathrm{g}^{-1}\right)$ is compared with $\mathrm{rGO} /$ nano-S (612 $\mathrm{mA} \mathrm{h} \mathrm{g}^{-1}$ ), it is again proved that the sulfur utilization ratio of the rGOF/nano-S hybrid structure at $0.1 \mathrm{C}$ is better than that of the $\mathrm{rGO} /$ nano-S structure. In addition, the rate performance [Figure $10 \mathrm{~B}$ ] shows that when the discharge rate is raised from 0.1 to $2.0 \mathrm{C}$, the discharge capacity of the $\mathrm{rGO} /$ nano-S hybrid material is still greater than $531 \mathrm{mAh} \mathrm{g}^{-1}$ (61\%). Figure $10 \mathrm{C}$ compares the cycling performance of the rGOF/nano-S and rGO/nano-S hybrid cathodes. The initial specific capacity of the $\mathrm{rGO} /$ nano-S cathode is $598 \mathrm{mAh} \mathrm{g}^{-1}$ and it remains $408 \mathrm{mAh} \mathrm{g}^{-1}$ (68.3\%) over 800 cycles, showing that the

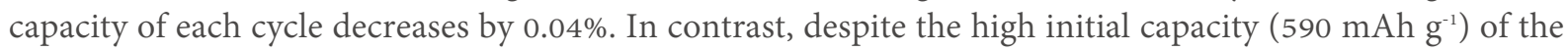
$\mathrm{rGO} /$ nano-S hybrids, their capacity is rapidly reduced to $181 \mathrm{mAh} \mathrm{g}^{-1}$ over 800 cycles and the capacity of each cycle is decreased by $0.09 \%$. This capacity decay is equivalent to the reported values in the literature $e^{[163]}$.

Like sulfur, selenium is also a chalcogen and may become a candidate material for cathodes in the future. The theoretical gravimetric capacity of Se is $675 \mathrm{mAh} \mathrm{g}^{-1}$, which is lower than S (1675 $\left.\mathrm{mAh} \mathrm{g}^{-1}\right)$, but its high density ( 2.5 times that of $\mathrm{S}$ ) contributes to a higher theoretical capacity density $\left(3253 \mathrm{mAh} \mathrm{cm}^{-3}\right)$, which is almost equal to $\mathrm{S}\left(3467 \mathrm{mAh} \mathrm{cm}^{-3}\right)$. Li-Se batteries have better output voltage and volumetric energy density. Volumetric energy is far most significant than gravimetric energy in portable devices due to its limited battery packaging space. Furthermore, the conductivity of Se $\left(1103 \mathrm{~S} \mathrm{~m}^{-1}\right)$ is better than $\mathrm{S}\left(51028 \mathrm{~S} \mathrm{~m}^{-1}\right)$, which indicates that Se has good electrochemical activity, a high utilization rate and fast electrochemical reaction with Li. Therefore, Se is believed to be a promising material for the manufacturing of high-energy batteries for transportation and household appliances. Cui et al ${ }^{[164]}$ recently used Se as a cathode material and noted that the consumption of active substances in bulk Se is $20.45 \%$. This phenomenon is generally not observed in Li-S batteries. Se has higher electrochemical activity and a weak shuttle effect compared to S. However, the synthesis of polyselenide during charge and discharge, weakens the interaction between the conductive substrate and Se, which leads to the shuttle effect and fades the cycling performance of the cathode and as a result, the full theoretical capacity of bulk Se cannot be achieved. This problem can be solved by using a porous conductive carbon matrix.

A Se composite containing only mesoporous carbon cyclic $\mathrm{Se}_{8}$ molecules (CMK-3) has been synthesized. $\mathrm{XRD}$ and Raman spectroscopic analysis show that it is because of the conversion of cyclic $\mathrm{Se}_{8}$ into $\mathrm{Se}_{\mathrm{n}}$ on the carbon channel. Due to the strong attraction between carbon mesopores and $\mathrm{Se}_{\mathrm{n}}, \mathrm{Se}_{\mathrm{n}}$ has high electrochemical performance. As a result, the cathode of Se gives a better capacity, close to the theoretical capacity of Se and maintains cycling stability ${ }^{[165]}$. The Se/CMK-3 cathode provides an excellent reversible discharge capacity $\left(\sim 600 \mathrm{mAh} \mathrm{g}^{-1}\right)$ over 50 cycles. The unique arrangement of Se molecules restrained in a matrix of mesoporous carbon decreases the shuttle effect and gives excellent cycling performance, high volumetric energy density and better conductivity for LIBs $^{[165]}$. It gives a reversible capacity of 516 and $306 \mathrm{mAh} \mathrm{g}^{-1}$ for LIBs over 900 cycles at 0.5 and $4 \mathrm{~A} \mathrm{~g} \mathrm{~g}^{-1}$, respectively.

A flexible Se/porous carbon nanofiber composite material (Se/PCNFs) was synthesized by infiltrating Se into the pores of CNFs and gave a reversible capacity of $516 \mathrm{mAh} \mathrm{g}^{-1}$ at $0.05 \mathrm{~A} \mathrm{~g}^{-1}$ over 900 cycles and $306 \mathrm{mAh} \mathrm{g}^{-1}$ at $4 \mathrm{~A} \mathrm{~g} \mathrm{~g}^{-1}$. The uniform distribution of Se in the three-dimensional PCNF framework reduces the shuttle effect of polyselenide in the cycling process and gives excellent conductivity, a better rate capability, high capacity and good cycling stability ${ }^{[166]}$. Se has higher electrical conductivity $\left(1 \times 10^{-3} \mathrm{Sm}^{-1}\right)$ than $\mathrm{S}\left(5 \times 10^{-28} \mathrm{~S} \mathrm{~m}^{-1}\right)$, which has led to Li-Se batteries receiving significant attention in recent years. It should be emphasized that $\mathrm{Se}$ is the neighbor of $\mathrm{S}$ in the periodic table, which makes them very similar in many properties. Thus, the general problems of Li-S batteries also exist for Li-Se batteries, but the Se advantages can make this kind of rechargeable batteries more useful. Nevertheless, the key focus remains on 


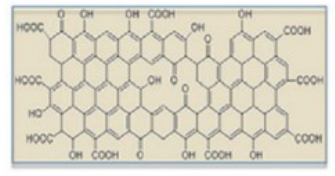

A

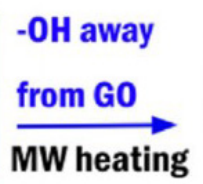

MW heating
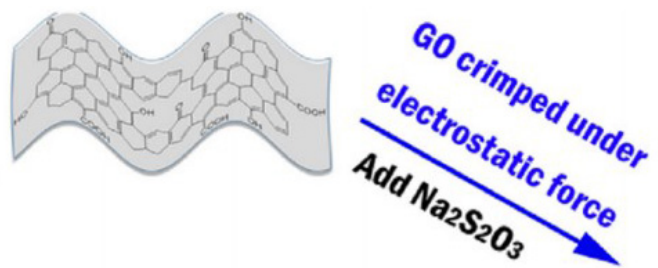
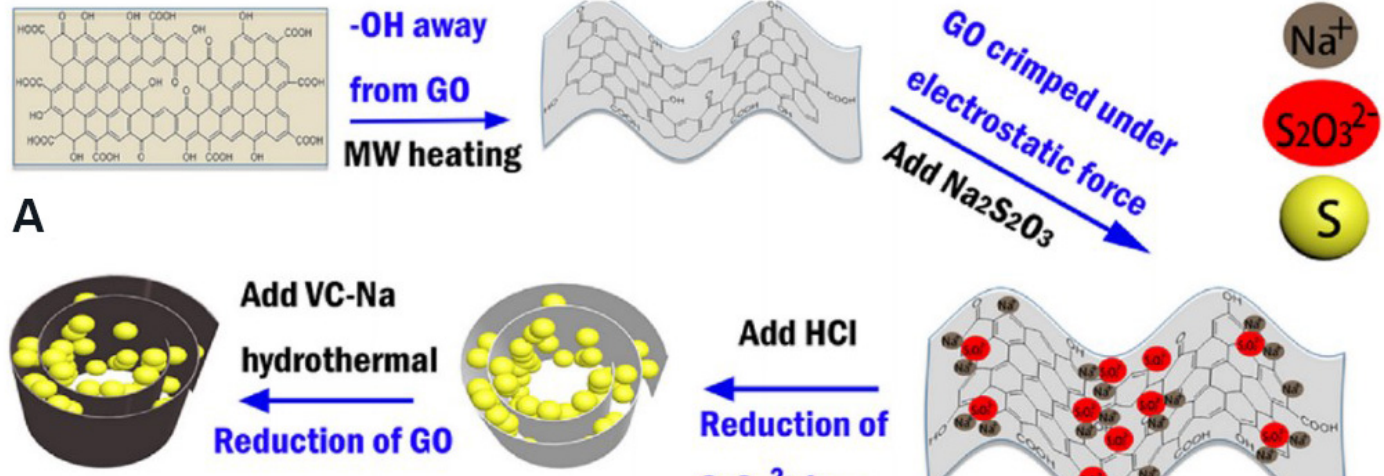

\section{Add $\mathrm{HCl}$}
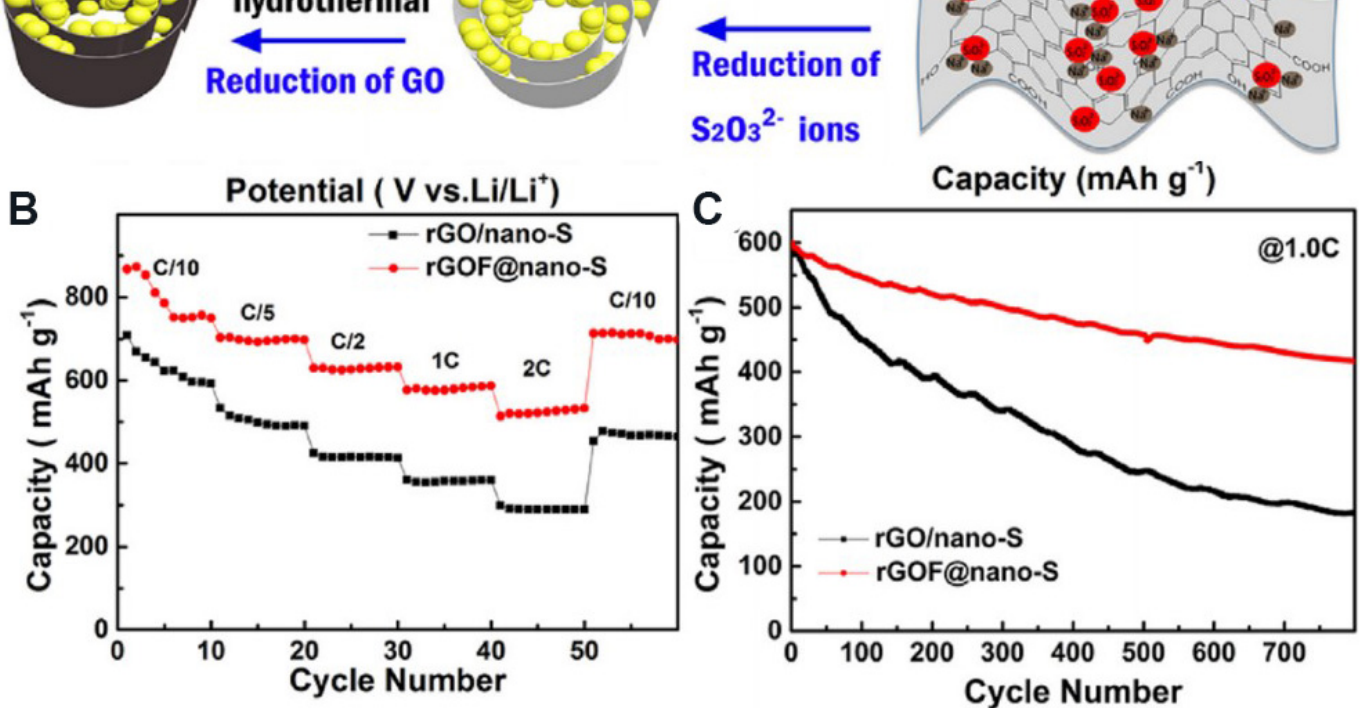

Figure 10. (A) Schematic representation of the synthesis of $\mathrm{rGOF/nano-S} \mathrm{hybrids.} \mathrm{(B)} \mathrm{Rate} \mathrm{capabilities} \mathrm{and} \mathrm{(C)} \mathrm{cycling} \mathrm{performance} \mathrm{of}$ $\mathrm{rGOF/nano-S} \mathrm{and} \mathrm{rGO/nano-S.} \mathrm{Reproduced} \mathrm{with} \mathrm{permission} \mathrm{from} \mathrm{Ref.}{ }^{[163]}$ (Copyright 2019, Electrochimica Acta, Elsevier).

Li-S batteries. There are some unique properties of Li-Se batteries that require special attention. Se is much more expensive than $\mathrm{S}$ and its specific energy is less, but its invaluable advantages make it an attractive option compared to $S^{[167]}$.

Te is in the same group as $\mathrm{O}, \mathrm{S}$ and $\mathrm{Se} . \mathrm{A}$ Te/C composite was prepared by injecting liquid Te into the pores of porous carbon at $600{ }^{\circ} \mathrm{C}$. The Te/C electrode material can provide $1400 \mathrm{mAh} \mathrm{cm}{ }^{-3}\left(224 \mathrm{mAh} \mathrm{g}^{-1}\right)$, a high reversible capacity at $312 \mathrm{mAh} \mathrm{cm}^{-3}$ and maintain $87 \%$ capacity over 1000 cycles. If the current is enhanced by $12,480 \mathrm{~mA} \mathrm{~cm}^{-3}\left(2000 \mathrm{~A} \mathrm{~g}^{-1}\right)$, the electrode can provide $500 \mathrm{mAh} \mathrm{cm}{ }^{-3}$ capacity. Te/C is a promising electrode material for $\mathrm{LIBs}^{[168]}$. rGO has excellent flexibility, can be used to construct highly conductive 3D skeletons and can be used in binder-free self-supporting lithium tellurium ( $\mathrm{Li}$ - Te) batteries with excellent electrochemical performance to obtain rich porous cathode materials. The initial capacity of a $0.2 \mathrm{C} \mathrm{Li-Te}$ cathode material was $2611 \mathrm{mAh} \mathrm{cm}^{-3}$ and the retention rate over 200 cycles was as high as $88 \%$, with a rate capacity at $10 \mathrm{C}$ of $1083 \mathrm{mAh} \mathrm{cm}^{-3}$. After 500 cycles, the 3D aerogel cathode maintained a capacity of $1685 \mathrm{mAh} \mathrm{cm}^{-3}$ at $1 \mathrm{C}$ and exhibited long-cycling performance at high current density. Because of these useful properties, the stated $3 \mathrm{D} \mathrm{rGO} / \mathrm{Te}$ nanowire aerogel has potential applications and can be utilized as a high-performance cathode for Li-Te batteries ${ }^{[169]}$.

Since it is complicated to use $\mathrm{F}_{2}$ gas as a cathode material, various fluorides, chlorides, sulfides and oxides have been examined. Subsequently, it was found that graphite fluoride is the most excellent cathode material for a primary LIB. The first Li/ $(\mathrm{CF})_{\mathrm{n}}$ battery was commercialized by Matsushita Battery Co., Ltd. in 
1973 in Japan. It was noticed in 1980 that fluorine is absorbed into graphite at room temperature and a fluorine-graphite intercalation compound was synthesized as a result. This material is an electric conductor and is significantly different from graphite fluoride, which was applied to a new graphite anode material using $\mathrm{KF}_{2} \mathrm{HF}$ for the electrolytic production of $\mathrm{F}_{2}$ gas ${ }^{[170]}$. The wettability of $\mathrm{KF}_{2} \mathrm{HF}$ melt with carbon anode is therefore reduced with increasing CF film having a low surface energy, which result in abrupt decrease in electrolytic current and simultaneously increase in cell potential. This phenomenon is known as the "anode effect". As a result of the "anodic effect", a spark or arc is observed between the cathode and anode and electrolysis cannot be sustained. Carbon materials react with $\mathrm{F}_{2}$ gas giving several different side products ( $\mathrm{CF}, \mathrm{C}_{2} \mathrm{~F}, \mathrm{CF}_{4}$ and $\mathrm{C}_{2} \mathrm{~F}_{6}$ ) depending on the crystalline nature of the raw carbon materials and reaction temperature ${ }^{[170]}$.

We can also use graphite oxide for smooth discharge but it is difficult due to the reaction products, such as $\mathrm{LiOH}$ and $\mathrm{Li}_{2} \mathrm{O}$, which are not as stable as $\mathrm{LiF}$. It gives a low discharge capacity because the diffusion of $\mathrm{Li}^{+}$ ions in graphite oxide is slow. However, the discharge properties can be modified by the fluorination of graphite oxide at low temperatures between $100-150^{\circ} \mathrm{C}$. The discharge capacity of fluorinated graphite oxides is similar to those of $(\mathrm{CF})_{n}$ samples. $\mathrm{C}_{\mathrm{x}} \mathrm{F}$ synthesized at room temperature contains $\mathrm{C}-\mathrm{F}$ covalent bonds and works as a cathode material in primary LIBs. It gives a higher discharge potential capacity but the current is reduced ${ }^{[170]}$. $\mathrm{Li} /(\mathrm{CF})_{\mathrm{n}}$ batteries have a long life and high stability because graphite fluoride cathode materials are stable compounds under extreme conditions. Organofluorine compounds have much higher stability against the reactions with $\mathrm{Li}$ and electrochemical oxidation, effectively enhancing the safety of $\mathrm{LIBs}^{[170]}$. F-SnO $\mathrm{S}_{2}$ nanoparticles were anchored uniformly on the sheets of rGO by a hydrothermal process. The load of $\mathrm{F}-\mathrm{SnO}_{2}$ in the composite $\left(\mathrm{F}-\mathrm{SnO}_{2} / \mathrm{rGO}\right)$ was high $(\sim 90 \%)$. The diffusion and conductivity of $\mathrm{Li}^{+}$ in the electrode are improved by doping $\mathrm{F}$ with $\mathrm{rGO}$, which enhances the rate performance, long-term cycling stability and reversible capacity of the composite material. The electrode provides a reversible capacity of 860 and $770 \mathrm{mAh} \mathrm{g}^{-1}$ at 1 and $2 \mathrm{~A} \mathrm{~g}^{-1}$, respectively, over 150 cycles. Furthermore, over 250 cycles at $500 \mathrm{~mA} \mathrm{~g}^{-1}$, the electrode can maintain a high reversible capacity of $733 \mathrm{mAh} \mathrm{g}^{-1}$. The composite has excellent electrochemical properties and can be used as a high-energy LIB anode material ${ }^{[171]}$.

Tin oxide $\left(\mathrm{SnO}_{2}\right)$ has a high theoretical capacity; however, its fast fading capability during cycling causes volume expansion, which prohibits its practical application in LIBs. However, if a FTO nanocomposite is used with rGO as an anode active material, it gives a high stability, rate capability and capacity. The composite material (FTO/rGO) has high structural stability through the processes of lithiation and delithiation. The nanocrystals of FTO are conductive and conducive to the synthesis of a stable and solid film of electrolytes. The FTO/rGO composite at a current density of $100 \mathrm{~mA} \mathrm{~g}^{-1}$ provides a discharge capacity of $1439 \mathrm{mAh} \mathrm{g}^{-1}$ and at a current density of $1000 \mathrm{~mA} \mathrm{~g}^{-1}$, provides a rate capacity of $1148 \mathrm{mAh} \mathrm{g}^{-1}$ after 200 cycles $^{[144]}$. Polyvinylidene fluoride and polyvinyl alcohol were also examined as potential binding materials for the $\mathrm{Li}, \mathrm{Na}, \mathrm{K}, \mathrm{Zn}, \mathrm{Al}$ and $\mathrm{Ag}_{2} \mathrm{O}$ electrodes.

Like $\mathrm{F}, \mathrm{Cl}$ is also a gas and cannot be used directly. It is instead used in the form of compounds. Polyaniline can be prepared by a usual chemical oxidation method and then the hydrogen atom on the six-membered ring was replaced by $\mathrm{HCl}$. As a result, polyaniline chloride was produced for high-energy secondary LIBs as a cathode material. A button-type battery was prepared and examined through a charge/discharge test, which shows an excellent initial discharge capacity of $\sim 980 \mathrm{mAh} \mathrm{g}^{-1[172]}$.

\section{D-block elements (transition metals)}

Transition metal oxides with different oxidation states are promising energy storage materials for supercapacitors and batteries. Fast surface redox storage (pseudocapacitive) techniques can allow devices to 
store far more energy than electrical double-layer capacitors (EDLCs). However, due to their low inherent electrical and ionic conductivity, only a few pseudocapacitive transition metal oxides can deliver significant power.

Scandium (Sc) is the first member of the first transition series. Alloys comprising Sc and Mg have showed a very promising storage capacity of $1500 \mathrm{mAh} \mathrm{g}^{-1}$, which is four times that of metal-based materials. Palladium-capped thin films of $\mathrm{Mg}_{\mathrm{S}} \mathrm{Sc}_{(1-\mathrm{x})}$ with different concentrations $(\mathrm{x}=0.50-0.90$ ) enhance the hydrogen storage capacity by $5 \%-20 \%$ compared to their bulk materials, even using higher discharge rates ${ }^{[173]}$. $\mathrm{Li}_{3} \mathrm{Sc}_{2}\left(\mathrm{PO}_{4}\right)_{3}$ is a promising electrolyte for Li rechargeable micro-batteries due to its resistance to dielectric breakdown, ease of preparation and stability in air. The formation of $\operatorname{Li}_{3}\left(\mathrm{Sc}_{2-\mathrm{x}} \mathrm{M}_{\mathrm{x}}\right)\left(\mathrm{PO}_{4}\right)_{3}\left(\mathrm{M}=\mathrm{Y}^{3+}\right.$ or $\mathrm{Al}^{3+}$ ) resulted in a considerable improvement in ionic conductivity, greater sinterability and a decrease of porosity. $\mathrm{Li}_{3} \mathrm{Sc}_{2}\left(\mathrm{PO}_{4}\right)_{3}$ is yielded by the electron beam evaporation of amorphous thin films of $\mathrm{Li}_{4.8} \mathrm{Sc}_{1.4}\left(\mathrm{PO}_{4}\right)_{3}$ with high ionic conductivity $\left(5 \times 10^{-5} \mathrm{~S} \mathrm{~cm}^{-1}\right)^{[174]}$.

Among all anode materials, $\mathrm{TiO}_{2}$ has the advantages of a comparatively high working voltage $\left(1.5 \mathrm{~V} v s . \mathrm{Li}^{+}\right.$ /Li) and extremely small volume change $(<4 \%)$, making it a promising electrode material. The small volume change, high working voltage and excellent long-term cycling stability avoid the synthesis of the solid electrolyte interface layer (SEI) and a lower irreversible capacity. The anatase form of $\mathrm{TiO}_{2}$ has a theoretical capacity of $335 \mathrm{mAh} \mathrm{g}^{-1}$; however, its poor ionic and electronic conductivity fade its rate performance and cycling stability. The use of specific facets, namely, (001), (101) or (010), for $\mathrm{Ti}^{3+}$ carbon coupling and doping (reduction or hydrogenation by $\mathrm{Mg}$ ) is a useful method for overcoming the above obstacles because these methods can provide greater electronic conductivity and shorter ion diffusion pathways.

In particular, a number of excellent studies have been carried out on $\mathrm{TiO}_{2} / \mathrm{MXene}, \mathrm{TiO}_{2} /$ graphene and $\mathrm{TiO}_{2} / \mathrm{C}^{[175]}$. The typical charge/discharge curves of graphene/Si, $\mathrm{TiO}_{2} /$ graphene/Si, $\mathrm{TiO}_{2} /$ graphene/SiNW, $\mathrm{TiO}_{2} /$ graphene/Ag/SiNW and $\mathrm{TiO}_{2} / \mathrm{N}$-graphene/Ag/SiNW nanocomposites show discharge capacities of 333.5, 525.9, 693.1, 836.7 and $966.1 \mathrm{mAh} \mathrm{g}^{-1}$, respectively, as presented in Figure 11A. The high Li storage capacity of $\mathrm{TiO}_{2} / \mathrm{N}$-graphene/Ag/SiNWs is due to the high specific surface area of the SiNWs and the high conductivity of graphene. The rate capabilities of the graphene/Si, $\mathrm{TiO}_{2} /$ graphene/Si, $\mathrm{TiO}_{2} /$ graphene/SiNW, $\mathrm{TiO}_{2} /$ graphene/Ag/SiNW and $\mathrm{TiO}_{2} / \mathrm{N}$-graphene/Ag/SiNW nanocomposites at different current rates are given in Figure $11 \mathrm{~B}$. As the current rate increased to $5 \mathrm{~A} \mathrm{~g} \mathrm{~g}^{-1}$, the specific capacity of the $\mathrm{TiO}_{2} / \mathrm{N}$ graphene/Ag/SiNW electrode decreased slowly, showing the highest specific capacity. The $\mathrm{TiO}_{2} / \mathrm{N}$ graphene/Ag/SiNW electrode had a high specific surface area, conductivity and mesoporosity. Figure 11C shows that all the EIS curves include semicircles in the range of high-frequency lines to the low-frequency range, which are fixed at a constant angle to the actual axis. The semicircle diameter of the $\mathrm{TiO}_{2} / \mathrm{N}$ graphene/Ag/SiNWs is much smaller than that of other semicircles, indicating that the $\mathrm{TiO}_{2} / \mathrm{N}$ graphene/ $\mathrm{Ag} / \mathrm{SiNW}$ s have interfacial and charge transfer resistance between the three electrodes. This is because $\mathrm{N}$-graphene/Ag substantially increases the electronic transport and its hollow structure enhances the ionic conductivity ${ }^{[176]}$.

Vanadium pentoxide $\left(\mathrm{V}_{2} \mathrm{O}_{5}\right)$ is a potential cathode material with the advantages of rich reserves, high energy density, low costs and easy preparation. The theoretical capacity of $\mathrm{V}_{2} \mathrm{O}_{5}$ at $2-4 \mathrm{~V}$ is $\sim 294 \mathrm{mAh} \mathrm{g}^{-1}$, which is superior to the conventional cathode materials $\mathrm{LiFePO}_{4}\left(176 \mathrm{mAh} \mathrm{g}^{-1}\right)$ and $\mathrm{LiMn}_{2} \mathrm{O}_{4}\left(148 \mathrm{mAh} \mathrm{g} \mathrm{g}^{-1}\right)$. Regardless of these advantages, the electrochemical performance of $\mathrm{V}_{2} \mathrm{O}_{5}$ is restricted by its sluggish diffusion of Li ions $\left(\sim 10-12 \mathrm{~cm}^{-2} \mathrm{~S}^{-1}\right)$ and its poor electrical conductivity $\left(10^{-3}\right.$ to $\left.10^{-2} \mathrm{~S} \mathrm{~cm}^{-1}\right)$. Moreover, the phase transitions of $\mathrm{Li}_{\mathrm{x}} \mathrm{V}_{2} \mathrm{O}_{5}$ during the charge/discharge process regularly cause structural instability and can decrease its cycling performance. These shortcomings have limited the practical application of $\mathrm{V}_{2} \mathrm{O}_{5}$ in 

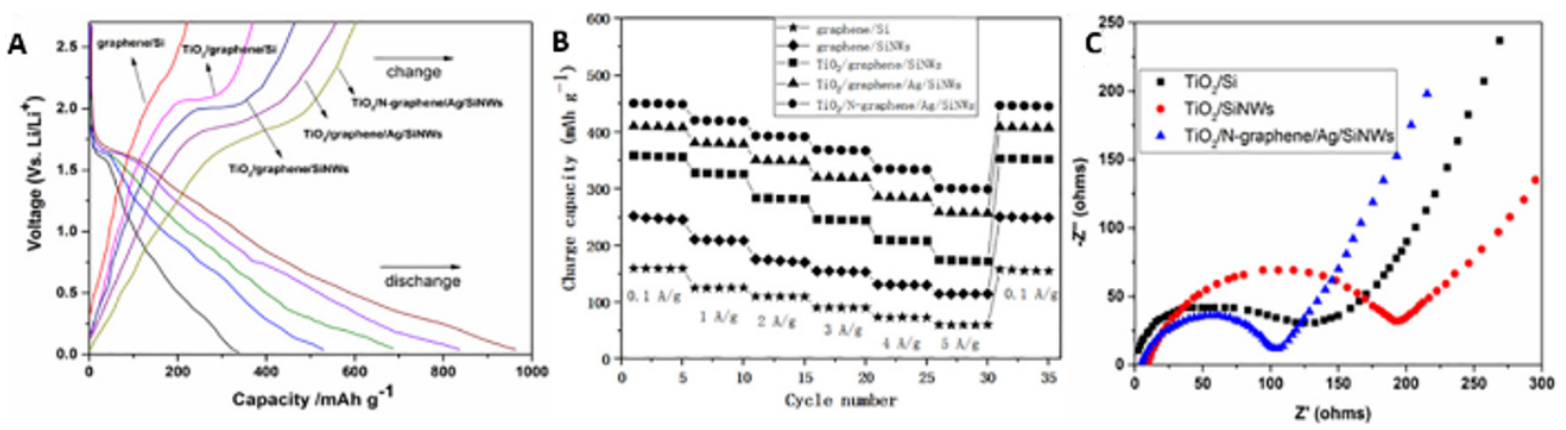

Figure 11. (A) Charge/discharge profiles, (B) comparison of rate capability and (C) ElS analysis of graphene/Si, $\mathrm{TiO}_{2} / \mathrm{graphene}_{\mathrm{Si}}, \mathrm{TiO}_{2}$ /graphene/ $\mathrm{SiNW}, \mathrm{TiO}_{2} /$ graphene/Ag/SiNW and $\mathrm{TiO}_{2} / \mathrm{N}$-graphene/Ag/SiNW electrodes. Reproduced with permission from Ref. ${ }^{[176]}$ (Copyright 2019, Materials Letters, Elsevier).

commercial LIBs ${ }^{[177]}$. $\mathrm{Ag}_{\mathrm{x}} \mathrm{V}_{2} \mathrm{O}_{5}$ shows higher discharge capacities, which seem to be credited to the higher diffusion of $\mathrm{Li}^{+}$in Ag-doped $\mathrm{V}_{2} \mathrm{O}_{5}$ compared to bare $\mathrm{V}_{2} \mathrm{O}_{5}$ thin-film cathode materials. The poor discharge capacity of $\mathrm{Ag}_{1.8} \mathrm{~V}_{2} \mathrm{O}_{5}$ films seems to be due to the cauliflower-like structure of the films. All thin-film solidstate batteries showed excellent reversibility up to 200 cycles. The energy density of the material is relatively low at $\sim 40 \mathrm{Wh} \mathrm{kg}^{-1}$; however, recent research showed that a modified electrolyte solution produces a $70 \%$ enhancement in energy density ${ }^{[178]}$.

The most important benefit of vanadium redox batteries (VRBs) is that it can be charged only by changing the electrolyte and can provide unlimited capacity by using a large storage tank. If the electrolyte is accidentally mixed, the battery will not be permanently damaged and it can be left uncharged for long periods without any effects. The disadvantage of VRBs is that compared with standard batteries, they are complex and their energy volume ratio is relatively low ${ }^{[178]}$. $\mathrm{Ti}_{3} \mathrm{C}_{2}$ MXenes provide a capacity of $410 \mathrm{mAh} \mathrm{g}^{-1}$ for LIBs. Interestingly, the capacity of MXenes can be as high as $800 \mathrm{mAh} \mathrm{g}^{-1}$ after intercalation with different cations, such as $\mathrm{Sn}^{4+}, \mathrm{NH}^{4+}$ and $\mathrm{Al}^{3+}$. Compared with the $\mathrm{Ti}_{3} \mathrm{C}_{2}$ MXene, the $\mathrm{V}_{2} \mathrm{C}$ MXene with a smaller molecular weight can obtain a higher theoretical LIB capacity of $940 \mathrm{mAh} \mathrm{g}^{-1}$. Unfortunately, the experimental capacity of $\mathrm{V}_{2} \mathrm{C}$ MXene is $260 \mathrm{mAh} \mathrm{g}^{-1}$ at $1 \mathrm{C}$, which is very far from the theoretical value. Recently, it has been found that the $\mathrm{V}_{2} \mathrm{C}$ MXene with Co ion intercalation can provide a $1100 \mathrm{mAh} \mathrm{g}^{-1} \mathrm{Li}^{+}$ storage capacity and better cycling stability ${ }^{[179]}$.

The Ragone diagram in Figure 12A gives the relationship between the density of power and energy for vanadium oxide with different $\mathrm{Na}, \mathrm{Ca}, \mathrm{Zn}$ and $\mathrm{H}_{2} \mathrm{O}$ interlayer ions and molecules, as well as materials other than vanadium oxide, such as $\mathrm{Na}_{2} \mathrm{~V}_{2}(\mathrm{PO})_{2} \mathrm{~F}_{3} / \mathrm{C}, \mathrm{VS}_{2}$ and $\mathrm{Z}_{\mathrm{n}} \mathrm{HCF}$. Compared with $\mathrm{Zn}_{0.25} \mathrm{~V}_{2} \mathrm{O}_{5}$ in the low power range and $\mathrm{Ca}_{0.25} \mathrm{~V}_{2} \mathrm{O}_{5}$ in the high power range, VONTs provide balanced power and energy density with superior performance in ZIBs. VONTs have a wider working voltage, high discharge capacity and better stability against over-discharge. In addition, the cathode also provides a relatively high discharge capacity between the comparative materials. These cathodes at different current densities of $0.3 \mathrm{~A} \mathrm{~g}^{-1}$ (1 C), $0.6 \mathrm{~A} \mathrm{~g}^{-1}$ (2.1 C), $1.2 \mathrm{~A} \mathrm{~g}^{-1}(4.7 \mathrm{C}), 2.4 \mathrm{~A} \mathrm{~g}^{-1}(11 \mathrm{C}), 4.8 \mathrm{~A} \mathrm{~g}^{-1}(30.5 \mathrm{C}), 7.2 \mathrm{~A} \mathrm{~g}^{-1}(60 \mathrm{C})$ and $9.6 \mathrm{~A} \mathrm{~g}^{-1}(109 \mathrm{C})$ retain specific capacities of $94.5 \%, 89.2 \%, 81.7 \%, 69.1 \%, 50 \%, 38 \%$ and $27.9 \%$, respectively, as shown in Figure $12 \mathrm{~B}$. The battery was tested at 0.3 and $0.1 \mathrm{~A} \mathrm{~g} \mathrm{~g}^{-1}$ and the discharge capacity recovered to 296 and $309 \mathrm{mAh} \mathrm{g}^{-1}$, respectively. As presented in Figure 12D, the cathode is activated for the first four cycles at $0.1 \mathrm{~A} \mathrm{~g}^{-1}$ to obtain the CV data. In this process, the CE slowly increased to $99.8 \%$ (the sixth cycle). The capacity retention rate of the cathode is $80.5 \%$ after 950 cycles at $2.4 \mathrm{~A} \mathrm{~g}^{-1}$, while the $\mathrm{CE}$ is close to $100 \%$ in all cycles, which shows that a minimal decrease in capacity produces outstanding durability under strong current fluctuation, as shown in Figure 12C. The reduction peaks shifted to a higher voltage and then stabilized at 

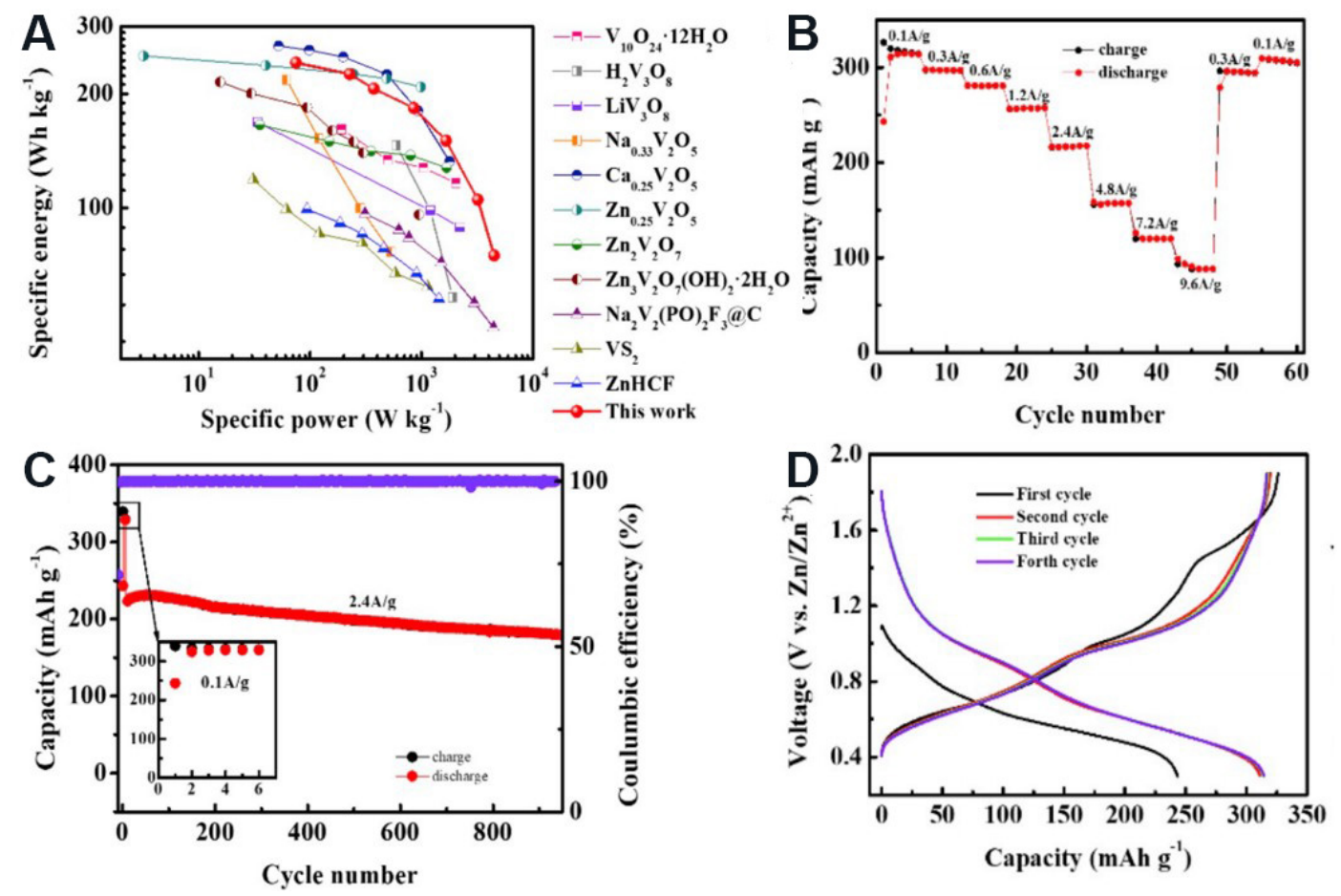

Figure 12. Electrochemical performance of coin cells with VONTs as cathode and $\mathrm{Zn}$ as anode in the range of $0.3-1.9 \mathrm{~V} v \mathrm{vs} . \mathrm{Zn} / \mathrm{Zn}^{+}:(\mathrm{A})$ Ragone plot of different materials; (B) rate performance at current densities from 0.1 to $9.6 \mathrm{~A} \mathrm{~g}^{-1}$; (C) charge/discharge curves; (D) cycling performance at a current density of $2.4 \mathrm{~A} \mathrm{~g}^{-1}$. Reproduced with permission from Ref. ${ }^{[180]}$ (Copyright 2019, Journal of Power Sources, Elsevier). VONTs: Vanadium oxide nanotubes.

0.419 and $0.815 \mathrm{~V}$, while the two oxidation peaks moved to the lower position and then stabilized at 0.736 and $1.1 \mathrm{~V}$, which proves that the change of peak value decreases with increasing cycling. The curve of the fourth cycle almost coincides with the curve of the third period. These phenomena show that the decrease of overpotential and enhancement of cycling stability are highly consistent with the curves of galvanostatic charge/discharge, as given in Figure 12 $\mathrm{D}^{[180]}$.

A comprehensive comparison, including cycle and charge/discharge tests and capital cost analyses, was provided for vanadium redox flow batteries (VRFBs) and iron-chromium redox flow batteries (ICRFBs). ICRFBs show similar energy efficiency with VRFBs at high current densities. Energy efficiencies of 78.4\% and $80.3 \%$ can be achieved for ICRFBs and VRFBs at $120 \mathrm{~mA} \mathrm{~cm}{ }^{2}$, respectively. Through the cycle test, the efficiencies of both RFBs were stable ${ }^{[181]}$.

Manganese $(\mathrm{Mn})$ can be reduced from $\mathrm{Mn}(\mathrm{IV})$ to $\mathrm{Mn}$ (II), which allows for full lithiation and gives $\mathrm{Li}_{2}$ $\mathrm{MnSiO}_{4}$, which may allow two Li-ion insertions/extractions for each transition metal and provides a theoretical capacity of $330 \mathrm{mAh} \mathrm{g}{ }^{-1[19]}$. It is reported that the capacity of a $\mathrm{Na}_{0.85} \mathrm{Li}_{0.17} \mathrm{Ni}_{0.21} \mathrm{Mn}_{0.64} \mathrm{O}_{2}$ cathode material is $95 \mathrm{mAh} \mathrm{g}^{-1}$ and it has better withholding capacity over 50 cycles. A single-crystal $\mathrm{Na}_{4} \mathrm{Mn}_{9} \mathrm{O}_{18}$ (orthogonal lattice structure) nanowire material with a capacity of $128 \mathrm{mAh} \mathrm{g}^{-1}$ and a cycling stability of more than 1000 times was also reported ${ }^{[182]}$.

Iron batteries have sufficient capabilities for commercial use in low-power projects and devices. The internal resistance of iron cells is high and therefore their discharge rate is limited. Poor transfer charge rates from the electrode of carbon to the $\mathrm{Fe}^{3+}$ in the cathode is because of the poor electrical conductivity of 
the electrolyte, poor ionic conductivity of the membrane and poor electrical contact among the components are several probable reasons for high resistance ${ }^{[183]}$. Iron batteries can oxidize $\mathrm{Fe}$ (II) to $\mathrm{Fe}$ (III) at the cathode and store energy by reducing $\mathrm{Fe}(\mathrm{II})$ to $\mathrm{Fe}(0)$ at the anode. Iron cells are non-toxic, efficient, highly stable and safe. Iron batteries have lower specific energy than commercial batteries but give the opportunity for safe handling and low-cost raw materials. Metal hydrides and Li are flammable, toxic, react strongly with water and oxidize in air. Iron is relatively non-toxic and is only marginally reactive with air and water (i.e., rust formation). Iron with sulfate solution is reliable and represents stable salt chemistry for all-iron batteries. As saturated potassium sulfate solution is mixed with iron chloride and the $\mathrm{pH}$ was adjusted to obtain the anodic electrolyte (iron(II) chloride), which is used as a cathode electrolyte ${ }^{[184]}$. Although iron(IV) can be easily synthesized, the safety concerns related to the high oxidation state, which prohibit its use. Other iron salt solutions were also examined, including solutions containing fructose, sucrose, ferric cyanide and EDTA. In solution, these unconventional systems exhibit similar behavior but the sulfate precursor exhibits the best Coulombic capacity. While using sulfate solution, less amount of iron is lost from the bulk of the metallic iron electrode over the charge/discharge process. During the reaction, the iron anode is oxidized, liberating electrons at the cathode ${ }^{[185]}$.

Iron oxides, especially $\mathrm{Fe}_{3} \mathrm{O}_{4}$ and $\mathrm{Fe}_{2} \mathrm{O}_{3}$, have attracted significant attention because of their high abundance, low processing costs, excellent theoretical capacity $\left(\sim 1000 \mathrm{mAh} \mathrm{g}^{-1}\right)$, strong corrosion resistance, nontoxicity and other advantages. High Li insertion potential and the good safety protection of nonflammability in large-scale applications are further advantages of iron oxide-based anode materials. The storage mechanism of iron oxide for Li depends on the redox reaction, i.e., the reduction of $\mathrm{Fe}_{2} \mathrm{O}_{3}$ to metal nanoclusters dispersed in the $\mathrm{Li}_{2} \mathrm{O}$ matrix and then the reduction to the initial oxidation state in the process of delithiation. The reaction mechanism of $\mathrm{Fe}_{2} \mathrm{O}_{3}$ with $\mathrm{Li}^{+}$is given by:

$$
\mathrm{Fe}_{2} \mathrm{O}_{3}+6 \mathrm{Li}^{+}+6 \mathrm{e}^{-} \leftrightarrow 3 \mathrm{Li}_{2} \mathrm{O}+2 \mathrm{Fe}
$$

The oxidation of $\mathrm{Fe}^{0}$ to $\mathrm{Fe}^{3+}$ gives three electrons, resulting in a high theoretical capacity for Li storage and is thermodynamically possible as shown in the above forward reaction. However, it seems that it is not feasible in thermodynamics to extract $\mathrm{Li}^{+}$from the $\mathrm{Li}_{2} \mathrm{O}$ matrix. In addition, the cyclability of iron oxides is poor because of the drastic volume decrease during cycling and has low conductivity, especially at high current density ${ }^{[186]}$. A $3 \mathrm{DG} / \mathrm{Fe}_{2} \mathrm{O}_{3}$ free-standing mechanical press was used to study the LIBs. The results show that the press has an excellent performance of $1129 \mathrm{mAh} \mathrm{g}^{-1} 2022 / 1 / 11$ at $0.2 \mathrm{~A} \mathrm{~g}^{-1}$ and excellent cycling stability over 130 cycles, while the capacity retention is $98 \%$ over 1200 cycles at $5 \mathrm{~A} \mathrm{~g}^{-1[187]}$. The direct anchoring of continuous MIO nanofilms on the surface of graphene nanosheets (GNSs) as LIB anode materials via an in situ thermal decomposition method was examined and the shrinking effect of the GNSs on the change of volume of MIO at the molecular level was reported. The MIO/GNS nanocomposite has an outstanding specific capacity of $\sim 1000 \mathrm{mAh} \mathrm{g}^{-1}$ at $100 \mathrm{~mA} \mathrm{~g}^{-1}$ and there is no capacity attenuation even over 400 cycles at $1000 \mathrm{~mA} \mathrm{~g}^{-1}$. This outstanding cycling performance is credited to the superior strain hosting capability of the MIO/GNS nanocomposite $e^{[188]}$.

From a comparison of the cycling properties of $\mathrm{Fe}_{3} \mathrm{O}_{4}-\mathrm{NP} / \mathrm{G}$ and $\mathrm{Fe}_{3} \mathrm{O}_{4}-\mathrm{NS} / \mathrm{G}$ composites at $0.2 \mathrm{C}$ for 160 cycles, the reversible capacity of the $\mathrm{Fe}_{3} \mathrm{O}_{4}-\mathrm{NS} / \mathrm{G}$ composite was maintained at $1025 \mathrm{mAh} \mathrm{g}^{-1}$ for 50 cycles and then decreased to $920 \mathrm{mAh} \mathrm{g}^{-1}$ for 100 cycles. It then began to increase, reaching $1070 \mathrm{mAh} \mathrm{g}^{-1}$ again after 160 cycles. In contrast, the reversible capacity of the $\mathrm{Fe}_{3} \mathrm{O}_{4}-\mathrm{NP} / \mathrm{G}$ composite rapidly decreased to $460 \mathrm{mAh} \mathrm{g}^{-1}$ after 50 cycles and then increased to $860 \mathrm{mAh} \mathrm{g}^{-1}$ after 160 cycles. For different nanostructured metal oxide electrodes, the capacity increased over a long cycle and it is believed that the irreversible partial reactivation of $\mathrm{Li}_{2} \mathrm{O}$ synthesized in the early cycle is due to the electrochemical grinding effect ${ }^{[189,190]}$. 
Spherical Fe/AuNPs were uniformly dispersed on the surface of rGO sheets. It was proved that the $\mathrm{Fe} / \mathrm{AuNPs}$-AETrGO composite has a high specific gravity of $1500 \mathrm{mAh} \mathrm{g}^{-1}$ and a high long-term cycling stability. The improved electrochemical performance of the Fe/AgNPs-AETrGO composite material is credited to the small size and uniform distribution of Fe/AgNPs on rGO sheets ${ }^{[191]}$. Co-B and Fe-B alloys examined as anode materials give a reversible capacity of 1100 and $1200 \mathrm{mAh} \mathrm{g}^{-1}$, respectively, at $100 \mathrm{~mA} \mathrm{~g}^{-1}$. The outstanding high capacities of $\mathrm{Co}-\mathrm{B}$ and $\mathrm{Fe}-\mathrm{B}$ anodes are due to the activation of $\mathrm{B}$ atoms inside the matrix of transition metal atoms and the negative electrode potential of $\mathrm{B}$ prevents the transition metals from passivation ${ }^{[128]}$. The charge/discharge capacity of $\mathrm{Fe}_{3} \mathrm{O}_{4} / \mathrm{rGO}\left(849.6 \mathrm{mAh} \mathrm{g}^{-1}\right)$ is greater than pristine $\mathrm{Fe}_{3} \mathrm{O}_{4}$ and $\mathrm{rGO}$, which may be due to the crystalline nature of $\mathrm{Fe}_{3} \mathrm{O}_{4}$ after calcination and the high conductivity of GO. The capacity of the $\mathrm{Fe}_{3} \mathrm{O}_{4} / \mathrm{rGO}$ battery decreased sharply during initial cycles and then increased gradually. This was attributed to the reversible formation of polymer gel films, which have the additional reversible capacity for the first few cycles, as shown in Figure 13A and B. The rate performance of $\mathrm{Fe}_{3} \mathrm{O}_{4} / \mathrm{rGO}$ was measured at various current densities, i.e., 0.05, 0.1, 0.2, 0.5, 1.0, 2.0 and $5.0 \mathrm{~A} \mathrm{~g}^{-1}$, and gave specific discharge capacities of $1188,1086,1011,903,811,718$ and $593 \mathrm{mAh} \mathrm{g}^{-1}$, as shown in Figure 13C. Figure 13D shows the charge/discharge curves of the $\mathrm{Fe}_{3} \mathrm{O}_{4} / \mathrm{rGO}$ anodes examined at various current densities. The insertion/extraction of $\mathrm{Li}^{+}$is reversible due to the approximate symmetric shape of the curves $^{[190]}$.

Today, cobalt (Co) is a very popular metal in the field of energy storage and materials science and is used in most commercial LIBs but it comes at a high price. $\mathrm{LiCoO}_{2}$ is the most effective commercial cathode material. In the literature, several examples of $\mathrm{N}$-doped carbon coating composites of $\mathrm{Co}_{3} \mathrm{O}_{4}$ have been reported $^{[192]}$. Co has received much attention in the field of energy storage because of its high energy density and thermal stability. Cathodes made with Co cannot catch fire on overheating, which is the main safety issue. Co used in ultrafine amorphous alloy powders ( $\mathrm{Co}-\mathrm{B}$ and $\mathrm{Fe}-\mathrm{B})$ as a anodic material show better electrochemical performance than pristine elements when used as an aqueous alkaline solutions for anodic materials. The discharge capacities of Co-B and Fe-B electrodes are 1100 and $1200 \mathrm{mAh} \mathrm{g}^{-1}$ at $100 \mathrm{~mA} \mathrm{~g}^{-1}$, respectively. It has been noted that the outstanding capacities of these alloys are because of the activation of $\mathrm{B}$ atoms in the extremely dispersed transition atoms. The B atoms hold the electrode potential to a negative side to avoid the transition atoms from passivation ${ }^{[128]}$. It is particularly attractive in several different cathode materials of rich nickel $\left(\mathrm{LiNi}_{\mathrm{x}} \mathrm{Co}_{\mathrm{y}} \mathrm{Mn}_{z} \mathrm{O}_{2}\right.$ ), which provide a capacity of $195 \mathrm{mAh} \mathrm{g}^{-1}$ with high capacity retention, making them ideal material for electric vehicles, although some problems limit the performance of the materials with increasing $\mathrm{Ni}$ content ${ }^{[193]}$.

Metal-organic frameworks and coordination polymers have high porosity, excellent composite properties, rich network topologies and broad application prospects as electrode materials in LIBs and supercapacitors. Three different phosphonates, $\mathrm{C}_{30} \mathrm{H}_{50} \mathrm{~N}_{6} \mathrm{Ni}_{2.67} \mathrm{Co}_{1.33} \mathrm{O}_{27} \mathrm{P}_{2}$ (PNC), $\mathrm{C}_{15} \mathrm{H}_{32} \mathrm{Co}_{2} \mathrm{~N}_{3} \mathrm{O}_{16} \mathrm{P}$ (PC1) and $\mathrm{C}_{30} \mathrm{H}_{50} \mathrm{~N}_{6} \mathrm{Ni}_{2.67} \mathrm{Co}_{1.33} \mathrm{O}_{27} \mathrm{P}_{2}$ (PNC), have the same structure. Ni and Co have similar oxidation states, the same coordination behavior and similar ionic radii $\left(\mathrm{Ni}^{2+}=0.700 \AA\right.$ and $\left.\mathrm{Co}^{2+}=0.745 \AA\right)$. Therefore, in the same crystallographic position, $\mathrm{Ni}^{2+}$ and $\mathrm{Co}^{2+}$ can be partially replaced easily, but the rate of occupancy of both ions is not the same. The chains are interconnected by H-bonding, which is provided by four free and five coordinated water molecules, forming a large number of hydrogen bonds between chains, resulting in a complex 3D hybrid framework, as shown in Figure $14 \mathrm{~A}$ and B. The specific capacity of PC1 for the first 20 cycles decreases and then increases slowly from the 21 st cycle at $50 \mathrm{~mA} \mathrm{~g}^{-1}$. This may be because of the electrolyte immersion in the anode and the irreversible change of the state of the active substance caused by the current influence, as shown in Figure 14C. The charge/discharge curves of PNC, PC1 and PN1 in the cycle tests are shown in Figure 14D. PC1 has the most stable cycling performance and highest cycle-specific capacity among the three phosphonates ${ }^{[194]}$. 

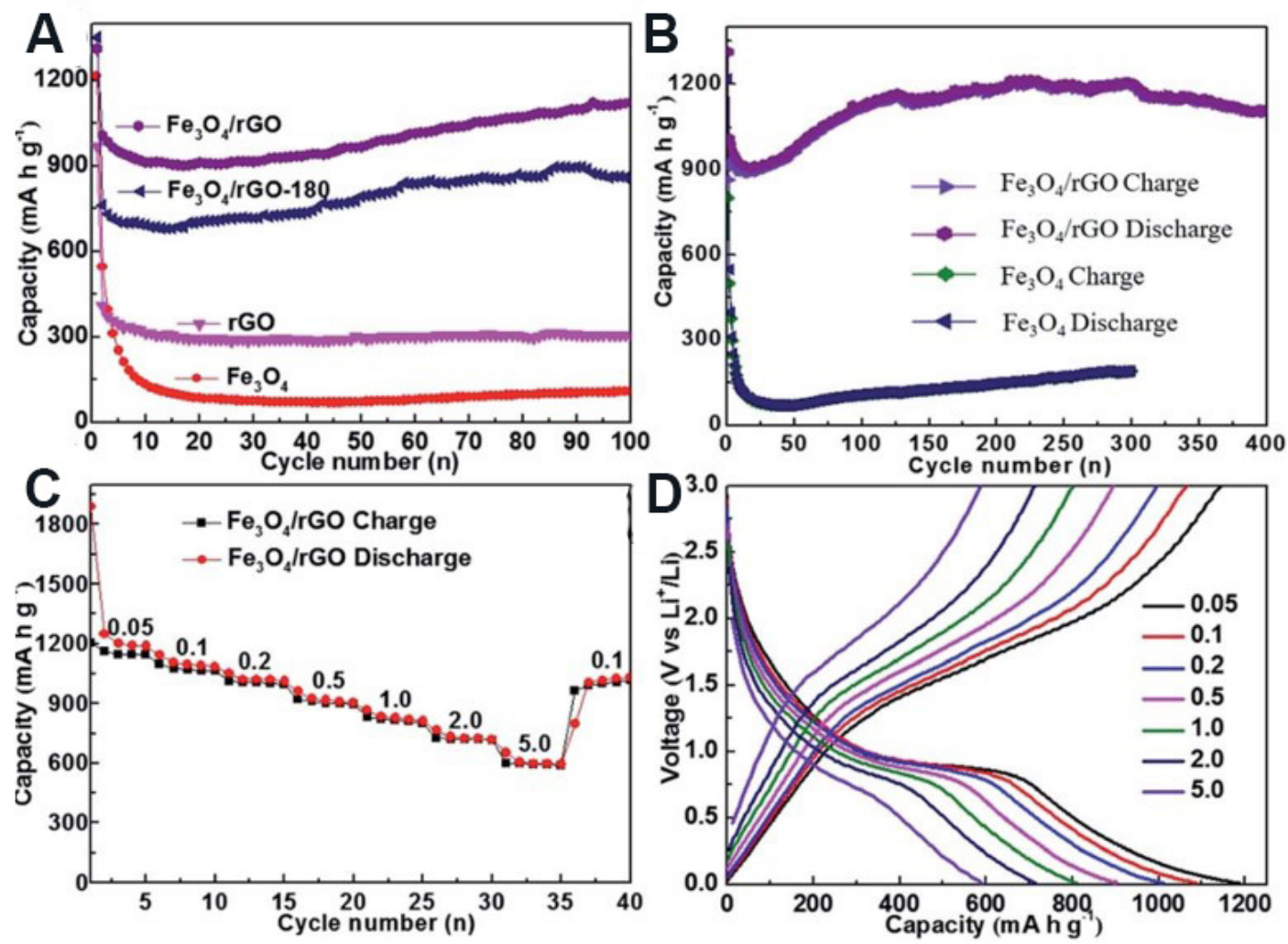

Figure 13. (A) Cycling performance of $\mathrm{Fe}_{3} \mathrm{O}_{4} / \mathrm{rGO} \mathrm{Fe}_{3} \mathrm{O}_{4} / \mathrm{rGO}-180, \mathrm{rGO}$ and $\mathrm{Fe}_{3} \mathrm{O}_{4}$ at $0.5 \mathrm{~A} \mathrm{~g}^{-1}$. (B) Long-term cycling of $\mathrm{Fe}_{3} \mathrm{O}_{4} / \mathrm{rGO}$ and $\mathrm{Fe}_{3} \mathrm{O}_{4}$. (C) Rate performance of $\mathrm{Fe}_{3} \mathrm{O}_{4} / \mathrm{rGO}$ electrode at 0.05-5 A g ${ }^{-1}$. (D) Charge/discharge curves of $\mathrm{Fe}_{3} \mathrm{O}_{4} / \mathrm{rGO}$. Reproduced with permission from Ref. ${ }^{[190]}$ (Copyright 2017, Royal Society of Chemistry).

a-Ni(OH $)_{2}$ is an excellent energy utilization material due to its high specific capacity and discharge potential. If the cation radius to be replaced is larger than $\mathrm{Ni}^{3+}(0.56 \mathrm{~A})$ in the state of charge, then the discharge level of a-Ni(OH) ${ }_{2}$ will be enhanced due to the change in Madelung energy at the Fermi level point of the nickel hydroxide electrode. $\mathrm{Mn}^{3+}$ ions are continuously oxidized to $\mathrm{Mn}^{4+}$ due to their incorporation into the sites of a-Ni(OH $)_{2}$, which enhances the discharge capacity. The results show that the continuous oxidation of $\mathrm{Mn}^{3+}$ cations in the interlayer gives poor cycling stability due to the lack of protons in the structural layer, while the number of large anions (like $\mathrm{SO}_{4}{ }^{2-}, \mathrm{NO}^{3-}$ and $\mathrm{CO}_{3}{ }^{2-}$ ) introduced as charge compensating species is limited due to the steric effect ${ }^{[12]}$.

$\mathrm{NiS}_{2} / \mathrm{NG}-\mathrm{S}$ is another promising electrode material and can be prepared by the partial etching of nickel in a graphene nanoshell, followed by sulfidation of the nickel and sulfur loading, as shown in Figure 15A. It is noted that the long-term cycling of NG/S and $\mathrm{NiS}_{2} / \mathrm{NG}$-S electrodes at a current density of $0.5 \mathrm{C}$ shows excellent stability and the attenuation is stable and slow from the first cycle. The specific capacity of the $\mathrm{NiS}_{2}$ /NG-S electrode is slightly higher than that of the NG/S electrode, while $\mathrm{NiS}_{2} / \mathrm{S}$ has poor cycling performance, low specific capacity and its capacity attenuation is fast. The initial specific capacities of the $\mathrm{NiS}_{2} / \mathrm{S}, \mathrm{NG} / \mathrm{S}$ and $\mathrm{NiS}_{2} / \mathrm{NG}-\mathrm{S}$ electrodes at a current density of $0.5 \mathrm{C}$ are 894, 973 and $1074 \mathrm{mAh} \mathrm{g}^{-1}$, giving capacity retentions of $67.45 \%, 80.45 \%$ and $78.12 \%$ with specific capacities of 603,783 and $839 \mathrm{mAh} \mathrm{g}^{-1}$, respectively, over 100 charge/discharge cycles, as shown in Figure 15B. The $\mathrm{NiS}_{2} / \mathrm{NG}-\mathrm{S}$ electrode shows superior electrochemical performance and stable charge/discharge curves at $1 \mathrm{C}$ for the first, 100th and 200 th cycles, as presented in Figure $15 \mathrm{C}$, while the $\mathrm{NiS}_{2} / \mathrm{S}$ cathode can be attributed to low conductivity, a lack of buffer space due to the absence of graphene and the slow diffusion rate of $\mathrm{Li}$ ions. The existence of 

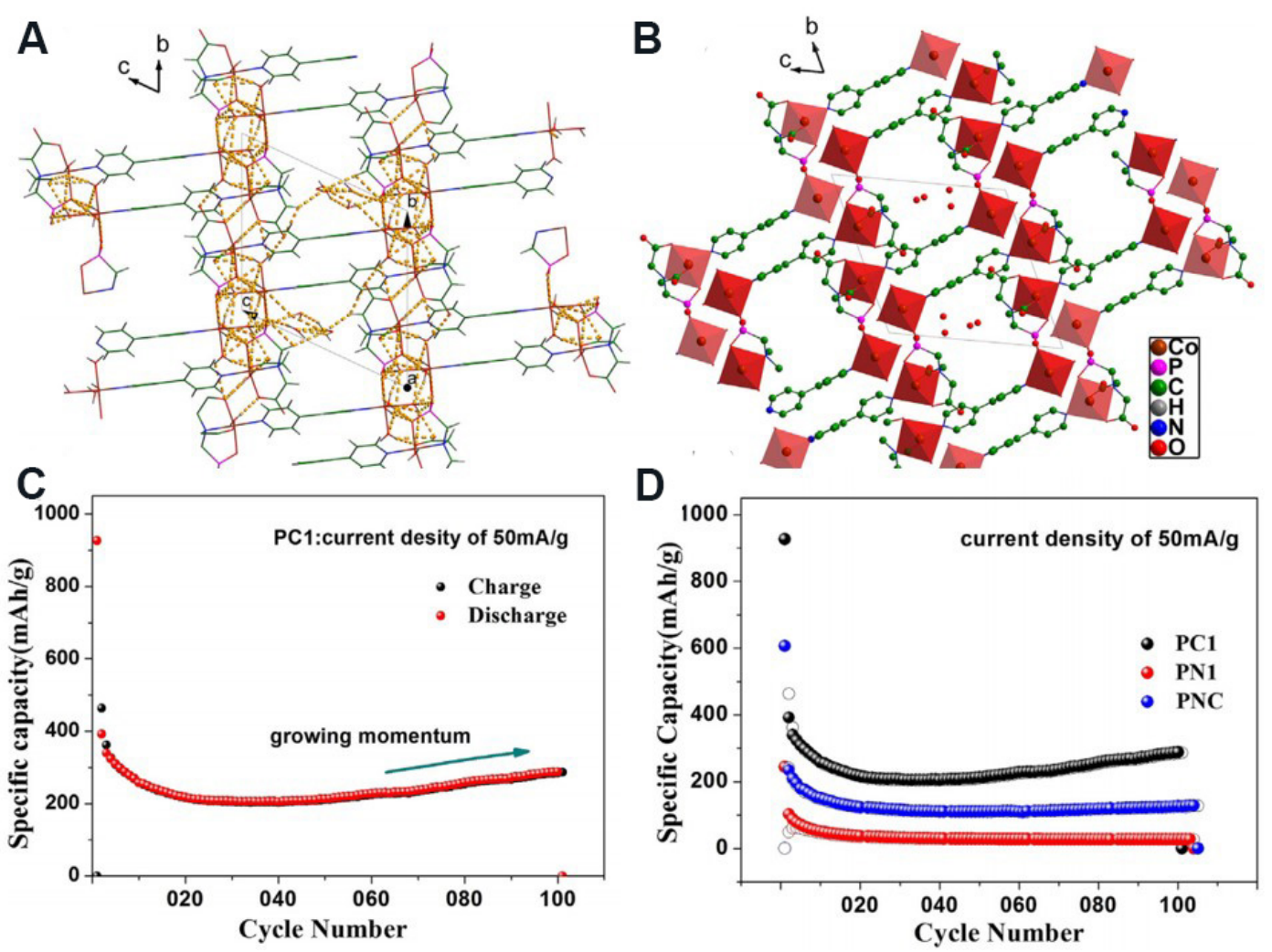

Figure 14. (A) Wireframe view of unit cell structure of cobalt phosphonate (PC1) along an axis, with dotted lines showing H-bonding among the chains (B). Polyhedron view of unit cell of $\mathrm{PC1}$, with hydrogen atoms omitted for clarity and the red dots showing free water molecules. (C) Cycling stability diagram of PC1. (D) Comparison of cycling stability of $\mathrm{C}_{15} \mathrm{H}_{32} \mathrm{~N}_{3} \mathrm{Ni}_{2} \mathrm{O}_{16} \mathrm{P}$ ( $\mathrm{PN1}$ ), $\mathrm{C}_{15} \mathrm{H}_{32} \mathrm{CO}_{2} \mathrm{~N}_{3} \mathrm{O}_{16} \mathrm{P}(\mathrm{PC}$ ) and $\mathrm{C}_{30} \mathrm{H}_{50} \mathrm{~N}_{6} \mathrm{Ni}_{2.67} \mathrm{Co}_{1.33} \mathrm{O}_{27} \mathrm{P}_{2}$ (PNC). Reproduced with permission from Ref. ${ }^{[194]}$ (Copyright 2019, Electrochemica Acta, Elsevier).
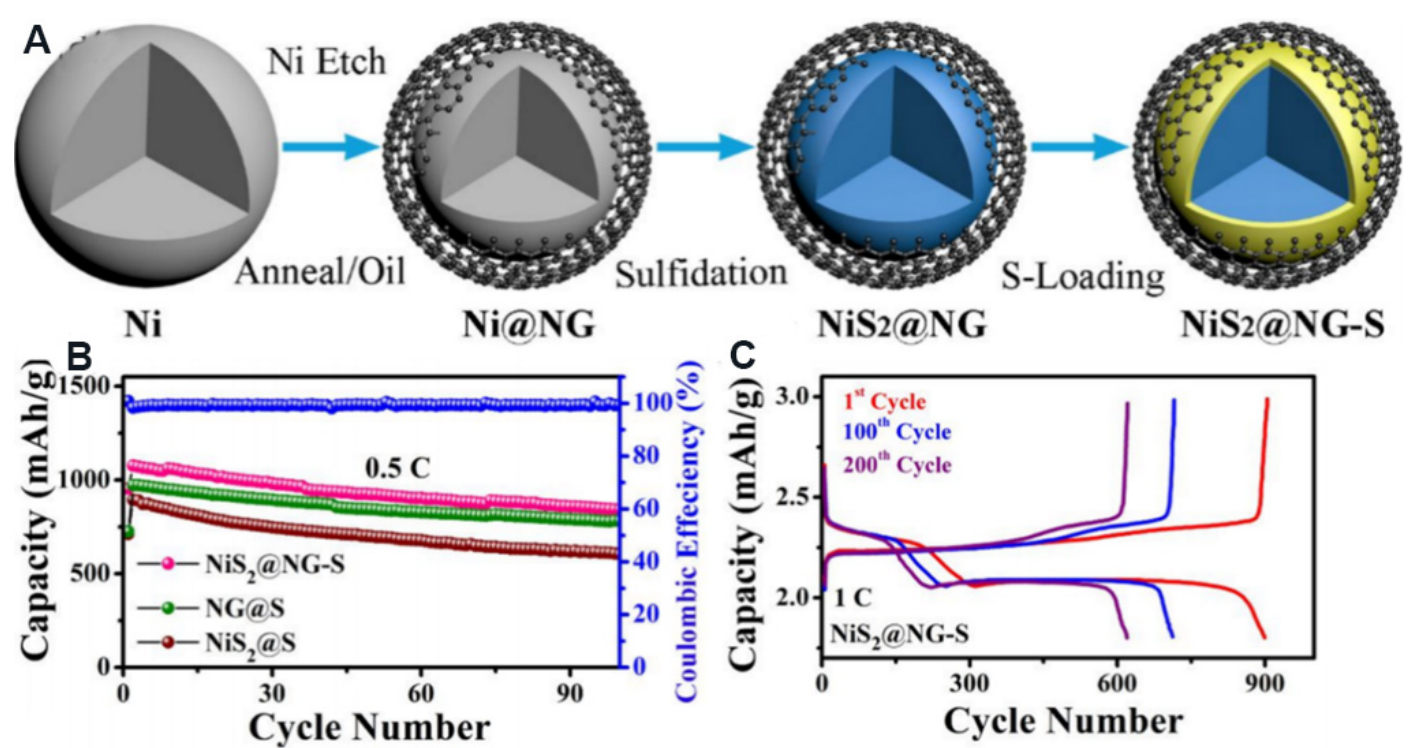

Figure 15. (A) Schematic representation of the synthesis of S-loaded $\mathrm{NiS}_{2} / \mathrm{NG}$-S yolk-shells. (B) Long-term cycling stability of $\mathrm{NiS}_{2} / \mathrm{S}_{\text {, }}$ $\mathrm{NG} / \mathrm{S}$ and $\mathrm{NiS}_{2} / \mathrm{NG}-\mathrm{S}$ electrodes at $0.5 \mathrm{C}$. (C) Corresponding charge/discharge curves of $\mathrm{NiS}_{2} / \mathrm{NG}-\mathrm{S}$ cathode after first, 100 th and 200th cycles at 1 C. Reproduced with permission from Ref. ${ }^{[195]}$ (Copyright 2020, American Chemical Society). 
the $\mathrm{NiS}_{2}$ nanoshell in the $\mathrm{NiS}_{2} / \mathrm{NG}-\mathrm{S}$ yolk-shell structure limits the chemical adsorption of lithium polysulfide (LiPS). However, the free space of the $\mathrm{NiS}_{2} / \mathrm{NG}$ yolk-shell and the NG/S nanoshell is conducive to a change in volume during the charge/discharge process and plays an important catalytic role in the LiPS transformation, resulting in excellent electrochemical performance for lithium-sulfur batteries. In the process of NG/S cathode cycling, Ni-based nanostructures are formed due to the presence of nickel residues (left during etching), which may play a vital role in the electrochemical performance of comparable batteries. In contrast, the slow redox reaction and poor conductivity of the bare $\mathrm{NiS}_{2} / \mathrm{S}$ cathode result in poor electrochemical performance ${ }^{[195]}$.

The first battery was invented in 1799 using only $\mathrm{Zn}$ and $\mathrm{Cu}$. $\mathrm{Cu}$, being more malleable and ductile than silicon, acts as an adhesive that combines the electrode material and prohibits the electronic separation of the particles of silicon upon charge/discharge cycling, thereby reducing capacity fade. A thin-film electrode (porous copper-coated silicon) synthesized by magnetron sputtering were evaluated for cycling efficiency, and rate capability in lithium-ion coin-cells, and compared to equivalent uncoated silicon thin-film electrodes. The layer of $\mathrm{Cu}$ between the electrolyte and electrochemically active material enhances the cycling efficiency and rate capability of the Si electrode and decreases capacity loss due to pulverization. The rate capability and energy decrease considerably if the thickness of $\mathrm{Cu}$ is higher because the active material of silicon will not be accessed. Therefore, to increase the rate capability and capacity retention in LIBs, it is recommended that the porosity and thickness of the $\mathrm{Cu}$ coating are optimized ${ }^{[196]}$.

The easily scalable synthesis of the Cu-based metal-organic framework $\left[\mathrm{Cu}_{2}\left(\mathrm{C}_{8} \mathrm{H}_{4} \mathrm{O}_{4}\right)_{4}\right]_{\mathrm{n}}$ is a promising candidate for LIBs due to the porosity of crystalline materials that can store $\mathrm{Li}^{+}$. The terephthalate network responds reversibly with $\mathrm{Li}$ and retains $84 \%$ of its energy retention after 50 cycles. In the initial cycle, the theoretical capacity is $\sim 95 \%$, i.e., $227 \mathrm{mAh} \mathrm{g}^{-1}$ at $24 \mathrm{~mA} \mathrm{~g}^{-1[197]}$. Unfortunately, most of the metal phosphides reported have an irregular particle size ranging from hundreds of nanometers to micrometers, thus providing limited cycling stability. The majority of metal phosphides have a limited number of charge/discharge cycles (30-150); however, $\mathrm{Cu}_{3} \mathrm{P}$ nanowires without additives grow directly on the $\mathrm{Cu}$ collector as anode materials. After phosphidation treatment, it has a stable cycling capacity and the retention rate was $\sim 70 \%$ over the 260 th cycle $^{[198]}$.

The electrochemical properties of yttrium-rich Li materials were studied by constant current charge/discharge experiments and EIS. The results show that a $\mathrm{Y}^{3+}$-doped lithium-rich electrode material has a capacity of $184.5 \mathrm{mAh} \mathrm{g}^{-1}$ over 40 cycles at $1 \mathrm{C}$ and a high capacity retention rate of $240.7 \mathrm{mAh} \mathrm{g}^{-1}$ over 40 cycles at $0.1 \mathrm{C}$. It is demonstrated that an appropriate amount of $\mathrm{Y}^{3+}$ substituted for $\mathrm{Mn}^{4+}$ in $\mathrm{Li}_{1.2} \mathrm{Mn}_{0.6-\mathrm{x} \times}$, $\mathrm{Ni}_{0.2} \mathrm{Y}_{\mathrm{x}} \mathrm{O}_{2}$ results in high initial columbic efficiency, cycling capacity and rate capability. The electrochemical enhancement of $\mathrm{Y}^{3+}$-doped materials has been confirmed due to the "super-large" radius of $\mathrm{Y}^{3+}$, which can promote the fast transfer of $\mathrm{Y}^{3+}$ ions by spreading the layered structure. The strong $\mathrm{Y}$-O bond can maintain the layered arrangement in the bulk and an extremely trace amount of $\mathrm{Y}_{2} \mathrm{O}_{3}$ is produced after excessive doping, which can protect the particles from the erosion of electrolytes and maintain $\mathrm{Li}^{+}$and oxygen vacancies. This material leads to advanced LIBs that could possibly resolve renewable energy storage and electric transport requirements ${ }^{[199]}$.

A high-performance composite (Nafion-ZrNT) membrane consisting of perfluoro sulfonic acid (Nafion) and $\mathrm{ZrO}_{2}$ nanotubes (ZrNTs) was fabricated for vanadium redox flow batteries (VRBs). The VRB with a composite membrane enhances the selectivity of ions and presents a low rate of self-discharge, high energy efficiency and high discharge capacity compared to a commercial Nafion-117 membrane. The incorporation of the Nafion matrix with ZrNTs shows high oxidative stability (99.9\%) and proton conductivity 
(95.2 $\mathrm{mS} \mathrm{cm}^{-1}$ ). Compared with the Nafion-117 membrane (280 $\left.\mathrm{mAh} \mathrm{g}^{-1}\right)$, the Nafion-ZrNT composite membrane has higher ion selectivity $\left(2.95 \times 10^{7} \mathrm{~s} \mathrm{~min} \mathrm{~cm}^{-3}\right)$, lower $\mathrm{V}^{+}$permeability $\left(3.2 \times 10^{-9} \mathrm{~cm}^{-2} \mathrm{~min}^{-1}\right)$ and higher discharge capacity $\left(987 \mathrm{mAh} \mathrm{g}^{-1}\right.$ ) over 100 cycles. Compared with the original membrane, the selfdischarge rate of the Nafion-ZrNT composite membrane is lower, upholding an open circuit voltage of $1.3 \mathrm{~V}$ for $330 \mathrm{~h}$, which is lower than that of the original membrane $(29 \mathrm{~h})$. These superior properties resulted in a higher voltage and CEs compared to the VRB with the Nafion-117 membrane at a current density of $40 \mathrm{~mA} \mathrm{~cm}^{-2[200]}$. Pristine zirconium- and nickel-modified $\mathrm{Li}_{2} \mathrm{MnO}_{3}$ samples were also studied, with the Nimodified material having a high discharge capacity and the Zr-modified electrode material showing less irreversible loss ${ }^{[201]}$.

Lubimstsev et al. ${ }^{[202]}$ showed that the origin of the high rate performance of $\mathrm{Nb}_{2} \mathrm{O}_{5}$ is due to the open channels between the sheets of $\mathrm{NbO}_{x}$, which effectively facilitate local charge transfer and reduce the energy barrier. The charge storage of $\mathrm{Nb}_{2} \mathrm{O}_{5}$ is not restricted by semi-infinite diffusion because of its low conductivity $\left(\sim 10^{-6} \mathrm{~S} \mathrm{~cm}^{-1}\right) . \mathrm{Nb}_{2} \mathrm{O}_{5}$ /graphene, $\mathrm{Nb}_{2} \mathrm{O}_{5} / \mathrm{CNT}$ and $\mathrm{Nb}_{2} \mathrm{O}_{5} /$ carbon core-shell composites are examples of nanostructured $\mathrm{Nb}_{2} \mathrm{O}_{5}$ /carbon materials used to enhance the conductivity of $\mathrm{Nb}_{2} \mathrm{O}_{5}$. $\mathrm{Nb}_{2} \mathrm{O}_{5}$ shows a high power capability and specific energy related to rapid $\mathrm{Li}^{+}$intercalation within the (001) or (110) planes, which depend on the phase of the crystals ${ }^{[203]}$. A comparative study of $\mathrm{TT}-\mathrm{Nb}_{2} \mathrm{O}_{5}, \mathrm{~T}-\mathrm{Nb}_{2} \mathrm{O}_{5}$ and $\mathrm{M}$ $\mathrm{Nb}_{2} \mathrm{O}_{5}$ showed that $\mathrm{T}-\mathrm{Nb}_{2} \mathrm{O}_{5}$ has excellent power treatment performance because of its rapid $2 \mathrm{D} \mathrm{Li}^{+}$ transport in the crystal structure and no phase transition occurs through the electrochemical reaction. Polymer-bound electrodes have been mostly synthesized by mixing $\mathrm{Nb}_{2} \mathrm{O}_{5}$ nanoparticles, fibers and nanosheets with conductive additives. An extremely thin electrode without conductive additives was prepared by directly injecting $\mathrm{Nb}_{2} \mathrm{O}_{5}$ nanoparticles on thin mesoporous films used as a current collector. However, this approach remains limited due to scalability ${ }^{[204]}$. T- $-\mathrm{Nb}_{2} \mathrm{O}_{5} / \mathrm{C}$ hybrid nanofiber mats were synthesized by treating $\mathrm{NbC}$ with $\mathrm{CO}_{2}$ gas, resulting in a capacity of $156 \mathrm{mAh} \mathrm{g}^{-1}$ from the high graphitization of the structure of carbon and the outstanding charge propagation in the nanofiber network $^{[204]}$. To explain the intercalation and diffusion energy barriers in materials, first-principles calculations can be applied, which provide new awareness of the phenomena of ion transport and electrochemical performance. For example, Monte Carlo simulations have been used to explain the origin of the high rate of monoclinic $\mathrm{Nb}_{2} \mathrm{O}_{5}$ and show that the open channel system of quasi-2 $\mathrm{D} \mathrm{NbO}_{\mathrm{x}}$ efficiently reduces the energy barrier of $\mathrm{Li}^{+}$from one site to another ${ }^{[202]}$.

Molybdenum disulfide $\left(\mathrm{MoS}_{2}\right)$ is like graphite in structure and consists of three atomic layers. The molybdenum layer is sandwiched between two sulfur layers. The large interlayer space and high surface area of $\mathrm{MoS}_{2}$ make it an ideal host for ion intercalation/deintercalation. Bulk $\mathrm{MoS}_{2}$ is used as an electrode material in LIBs. However, in the process of ion intercalation, the large volume expansion often leads to structural instability ${ }^{[205]}$. The electrochemical performance and stability of mesoporous $\mathrm{MoS}_{2}$ are the same as that of mesoporous $\mathrm{MoSe}_{2}$. The key difference between $\mathrm{MoSe}_{2}$ and $\mathrm{MoS}_{2}$ lies in the well-defined redox system of $\mathrm{MoSe}_{2}$, which is characterized by a flat platform on the galvanostatic profile and a well-shaped peak pair in its cyclic voltammogram. Wang et al. ${ }^{[206]}$ prepared core-shell $\mathrm{MoSe}_{2} / \mathrm{C}$ nanocomposites by modifying hollow carbon nanofibers with small-sized and ultra-thin $\mathrm{MoSe}_{2}$ nanosheets as an anode material for LIBs and they retain $100 \%$ of their initial capacity and specific capacity of $658 \mathrm{mAh} \mathrm{g}^{-1}$ over 100 cycles at a current density of $0.5 \mathrm{~mA} \mathrm{~g}^{-1}$. MoSe $e_{2}$ has a large interlayer spacing (compared to $\mathrm{MoS}_{2}$ ) and is thus suitable for providing accommodation for large metal cations, like $\mathrm{Na}$, and has better performance than $\mathrm{MoS}_{2}$. Morales et al. ${ }^{[207]}$ suggested that $\mathrm{Li}_{x} \mathrm{MoSe}_{2}$ is subjected to structural change by the $\mathrm{x}$ value but the $\mathrm{d}$ spacing is almost the same during the process of intercalation/deintercalation. $\mathrm{MoS}_{2}$ undergoes a structural change at $1.1 \mathrm{~V} v s$. $\mathrm{Li} / \mathrm{Li}^{+}$with $\mathrm{Li}$ intercalation/deintercalation because of conversion from $2 \mathrm{H}-\mathrm{MoS}_{2}$ to $2 \mathrm{~T}-\mathrm{Li}_{x} \mathrm{MoS}_{2}$. This phase transformation is characterized by the cathodic peak at $1 \mathrm{~V}$ in $\mathrm{CV}$. A similar performance is also 
observed for $\mathrm{MoSe}_{2}{ }^{[168]}$. The results show that the theoretical adsorption capacity of $335 \mathrm{mAh} \mathrm{g}^{-1} \mathrm{can}$ be attained by a double-sided $\mathrm{Na}^{+}$adsorption method for monolayer $\mathrm{MoS}_{2}$. A comparative study shows that the activation barrier of monolayer $\mathrm{MoS}_{2}$ is $0.11 \mathrm{eV}$, while the interlayer migration barrier of bulk $\mathrm{MoS}_{2}$ is $0.70 \mathrm{eV}$, confirming that $\mathrm{Na}^{+}$diffusion in monolayer $\mathrm{MoS}_{2}$ is faster than in bulk $\mathrm{MoS}_{2}$. CNT/MoS 2 was fabricated and showed outstanding electrochemical properties with a specific capacity of $1298 \mathrm{mAh}^{-1[208]}$.

The structure of intercalated ions $\left(\mathrm{Mo}_{2} \mathrm{CrC}_{2}\right)$ and three highly symmetric positions in the Brillouin region are given in Figure 16A-D. The calculation of binding energy is determined by the Mo atom, C atom and metal ion at the top of the $\mathrm{Cr}$ atom on both sides of the MXene. Therefore, considering the dispersion interaction, $\mathrm{Li}^{+}, \mathrm{Na}^{+}, \mathrm{K}^{+}$and $\mathrm{Mg}^{2+}$ ions were considered. To test the energy stability of metal ions on the monolayer $\mathrm{Mo}_{2} \mathrm{CrC}_{2}$ MXene, the average calculated adsorption energy of $\mathrm{Li}^{+}, \mathrm{Na}^{+}, \mathrm{K}^{+}$and $\mathrm{Mg}^{2+}$ in different states has similar adsorption sites, as shown in Figure 16E. Using the PBE functional, the binding energies of these metal ions are calculated. When metal ions are adsorbed on the top of the Mo site, they move spontaneously to the top of the $\mathrm{Cr}$ site. After the adsorption of $\mathrm{Li}^{+}, \mathrm{Na}^{+}, \mathrm{K}^{+}$and $\mathrm{Mg}^{2+}$, the adsorption energy is negative. This shows that these ions can be adsorbed by MXenes $\left(\mathrm{Mo}_{2} \mathrm{CrC}_{2}\right) . \mathrm{K}^{+}$has better adsorption energy than the other ions, which may be related to its strong interaction with the MXene surface ${ }^{[209]}$.

Ag-Ca alloy batteries are a subtype of lead-acid batteries that are used instead of novel lead-calcium or traditional lead-antimony alloys. They are known for their resistance to the destructive effects of high temperatures and corrosion. The high energy density characteristics of silver oxide batteries are used in the aerospace industry and the military. They can also withstand high energy flow. Thin metallic coatings, such as $\mathrm{Ag}$, have been shown to increase the cycling stability and capacity of Si materials. $\mathrm{Ag} / \mathrm{TiO} \mathrm{O}_{2}-\mathrm{NTS}$ composites can be easily prepared by a classical silver mirror reaction. Ag as an additive has high conductivity. At a high charge/discharge rate, the cycling stability and reversible capacity of $\mathrm{TiO}_{2}$ nanotubes are enhanced and their cell polarization is reduced ${ }^{[210]}$. MXene/Ag composite material consisting of layered MXene films and nanosized Ag particles was synthesized directly by reducing $\mathrm{AgNO}_{3}$ on the surface of a $\mathrm{Ti}_{3} \mathrm{C}_{2}(\mathrm{OH})_{0.8} \mathrm{~F}_{1.2}$ MXene. The composite has an initial specific capacity of $\sim 550 \mathrm{mAh} \mathrm{g}^{-1}$ and reversible capacities of $310 \mathrm{mAh} \mathrm{g}^{-1}(\mathrm{C})$ and $150 \mathrm{mAh} \mathrm{g}^{-1}(50 \mathrm{C})$. The composite can withstand almost decaying capacity at different current densities, even above 5000 cycles $^{[211]}$. The main reason is the reduced interfacial resistance and the reduction of $\mathrm{Ti}(\mathrm{III})$ to $\mathrm{Ti}(\mathrm{II})$ through charge/discharge for long cycling with extremely high capacity.

$\mathrm{Ag} / 1 \mathrm{D}-\mathrm{TiO}_{2}$ and $\mathrm{Au} / 1 \mathrm{D}-\mathrm{TiO}_{2}$, fabricated through a simple one-step electrospinning method, can enhance the electrochemical properties of $1 \mathrm{D} \mathrm{TiO}_{2}$. The electronic configurations were maintained and the particle size of the $\mathrm{TiO}_{2}$ consisting of the $1 \mathrm{D}$ nanostructure was decreased after the doping of $\mathrm{Au}$ or $\mathrm{Ag}$ nanoparticles into $1 \mathrm{D} \mathrm{TiO}_{2}$. The inserted $\mathrm{Au}$ or $\mathrm{Ag}$ nanoparticles not only reduce the charge transport of $\mathrm{TiO}_{2}$ nanoparticles but also act as conductive agents. $\mathrm{For} \mathrm{Li}^{+}$storage performance, the storage capacity was increased by $20 \%$ or more compared to pristine $1 \mathrm{D} \mathrm{TiO}_{2}$. The better charge transfer and smaller particle size contributed to the improved cycling stability and electrochemical properties of $\mathrm{Au} / 1 \mathrm{D}-\mathrm{TiO}_{2}$ and $\mathrm{Ag} / 1 \mathrm{D}$ $\mathrm{TiO}_{2}$. In contrast, due to the poor crystalline nature, $\mathrm{Ag} / 1 \mathrm{D}-\mathrm{TiO}_{2}$ shows less considerable changes than $\mathrm{Au} / 1 \mathrm{D}-\mathrm{TiO}_{2}$ after the incorporation of $\mathrm{Ag}^{[212]}$. Ag-doped vanadium oxide $\left(\mathrm{Ag} / \mathrm{V}_{2} \mathrm{O}_{5}\right)$ thin films exhibit higher discharge capacities due to the higher diffusion of $\mathrm{Li}^{+}$compared to non-doped $\mathrm{V}_{2} \mathrm{O}_{5}$ film cathodes. $\mathrm{V}_{2} \mathrm{O}_{5}$ films show a poor discharge capacity than $\mathrm{Ag} / \mathrm{V}_{2} \mathrm{O}_{5}$, which appears to be due to a cauliflower-like structure. All the thin-film batteries show outstanding reversibility over 200 cycles $^{[213]}$. A $\operatorname{Li}_{4} \mathrm{Ti}_{5} \mathrm{O}_{12}$ (LTO)/Ag composite was prepared by a simple chemical deposition process. In the voltage range of 1.0-2.5 $\mathrm{V}\left(v s . \mathrm{Li}^{+}\right.$ /Li), after 120 charge/discharge cycles at $30 \mathrm{C}$, the high power capacity of the material reaches $131 \mathrm{mAh} \mathrm{g}^{-1}$, maintaining more than $98 \%$ of the initial capacity. Nanosized Ag particles $(<10 \mathrm{~nm})$ were anchored on the 

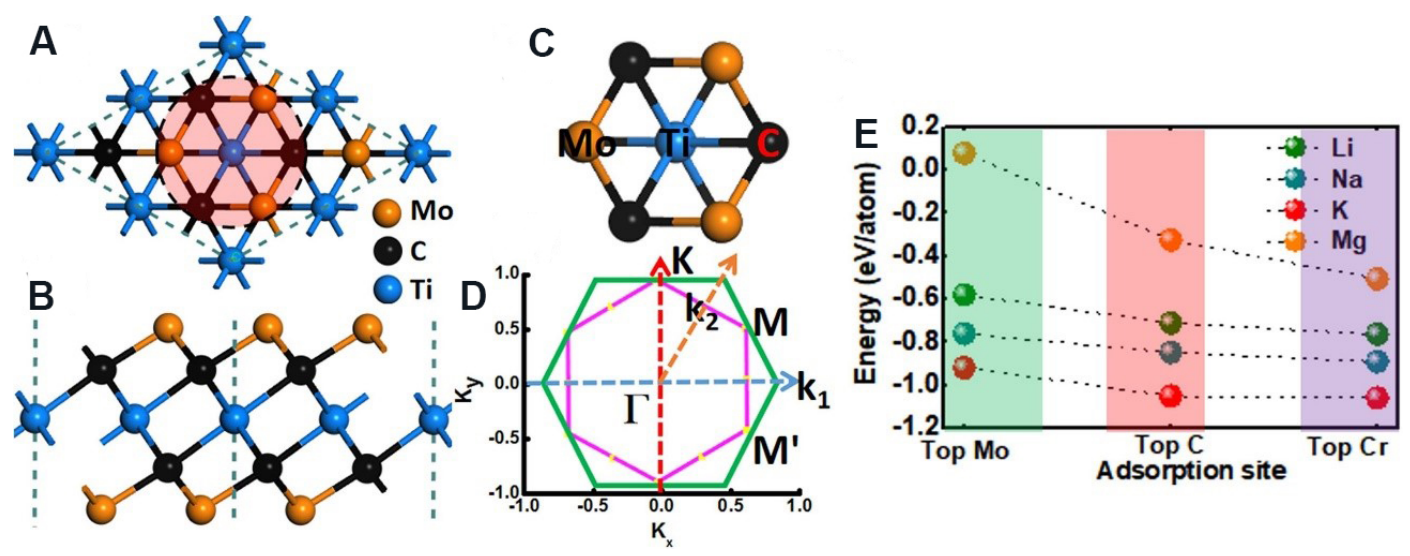

Figure 16. Structures of $\mathrm{Mo}_{2} \mathrm{CrC}_{2}$ supercell $(2 \times 2 \times 1)$ : (A) top view; (B) side view; (C) considered adsorption sites on the surface of $\mathrm{Mo}_{2} \mathrm{CrC}_{2}$ monolayer (top view). (D) Schematic diagram of top-view $\mathrm{Mo}_{2} \mathrm{CrC}_{2}$ with three high-symmetry sites. (C) Adsorption energy of metal ions in the first layer is located at $\mathrm{Mo}, \mathrm{Cr}$ and $\mathrm{C}$ atom sites on both sides for $\mathrm{Mo}_{2} \mathrm{CrC}_{2}$ monolayer surface. (E) To test the energy stability of metal ions on the monolayer $\mathrm{Mo}_{2} \mathrm{CrC}_{2} \mathrm{MXene}$, the average calculated adsorption energy of $\mathrm{Li}^{+}, \mathrm{Na}^{+}, \mathrm{K}^{+}$and $\mathrm{Mg}^{2+}$ in different states has similar adsorption sites. Reproduced with permission from Ref. ${ }^{[209]}$ (Copyright 2020, Applied Surface Science, Elsevier).

surface of the nanocrystalline LTO $(90 \mathrm{~nm})^{[214]}$.

Tungsten (W), also known as wolfram, is a chemical element with atomic number 74 . Kumagai et al. ${ }^{[215]}$ showed that monoclinic $\mathrm{WO}_{3}$ particles synthesized by the moderate heating of $\mathrm{H}_{2} \mathrm{WO}_{4}$ show better cycling efficiency. Because the electrode materials interact with $\mathrm{Li}$ via the mechanism of intercalation, $\mathrm{Li}^{+}$diffusion in the host lattice plays a significant role. Therefore, it is attractive to find a structure of $\mathrm{WO}_{3}$ that facilitates the diffusion of $\mathrm{Li}^{+}$and it is generally believed that by reducing the size of the material down to the nanometer scale, a significant enhancement in their properties is observed. The performance of hexagonal $\mathrm{WO}_{3}$ nanorods as anode materials of LIBs has also been studied. The first cycle discharge capacity was $215 \mathrm{mAh} \mathrm{g}^{-1}$. $\mathrm{WO}_{3}$ hollow nanospheres have a high initial discharge capacity of more than $1054 \mathrm{mAh} \mathrm{g}^{-1}$ at a charge/discharge rate of $0.2 \mathrm{C}$. The electrode based on hollow particles maintains structural integrity even at a high current density of $2000 \mathrm{~A} \mathrm{~g} \mathrm{~g}^{-1[26]}$.

$\mathrm{ReS}_{2}$ nanosheets can be used as energy storage materials for LIBs. The growth of $\mathrm{ReS}_{2}$ nanosheets was oriented vertically on the surface of the substrate. This achieves two significant goals. First, it greatly enhances the surface area of the nanosheet and second, it exposes the sharp edges of the $\mathrm{ReS}_{2}$ nanosheets. The vertically grown $\mathrm{ReS}_{2}$ nanosheets can be used as electrocatalysts and polysulfide immobilizers in the hydrogen evolution reaction and lithium-sulfur batteries. Over 300 charge/discharge cycles, the specific capacity of a Li-S battery with a vertical $\mathrm{ReS}_{2}$ nanosheet catalyst was kept above $750 \mathrm{mAh} \mathrm{g}^{-1}$ and the capacity loss per cycle was only $0.063 \%$, which is far better than the pristine one (i.e., without $\operatorname{ReS}_{2}$ ). When it is tested under similar conditions, the capacity loss per cycle was $0.184 \%^{[217]}$.

The specific capacity of gold-coated porous $\mathrm{Si}$ is greater than $2500 \mathrm{mAh} \mathrm{g}^{-1}$ after 75 cycles and can attain $3000 \mathrm{mAh} \mathrm{g}^{-1}$ for over 50 cycles at $100 \mu \mathrm{A} \mathrm{cm}^{-2}$ with high CEs above $95 \%$. In contrast, non-Au-coated porous Si had a capacity of $500 \mathrm{mAh} \mathrm{g}^{-1}$ at the very first cycle, which rapidly decreased to $76 \mathrm{mAh} \mathrm{g}^{-1}$ after the 10 th cycle at a constant current rate of $50 \mu \mathrm{A} \mathrm{cm}^{-2}$, which is a considerable enhancement over Au-plated nonporous silicon. When the current is constant at $100 \mu \mathrm{A} \mathrm{cm}{ }^{-2}$, the maximum capacity of Au-plated nonporous $\mathrm{Si}$ is $1 \mathrm{mAh} \mathrm{g}^{-1}$ and it faded over 10 cycles to $0.25 \mathrm{mAh} \mathrm{g}^{-1}$, illustrating the importance of internal pores. The internal pores formed by the combination of porous Si and Au enhance the capacity and longterm cycling capacity of $\mathrm{LIBs}^{[141]}$. $\mathrm{NiCO}_{2} \mathrm{O}_{4} / \mathrm{Au}$ nanotube electrodes have an excellent capacity of 
$732.5 \mathrm{mAh} \mathrm{g}^{-1}$ at a current density of $100 \mathrm{mAg}^{-1}$, even over 200 cycles with excellent cycling stability. Au nanoparticles can be inserted into the whole electrode to form $3 \mathrm{D}$ networks, which act as mechanical anchoring points or adhesion centers to firmly fix adjacent $\mathrm{NiCo}_{2} \mathrm{O}_{4}$ particles. Due to the stress or strain caused by the rapid ion/electron transfer during cycling, high volume expansion resistance occurs ${ }^{[218]}$. An aniline [polyaniline (PANI)-1] and 4-para-phenylenediamine (PPDA) composite material was synthesized on the surface of the Au plate and used for LIBs. The maximum discharge capacity of the cathode material (PANI-PPDA/Au) is $103.2 \mathrm{mAh} \mathrm{g}^{-1}$ and the decay rate is $0.147 \mathrm{mAh} \mathrm{g}^{-1}$ at a charge/discharge rate of $0.4 \mathrm{~mA} \mathrm{~g}^{-1[219]}$.

Magnesium-gallium (Mg-Ga) amalgam has been used as an anode material for a seawater activated battery. Under different current densities, the annealing sheets of $\mathrm{Mg}-4 \% \mathrm{Ga}-2 \% \mathrm{Hg}$ have the largest negative corrosion potential. The Mg-4\%Ga-2\% Hg alloy has a higher negative corrosion potential than AP65 and AZ31 alloys. EIS showed that the interface process of $\mathrm{Mg}-\mathrm{Ga}-\mathrm{Hg}$ alloy/seawater is determined by the activation control reaction. The electrochemical properties of the $\mathrm{Mg}-4 \% \mathrm{Ga}-2 \% \mathrm{Hg}$ alloy were improved by $\mathrm{Mg}_{21} \mathrm{Ga}_{5} \mathrm{Hg}_{3}$ and $\mathrm{Mg}_{3} \mathrm{Hg}$ phases. The prototype battery with $\mathrm{CuCl}$ as a cathode and $\mathrm{Mg}-4 \% \mathrm{Ga}-2 \% \mathrm{Hg}$ alloy used as an anode shows good discharge performance due to the microstructure and discharge characteristics of the alloy ${ }^{[220]}$.

\section{F-block elements (lanthanides and actinides)}

Heavier transition metals can also be used to replace $\mathrm{LiMn}_{2} \mathrm{O}_{4}$; however, they are far from ideal alternatives due to cost and size issues. In regards to this, only a very small amount of dopant can be applied, since this can increase the stability of the spinel due to stronger $\mathrm{M}-\mathrm{O}$ bonds for transition metals ${ }^{[221]}$. Furthermore, lanthanides are heavier than the first two rows of transition metals, thereby limiting the performance of electrodes in portable devices. Therefore, little attention has been given to lanthanide compounds in connection with LIB electrodes. The majority of research into lanthanides for energy storage is devoted to solid electrolytes based on fast lithium-ion conducting perovskites. This does suggest the potential of finding a suitable lanthanide series with an appropriate redox couple and conventionally occurring oxides. TMOs can alter their oxidation state in solution (e.g., $\mathrm{Ce}^{3+}$ to $\mathrm{Ce}^{4+}$ ), which is also an attractive phenomenon. Redox active electrolytes can compensate for the loss of energy density caused by the improvement of an open electrode structure, thus improving the accessibility of ions. A significant enhancement was noted in the electrochemical performance of numerous pseudocapacitive metal oxides, including $\mathrm{Nb}_{2} \mathrm{O}_{5}$ and $\mathrm{CeO}_{2}{ }^{[222]}$.

Gd is a high neutron absorber, which makes it unsuitable for NPD experiments. $\mathrm{Gd}_{2} \mathrm{TiO}_{5}$ has a $\mathrm{Ti}_{41} / \mathrm{Ti}_{31}$ redox couple, comparable to the commercialized anode $\left(\mathrm{Li}_{4} \mathrm{Ti}_{5} \mathrm{O}_{12}\right)$ of LIBs. This $\mathrm{Ti}_{41} / \mathrm{Ti}_{31}$ redox couple creates a stable voltage of $1.55 \mathrm{~V}$ against $\mathrm{Li}$, which deposits $\mathrm{Li}$ on the surface of the anode (dendrites), thereby enhancing the safety of LIBs. Thus, $\mathrm{Li}_{4} \mathrm{Ti}_{5} \mathrm{O}_{12}$ anodes can provide safer and longer life to LIBs. Taking advantage of the comparable $\mathrm{Ti}_{41} / \mathrm{Ti}_{31}$ redox couple, $\mathrm{Gd}_{2} \mathrm{TiO}_{5}$ has a structure with comparatively large channels running beside the $\mathrm{c}$ axis, which may be feasible for $\mathrm{Li}$ or $\mathrm{Na}$ ion anode or insertion/extraction processes. Gd was initially selected as it is situated in the middle of the lanthanide series and is a good starting point to determine the effect of lanthanides on the electrochemical performance of electrodes. $\mathrm{Gd}_{2} \mathrm{TiO}_{5}$ has an interstitial-rich channel structure, which may be suitable for the insertion and extraction of $\mathrm{Li}^{+}$during the charge/discharge process. The typical form of ion transport in electrodes tends to be intercalation or vacancies, whereas this material may provide the chance for ion transport through mobile interstitials. It was found that for LIBs, the capacity is $45 \mathrm{mAh} \mathrm{g}^{-1}$ over 20 cycles at $4 \mathrm{~mA} \mathrm{~g}^{-1[223]}$. $\mathrm{Na}_{2} \mathrm{Ti}_{3} \mathrm{O}_{7}$ (NTO) is an insertion-type anode material. The octahedral layer of $\mathrm{TiO}_{6}$ can accommodate $\mathrm{Na}^{+}$ reversibly during cycling, with a theoretical capacity of $178 \mathrm{mAh} \mathrm{g}^{-1}$. In addition, NTO also has an effective low charge/discharge platform of $0.3 \mathrm{~V}$, which is the first reversible reaction between oxides and $\mathrm{Na}$ at such 
a low voltage. Due to the above shortcomings, it is essential to enhance the intrinsic conductivity of NTO. It is found that the capacity and conductivity of the metal oxide electrode can be improved by the creation of lattice defects in the crystal. As dopants in the electrode of LIBs, lanthanides ions can considerably enhance both the rate performance and capacity of the electrode. Even a small amount of lanthanide leads to an improvement in the rate performance and specific capacity of LIBs. The discharge capacities of NTO and NTO:Yb are 44.9 and $89.4 \mathrm{mAh} \mathrm{g}^{-1}$ at $30 \mathrm{C}$ and 214.1 and $153.1 \mathrm{mAh} \mathrm{g}^{-1}$ at $1 \mathrm{C}$, respectively [Figure 17A]. The discharge capacity of NTO is $43.9 \mathrm{mAh} \mathrm{g}^{-1}$ and the retention capacity is $34.58 \%$, while the discharge capacity of NTO:Yb remains at $71.6 \mathrm{mAh} \mathrm{g}^{-1}$ with a capacity retention of $\sim 46.02 \%$ over 1500 cycles at $5 \mathrm{C}$ [Figure $17 \mathrm{~B}$ ]. The reversible capacity may be reduced and the capacity may fade after a few cycles at $5 \mathrm{C}$ due to the enhancing polarization caused by a side reaction or the formation of an SEI layer ${ }^{[224]}$.

Doped samples of NTO show high electrochemical performance compared to pure NTO. Such a highperformance NTO anode was achieved without carbon coating and nanosizing. The insertion of lanthanides into the NTO structure causes a lattice distortion, resulting in the formation of oxygen vacancies, which considerably enhance faster charge storage kinetics and increase the donor density and electronic conductivity, thereby ensuring long-time cycling performance and superior rate performance ${ }^{[225]}$. A uranium-doped $\mathrm{LiMn}_{2} \mathrm{O}_{4}$ cathode exhibited outstanding cyclability in comparison with a pristine $\mathrm{LiMn}_{2} \mathrm{O}_{4}$ cathode. The $\mathrm{LiU}_{0.01} \mathrm{Mn}_{1.99} \mathrm{O}_{4}$ base cathode retains capacity at $\sim 100 \%$ of its initial capacity over 100 cycles. Since the quantity of dopants is minimal, there is no cost issue and is thus suitable for commercialization. In contrast, since only a small amount of dopant is required, it does not decrease the theoretical capacity but does decrease the lattice constant ${ }^{[226]}$. Finally, we summarize all the electrochemical performances of NTO:Ln samples in Figure 17C. The long-term cycling performance illustrates that $\mathrm{Ln}^{3+}-$ doped samples have better electrochemical performance than that of pristine $\mathrm{NTO}^{[225]}$.

\section{Hybrid materials}

An approach to prepare electrochemical energy storage materials is to synthesize strongly coupled hybrids of inorganic and organic carbon nanomaterials, such as graphene, carbon nanotubes, chalcogenides, metal carbides and nitrides (MXenes) ${ }^{[227]}$. Inorganic nanohybrid materials present a new route for preparing electrode materials with better electrochemical performance, synthesized by simple physical mixtures of conducting carbon materials and electrochemically active inorganic particles. Graphene, carbon nanotubes, metal carbides and nitrides, with various degrees of oxidation, offer novel substrates for the growth of nanoparticles. The interactions between the oxidized carbon substrates and inorganic precursors provide control over the structure, morphology and size of the inorganic nanoparticles. The conductivity of electrons and ions is very important to improve the rate performance of battery electrodes, especially when large and multivalent ions are applied in electrolytes. The theoretical values of the energy density of thin electrodes are much higher than the theoretical values of thick films.

A transition to $3 \mathrm{D}$ nanostructures (such as $\mathrm{T}-\mathrm{Nb}_{2} \mathrm{O}_{5}^{[227]}$ or $\mathrm{MnO}_{2}$ spinel) is required to enhance the access of ions to the surface of electrochemically active materials and decrease both macroscopic electrode strain and diffusion limitations through the charge/discharge process. 3D architectures permit the use of thicker electrodes $^{[228]} \cdot 2 \mathrm{D}$ materials, like transition metal carbides, dichalcogenides, nitrides and oxides, can store larger metallic ions $\left(\mathrm{Na}^{+}, \mathrm{K}^{+}, \mathrm{Mg}^{2+}\right.$ and $\left.\mathrm{Al}^{3+}\right)$ in between their layers. They are therefore recommended as promising anode materials for post-LIBs ${ }^{[229]}$, where the substrate material (MXene, graphene, and carbon nanotubes) acts as a conductive substrate for the active material and therefore gives mechanical strength and stability to the structure. In addition, they also increase the conductivity of the electrodes. Some "spacer reagents" can be incorporated between the layers to prevent from restacking and also enhance the electrochemical performance of the electrodes ${ }^{[230]}$. A computational study showed that the functional groups in Li-S battery electrode materials are polar and therefore, due to the anchoring property on polysulfides, 

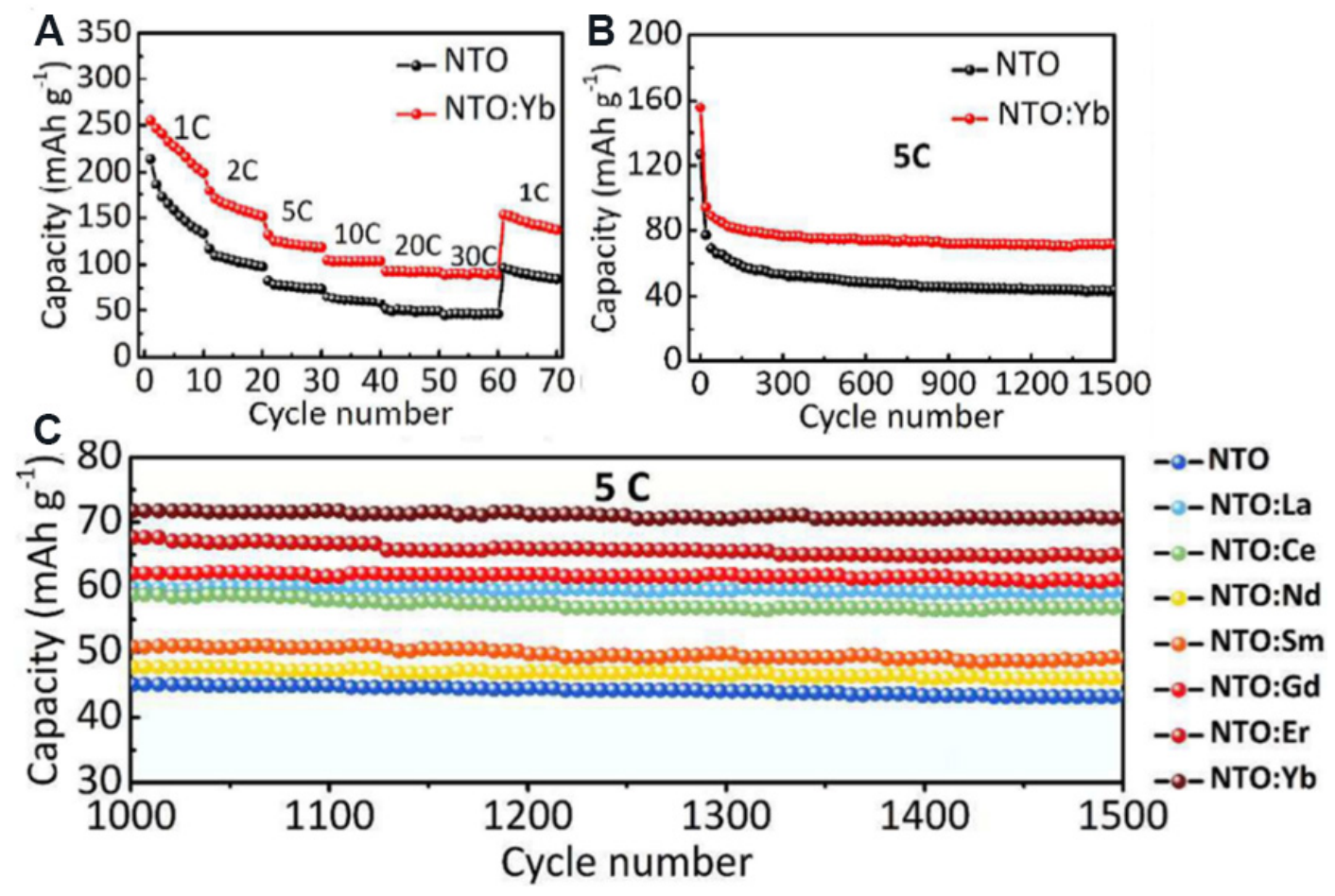

Figure 17. (A) Rate and (B) cycling performance of NTO and NTO:Yb in a half cell. (C) Cycling performance of NTO:Ln and NTO (Ln = $\mathrm{La}, \mathrm{Er}, \mathrm{Gd}, \mathrm{Sm}, \mathrm{Ce}, \mathrm{Nd}$ or $\mathrm{Yb}$ ) at a current rate of $5 \mathrm{C}$ with a cycle number of 1000 to 1500 . Reproduced with permission from Ref. ${ }^{[224]}$ (Copyright 2012, American Chemical Society). NTO: $\mathrm{Na}_{2} \mathrm{Ti}_{3} \mathrm{O}_{7}$.

they can easily accommodate metal oxides ${ }^{[231]}$. The properties of bulk transition metal dichalcogenides have different characteristics, such as metallic $\left(\mathrm{NbS}_{2}\right.$ and $\left.\mathrm{VSe}_{2}\right)$, semiconductors $\left(\mathrm{MoS}_{2}, \mathrm{WS}_{2}, \mathrm{WTe}_{2}\right.$ and $\left.\mathrm{TiSe}_{2}\right)$, insulators $\left(\mathrm{HfS}_{2}\right)$ and low-temperature superconductors $\left(\mathrm{TaS}_{2}\right.$ and $\left.\mathrm{NbSe}_{2}\right)$. These materials are converted into monolayers or few layers and also preserves their characteristics due to their confinement effects and gives additional characteristics ${ }^{[232]}$. A liquid exfoliation process was employed to synthesize mono- and multilayer nanosheets of inorganic compounds, such as $\mathrm{MoTe}_{2}, \mathrm{WS}_{2}, \mathrm{MoSe}_{2}, \mathrm{NbSe}_{2}, \mathrm{MoS}_{2}, \mathrm{NiTe}_{2}, \mathrm{TaSe}_{2}, \mathrm{~h}$ $\mathrm{BN}$ and $\mathrm{Bi}_{2} \mathrm{Te}_{3}{ }^{[233]}$.

\section{MXenes}

MXenes were first discovered by Naguib et al. ${ }^{[234]}$ in 2011 and they now represent the largest family of 2D materials. We can synthesize MXenes by the etching of selective atoms (A) from the MAX phase with the help of HF. The general formula of the MAX phase is $\mathrm{Mn}^{1+} \mathrm{AX}_{\mathrm{n}}$, where $\mathrm{A}$ is a group A element, $\mathrm{M}$ is a transition metal, $\mathrm{n}$ can be 1,2 or 3 and $\mathrm{X}$ is nitrogen and/or carbon. MAX has a large family (more than 60 phases) of ternary metal nitrides and carbides ${ }^{[5]}$. Various MXenes have been experimentally fabricated to date, including $\mathrm{Ti}_{3} \mathrm{C}_{2}, \mathrm{Ti}_{2} \mathrm{C}, \mathrm{Ti}_{3} \mathrm{CN}, \mathrm{V}_{2} \mathrm{C},\left(\mathrm{V}_{0.5} \mathrm{Cr}_{0.5}\right)_{3} \mathrm{C}_{2}, \mathrm{Nb}_{2} \mathrm{C}\left(\mathrm{Ti}_{0.5} \mathrm{Nb}_{0.5}\right)_{2} \mathrm{C}$ and $\mathrm{Ta}_{4} \mathrm{C}_{3}$. Due to their high conductivity compared to graphene, MXenes have attracted significant consideration. Shein et al..$^{[235]}$ examined the relative stability and structural features of MXenes $\left(\operatorname{Tin}^{+1} \mathrm{Nn}\right.$ and $\operatorname{Tin}^{+1} \mathrm{Cn}$ ). According to DFT calculations, by changing the surface terminators with a tunable bandgap, the conductivity of MXenes may be controlled. MXenes, where the surface of the sheet is terminated with surface terminators (i.e., - $\mathrm{OH},-\mathrm{F}$ and -O), are semiconductors but nonterminated MXenes have high conductivity and are metallic. The theoretical specific capacity of bare $\mathrm{Ti}_{3} \mathrm{C}_{2}$ is $320 \mathrm{mAh} \mathrm{g}^{-1}$; however, the addition of a terminator group limits its storage capacity. The results show that the specific capacities of $\mathrm{Ti}_{3} \mathrm{C}_{2}(\mathrm{OH})_{2}$ and $\mathrm{Ti}_{3} \mathrm{C}_{2} \mathrm{~F}_{2}$ are 130 and $67 \mathrm{mAh} \mathrm{g}^{-1}$, respectively ${ }^{[236]}$. DFT calculations show that in $\mathrm{Li}-, \mathrm{Na}-, \mathrm{K}$ - and $\mathrm{Ca}$-ion batteries, $\mathrm{Ti}_{3} \mathrm{C}_{2}$ can be 
used as an electrode material. The atomic content of $\mathrm{Li}, \mathrm{Na}$ and $\mathrm{K}$ has a linear relationship with the capacity. The theoretical capacities of $\mathrm{Li}, \mathrm{Na}, \mathrm{Ca}$ and $\mathrm{K}$ are $447.8,351.8,319.8$ and $191.8 \mathrm{mAh} \mathrm{g}^{-1}$, respectively ${ }^{[237]}$.

Kurtoglu et al. ${ }^{[238]}$ found that the elasticity of steel (400 GPa) is less than that of MXenes (> $500 \mathrm{GPa}$ ), which confirms that MXenes have comparatively high rigidity. It has been discovered that MXenes have a relatively similar capacity $\left(372 \mathrm{mAh} \mathrm{g}^{-1}\right.$ ) as graphite electrodes for Li in LIBs; however, they have outstanding potential regarding cycling. For example, additive-free MXenes can retain a reversible capacity of $110 \mathrm{mAh} \mathrm{g}^{-1}$ at a cycling rate of $36 \mathrm{C}$, while graphite cannot maintain this capacity at such a high cycling rate, which may be due to the smallest diffusion barrier for Li atoms in $\mathrm{Ti}_{3} \mathrm{C}_{2}$. With the help of DFT calculations, it has been determined that graphite and anatase $\mathrm{TiO}_{2}(0.35-0.65 \mathrm{eV})$ have a greater diffusion barrier of $\mathrm{Li}$ atoms than $\mathrm{Ti}_{3} \mathrm{C}_{2}(0.07 \mathrm{eV})^{[28]}$. MXenes can also be synthesized from a new layered ternary and quaternary compound $\left\{\mathrm{Mn}[\mathrm{Al}(\mathrm{Si})]_{4}\right.$ or $\left.\mathrm{C}_{3} \mathrm{MnAl}_{3} \mathrm{C}_{2}\right\}$, which acts as a precursor for the preparation of MXenes. They synthesized $\mathrm{Zr}_{3} \mathrm{C}_{2} \mathrm{~T}_{\mathrm{x}}$ and $\mathrm{Hf}_{3} \mathrm{C}_{2} \mathrm{~T}_{\mathrm{x}}$ by eliminating the $(\mathrm{AlC})_{\mathrm{x}}$ units from $\mathrm{Zr}_{3} \mathrm{Al}_{3} \mathrm{C}_{5}$ in the presence of a $50 \%$ concentrated solution of HF. The synthesized $2 \mathrm{D}$ MXene $\left(\mathrm{Hf}_{3} \mathrm{C}_{2} \mathrm{~T}_{z}\right)$ material shows an excellent reversible volumetric capacity $\left(1567 \mathrm{mAh} \mathrm{cm}^{-3}\right)$ at $200 \mathrm{~mA} \mathrm{~g}^{-1}$ over 200 cycles for LIBs ${ }^{[239]}$. Li et al. ${ }^{[240]}$ used hydrogen peroxide $\left(\mathrm{H}_{2} \mathrm{O}_{2}\right)$ to open the sheets and use it as an electrode material to give an excellent capacity of $389 \mathrm{mAh} \mathrm{g}^{-1}$ over 50 cycles at $100 \mathrm{~mA} \mathrm{~g}^{-1}$ and an excellent rate capability of $150 \mathrm{mAh} \mathrm{g}^{-1}$ at $5 \mathrm{~A} \mathrm{~g}^{-1}$.

In 2013, Mashtalir et al. ${ }^{[241]}$ synthesized a "paper" of $\mathrm{Ti}_{3} \mathrm{C}_{2}$ colloidal solution by reacting with DMSO, which gives the electrode a controlled capacity of $410 \mathrm{mAh} \mathrm{g}^{-1}$ at $1 \mathrm{C}$ and $110 \mathrm{mAh} \mathrm{g}^{-1}$ at $36 \mathrm{C}$ over 700 cycles. The enhancement of capacity may lead to the formation of an additional Li layer on the surface of the lithiated terminated MXene. The theoretical capacity of $320 \mathrm{mAh} \mathrm{g}^{-1}$ was expected by Kurtoglu et al. ${ }^{[238]}$ for Li intercalation of bare $\mathrm{Ti}_{3} \mathrm{C}_{2}$. Zhou et al. ${ }^{[242]}$ proved the synthesis of a $2 \mathrm{D} \mathrm{Hf}_{3} \mathrm{C}_{2} \mathrm{~T}_{z}$ MXene by etching $\mathrm{Hf}_{3}[\mathrm{Al}(\mathrm{Si})]_{4} \mathrm{C}_{6}$ in an aqueous solution of HF. For LIBs, this $2 \mathrm{D} \mathrm{Hf}_{3} \mathrm{C}_{2} \mathrm{~T}_{2}$ MXene material showed a better reversible volumetric capacity of $1567 \mathrm{mAh} \mathrm{cm}^{-3}$, over 200 cycles at $200 \mathrm{~mA} \mathrm{~g}^{-1}$. To synthesize the multilayered $\mathrm{Ti}_{3} \mathrm{CNT}_{\mathrm{x}}$ MXene, Zhang et al. ${ }^{[203]}$ used environmentally-friendly LiF and $\mathrm{HCl}$, unlike the directly HF etching etchant. In order to obtain the $\mathrm{Ti}_{3} \mathrm{CNT}_{\mathrm{x}}$ MXene with minimum restacking ability, they developed a freeze-dried method, which gives a specific discharge capacity of $300 \mathrm{mAh} \mathrm{g}^{-1}$ over 1000 cycles at $0.5 \mathrm{~A} \mathrm{~g}^{-1}$. The new $2 \mathrm{D} \mathrm{Nb} \mathrm{N}_{2}$ was examined for LIBs. At room temperature, the layered sample was successfully synthesized by etching of $\mathrm{Al}$ atoms from $\mathrm{Nb}_{2} \mathrm{AlC}$. A reversible capacity of $170 \mathrm{mAh} \mathrm{g}^{-1}$ over 150 cycles was achieved for $\mathrm{Nb}_{2} \mathrm{C}$ at $1 \mathrm{C}$, while a reversible capacity of $110 \mathrm{mAh} \mathrm{g}{ }^{-1}$ was attained at $10 \mathrm{C}$, respectively, with good cycling stability ${ }^{[236]}$.

Although the specific capacity of MXenes for LIBs $\left(372 \mathrm{mAh}^{-1}\right)$ is analogous to the specific capacity of a commercial graphitic electrode, MXenes have excellent rate performance at high rates, whereas graphite cannot hold a high cycling rate. This may be due to the smaller diffusion barrier of the Li atoms on the surface of $\mathrm{Ti}_{3} \mathrm{C}_{2}^{[236]}$. For the charge/discharge process, the diffusion barrier is the key factor to determine the discharge rate of the battery. In good agreement with earlier reported values, the diffusion barrier for Li is $0.068 \mathrm{eV}$, for $\mathrm{Na}$ is $0.096 \mathrm{eV}$, for $\mathrm{K}$ is $0.103 \mathrm{eV}$, for $\mathrm{Ca}$ is $0.118 \mathrm{eV}$ and for commercial graphite the diffusion barrier is $0.30 \mathrm{eV}$, which shows that $\mathrm{Ti}_{3} \mathrm{C}_{2}$ is the most promising high-rate electrode material. For improving the performance, having high capacity MXene with metal oxides is an alternative choice. The "conventional method" and "MXene bonding method" are used for the preparation of traditional polymer-bonded HC electrodes. Ahmed et al. ${ }^{[243]}$ proposed an atomic layer deposition technique to synthesize a $\mathrm{SnO}_{2} / \mathrm{Ti}_{3} \mathrm{C}_{2} \mathrm{~T}_{\mathrm{x}}$ composite material for LIBs as anode materials. The $\mathrm{SnO}_{2} / \mathrm{MXene}$ electrode coated with $\mathrm{HfO}_{2}$ gives a discharge specific capacity of $843 \mathrm{mAh} \mathrm{g}^{-1}$ at $500 \mathrm{~mA} \mathrm{~g}^{-1}$ over 50 cycles. Zhang et al ${ }^{[24]}$ also fabricated a $\mathrm{Co}_{3} \mathrm{O}_{4} @ \mathrm{Ti}_{3} \mathrm{C}_{2} \mathrm{~T}_{\mathrm{x}}$ composite material successfully. A capacity of $999.3 \mathrm{mAh} \mathrm{g}^{-1}$ at $500 \mathrm{~mA} \mathrm{~g}^{-1}$ was achieved 
after 900 cycles. An effective strategy was used by Lin et al. ${ }^{[245]}$ in 2015 to synthesize $\mathrm{Ti}_{3} \mathrm{C}_{2} \mathrm{~T}_{\mathrm{x}} /$ carbon nanofibers, which are in a multi-stacked form.

Mashtalir et al. ${ }^{[246]}$ worked on the delaminated $\mathrm{Nb}_{2} \mathrm{CT}_{\mathrm{x}} / \mathrm{CNT}$ composite material for LIBs in the same year. The free-standing CNT/MXene composite "paper" electrode, used as an anode material shows best cycling performances and recycling capacity of $400 \mathrm{mAh} \mathrm{g}^{-1}$ at $0.5 \mathrm{C}$. Ren et al. ${ }^{[247]}$ synthesized porous a 2D MXene $\left(\mathrm{p}-\mathrm{Ti}_{3} \mathrm{C}_{2} \mathrm{~T}_{\mathrm{x}}\right)$ in aqueous solutions at room temperature. A flexible electrode was fabricated by the addition of CNTs $\left(\mathrm{p}-\mathrm{Ti}_{3} \mathrm{C}_{2} \mathrm{~T}_{\mathrm{x}} / \mathrm{CNT}\right.$ ) and it exhibited a distinctly improved $\mathrm{Li}^{+}$storage capability of $\sim 500 \mathrm{mAh} \mathrm{g}^{-1}$ at $0.5 \mathrm{C}$ after 100 cycles and rate performance of $330 \mathrm{mAh} \mathrm{g}^{-1}$ at $10 \mathrm{C}$ was achieved compared with pristine $\mathrm{Ti}_{3} \mathrm{C}_{2} \mathrm{~T}_{\mathrm{x}}$. They also prepared porous $\mathrm{V}_{2} \mathrm{CT}_{\mathrm{x}}$ and $\mathrm{Nb}_{2} \mathrm{CT}_{\mathrm{x}}$ MXenes using the same method. Wu et al. ${ }^{[248]}$ synthesized $\mathrm{MoS}_{2} \mathrm{Ti}_{3} \mathrm{C}_{2}-\mathrm{MXene} / \mathrm{C}$ nanocomposites by a simple carbon nanoplating method, where the reversible discharge capacity was $1750 \mathrm{mAh} \mathrm{g}^{-1}$ at $0.2 \mathrm{~A} \mathrm{~g}^{-1}$ and $1200 \mathrm{mAh} \mathrm{g}^{-1}$ over 700 cycles at $1 \mathrm{~A} \mathrm{~g}^{-1}$. Rakhi et al. ${ }^{[249]}$ synthesized a MXene coated with whiskers of nanocrystalline $\varepsilon-\mathrm{MnO}_{2}$. The $\mathrm{MXene} / \varepsilon-\mathrm{MnO}_{2}$ showed outstanding cycling performance ( $88 \%$ retention) over 10,000 cycles.

Specifically, the MXene substrate with high conductivity can effectively remove the aggregation of $\mathrm{MoSe}_{2}$ nanosheets and improve the electronic conductivity, while the carbon layer gives strength to the composite structure and further improve the overall conductivity of the hybrid nanosheets, as shown from the EIS results given in Figure 18. The strong chemical interaction at the interface of the MXene and $\mathrm{MoSe}_{2}$ improves the durability of the structure and promotes the charge transfer dynamics. Therefore, $\mathrm{MoSe}_{2}$ /MXene/C has a high rate performance of $183 \mathrm{mAh} \mathrm{g}^{-1}$ at $10 \mathrm{~A} \mathrm{~g}^{-1}$ and an outstanding reversible capacity of $355 \mathrm{mAh} \mathrm{g}^{-1}$ at $200 \mathrm{~mA} \mathrm{~g}^{-1}$. The EIS measurements of $\mathrm{MoSe}_{2} / \mathrm{MXene} / \mathrm{C}, \mathrm{MoSe}_{2} / \mathrm{MXene}, \mathrm{MoSe}_{2}$ and MXene after several cycles show straight lines (low-frequency range) and semicircle depressions (middle- and highfrequency ranges), respectively, as given in Figure 18. The high-frequency semicircle is related to the surface contact resistance, while the low-frequency slope line represents the diffusion and phase transformation of ions in the electrode. This clearly shows that $\mathrm{MoSe}_{2} / \mathrm{MXene/C}$ has the smallest high-frequency concave semicircle and the smaller interfacial resistance. The proposed design strategy provides a broad prospect for the development of more useful PIBs electrode materials ${ }^{[250]}$.

Zou et al. ${ }^{[211]}$ produced a MXene/Ag composite material of layered MXene films and Ag nanoparticles. $\mathrm{AgNO}_{3}$ is reduced in the presence of MXene $\left[\mathrm{Ti}_{3} \mathrm{C}_{2}(\mathrm{OH})_{0.8} \mathrm{~F}_{1.2}\right]$ and a MXene/Ag composite material is synthesized. The MXene/Ag composite material shows a better starting specific capacity of $550 \mathrm{mAh} \mathrm{g}^{-1}$. Furthermore, this sample also shows reversible capacities of $150 \mathrm{mAh} \mathrm{g}^{-1}$ at $50 \mathrm{C}$ and $310 \mathrm{mAh} \mathrm{g}^{-1}$ at $1 \mathrm{C}$ even over 5000 cycles. This is due to the close connection of the conversion of $\mathrm{Ti}$ (III) to $\mathrm{Ti}(\mathrm{II})$ and the reduction of the interfacial resistance during the charge/discharge process. $\mathrm{Sn}^{4+}$ was successfully introduced inside the interlamination of an alkylated $\mathrm{Ti}_{3} \mathrm{C}_{2}$. Because of the synergistic effect of the $\mathrm{Sn}^{4+}$ between the layers of alkyl- $\mathrm{Ti}_{3} \mathrm{C}_{2}$ matrix layers, it plays an important supporting role among the alk- $\mathrm{Ti}_{3} \mathrm{C}_{2}$ matrix layers and this process is known as the "pillar effect". The nanocomposites show a capacity of $635 \mathrm{mAh} \mathrm{g}^{-1}$ and a better volumetric capacity of $1375 \mathrm{mAh} \mathrm{cm}^{-3}$ at a high current density of $216.5 \mathrm{~mA} \mathrm{~cm}^{-3}\left(100 \mathrm{mAh} \mathrm{g}^{-1}\right)$, which is considerably greater than the graphite electrode $\left(550 \mathrm{mAh} \mathrm{cm}^{-3}\right)$ over 50 cycles. These nanocomposite materials hold a specific volumetric capacity of $504.5 \mathrm{mAh} \mathrm{cm}^{-3}$ and a reversible charge capacity of $233 \mathrm{mAh} \mathrm{g}^{-1}$ even at an extremely high current density of $6495 \mathrm{~mA} \mathrm{~cm}^{-3}\left(3 \mathrm{~A} \mathrm{~g}^{-1}\right)^{[211]}$.

Among the various MXenes, $\mathrm{Ti}_{3} \mathrm{C}_{2}$ and $\mathrm{Ti}_{2} \mathrm{C}$ have been extensively studied. For example, $\mathrm{Ti}_{3} \mathrm{C}_{2}$ gives a capacity of $410 \mathrm{mAh} \mathrm{g}^{-1}$ for LIBs. Interestingly, by intercalation with different cations, such as $\mathrm{NH}^{4+}, \mathrm{Al}^{3+}$ and $\mathrm{Sn}^{4+}$, the capacity can be greatly increased to $\sim 800 \mathrm{mAh} \mathrm{g}^{-1}$. As a comparison, $\mathrm{V}_{2} \mathrm{C}$ MXene has a small molecular weight that can attain a higher theoretical LIB capacity of $940 \mathrm{mAh}^{-1}$. Unfortunately, the 


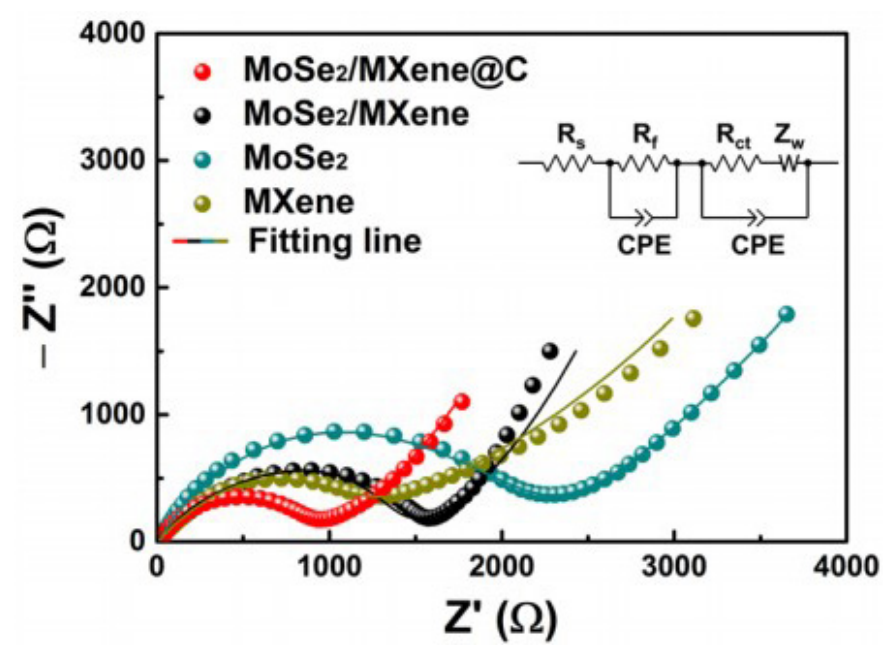

Figure 18. EIS results of $\mathrm{MoSe}_{2} / \mathrm{MXene} / \mathrm{C}, \mathrm{MoSe}_{2} / \mathrm{MXene}, \mathrm{MoSe}_{2}$ and $\mathrm{MXene}$ anodes after several cycles. The inset shows the corresponding equivalent circuits for data fitting, where Rct, Zw, RF, CPE and RS represent contact resistance, constant-phase element, electrolyte resistance, charge-transfer resistance and Warburg ion-diffusion resistance, respectively. Reproduced with permission from Ref. $^{[250]}$ (Copyright 2019, American Chemical Society).

experimental $\mathrm{V}_{2} \mathrm{C}$ MXene shows only $260 \mathrm{mAh} \mathrm{g}^{-1}$ capacity at $1 \mathrm{C}$, which is significantly lower than the theoretical value. However, recently it has been noted that $\mathrm{V}_{2} \mathrm{C}$ has excellent storage capacity $\left(1100 \mathrm{mAh} \mathrm{g}^{-1}\right)$ for $\mathrm{Li}^{+}$and good cycling stability after intercalation with $\mathrm{Co}^{[179]}$.

\section{Graphene oxide}

In 1958, Hummers synthesized GO using the most commonly used method today by treating oxidizing graphite with $\mathrm{NaNO}_{3}$ and $\mathrm{KMnO}_{4}$ in the presence of $\mathrm{H}_{2} \mathrm{SO}_{4}{ }^{[251]}$. It is noteworthy that these processes release poisonous gases, such as $\mathrm{NO}_{2}, \mathrm{~N}_{2} \mathrm{O}_{4}$ and $\mathrm{ClO}_{2}$, which may cause an explosion. Brodie was the first to synthesize GO in 1859 when a small amount of potassium chlorate $\left(\mathrm{KClO}_{3}\right)$ was reacted with graphite in the presence of fuming nitric acid ${ }^{[252]}$. Graphene oxide is synthesized from monolayer films, like sheets of GO, which was planned more than a century ago. The properties of graphene oxide depend upon its extent of oxidation and special properties, like optical and electronic behavior. A large film of graphite can be synthesized from GO because it is water soluble and can be used as a component of the cathode and also as a binder in LIBs for carbon products. Moreover, its hydrophilicity allocates it on substrates uniformly, which is essential for applications in the field of electronics ${ }^{[253]}$. The treatment of multiwalled carbon nanotubes with concentrated $\mathrm{H}_{2} \mathrm{SO}_{4}, \mathrm{KMnO}_{4}$ and then phosphoric acid $\left(\mathrm{H}_{3} \mathrm{PO}_{4}\right)$ gives graphene oxide nanoribbons in a scalable manner. This process is known as the "improved method" and can be used to synthesize improved GO. The basal plane of GO produced by the Hummers method is comparatively small $^{[2]}$. The majority of GO presented was fabricated based on Offerman's process and the Hummers method, which offers little control over the degree of functionalization and is a time-consuming method.

Due to the very weak Van der Walls interaction, GO shows very low thermal stability ${ }^{[254]}$. Anchoring of metal and non-metal oxides on sheets of graphene increases the cycling stability and electrochemical reversibility of the composite materials. Bismuth oxide $\left(\mathrm{Bi}_{2} \mathrm{O}_{3}\right)$ has a high theoretical capacity of $690 \mathrm{mAh} \mathrm{g}^{-1}$. A Bi $\mathrm{O}_{3} / \mathrm{rGO}$ composite was synthesized by a hydrothermal process, which gives better cycling stability and electrochemical reversibility compared to bare $\mathrm{Bi}_{2} \mathrm{O}_{3}$ nanoparticles. $\mathrm{Bi}_{2} \mathrm{O}_{3} / \mathrm{rGO}$ used as an anodic material shows an outstanding initial capacity of $900 \mathrm{mAh} \mathrm{g}^{-1}$ at $0.1 \mathrm{C}$ and a rate capability of $270 \mathrm{mAh} \mathrm{g}^{-1}$ at $10 \mathrm{C}$ and $347.3 \mathrm{mAh} \mathrm{g}^{-1}$ at $1 \mathrm{C}$, with a capacity retention rate over $79 \%$ after 100 cycles, which is much higher than for bare $\mathrm{Bi}_{2} \mathrm{O}_{3}$ nanocrystals ${ }^{[159]}$. The strong interaction between the nanoparticles of 
$\mathrm{Co}_{3} \mathrm{O}_{4}$ and graphene sheets is beneficial to control the volume expansion and the accumulation of $\mathrm{Co}_{3} \mathrm{O}_{4}$ NPs during the charge/discharge process, which gives a capacity of $\sim 935 \mathrm{mAh} \mathrm{g}^{-1}$ over 30 cycles compared to bare graphene nanosheets and $\mathrm{Co}_{3} \mathrm{O}_{4}$ nanoparticles ${ }^{[133,255]}$. An $\mathrm{SnO}_{2} /$ graphene nanocomposite used as a LIB anode material have a reversible capacity of 432 and $638 \mathrm{mAh} \mathrm{g}^{-1}$, respectively, over 100 and 150 cycles at $20 \mathrm{~mA} \mathrm{~g}^{-1[256]}$.

Alloys

In order to design better electrode materials with outstanding microstructures, corrosion resistance and hardness, the edifice of different elements can be applied. For this purpose, alloying is the best choice due to the potential for superior electrochemical properties and electronic conductivity. Alloys of $\mathrm{Sb}$ and $\mathrm{Sn}$, such as $\mathrm{Cu}_{6} \mathrm{Sn}_{5}, \mathrm{SnSb}, \mathrm{Mo}_{3} \mathrm{Sb}_{7}$ and $\mathrm{Cu}_{2} \mathrm{Sb}$, have received particular attention because of their enhanced rate capability and long-term cycling performance. Such intermetallic candidates have outstanding properties compared to pure elemental electrodes since they are expected to show better capacity retention at very low temperatures $(2.2 \mathrm{~K})$ and low operating voltages $(0.9 \mathrm{~V})$ and possess excellent capacity retention $v s$. Li. One such candidate is $\mathrm{Mo}_{3} \mathrm{Sb}_{7}$. This electrode material gives a reversible capacity of $494 \mathrm{mAh} \mathrm{g}^{-1}$ and its volumetric capacity $\left(4273 \mathrm{mAh} \mathrm{cm}^{-3}\right)$ is comparatively close to pristine $\mathrm{Sb}\left(4422 \mathrm{mAh} \mathrm{cm}^{-3}\right)^{[155]}$. The alloys of lead and antimony are also applied in the assembly of lead-acid grid battery because of the soft nature of pure lead. It has been found that the introduction of small amounts of elements, like selenium and arsenic, to the alloys of lead-antimony, significantly enhances the electrochemical performance and mechanical properties of batteries ${ }^{[192,208,211]}$. However, due to the dendrite structure of $\mathrm{Pb}$-Sb alloys with $\mathrm{Sb}$ contents of 1.5-3.5 wt.\%, they become very brittle, hard and easy to $\operatorname{crack}^{[257]}$.

$\mathrm{Na}$ can produce alloys with different elements like tin $\left(\mathrm{Na}_{15} \mathrm{Sn}_{4}\right)$, bismuth $\left(\mathrm{Na}_{3} \mathrm{Sb}\right)$, germanium $\left(\mathrm{Na} a_{3} \mathrm{Ge}\right)$ and lead $\left(\mathrm{Na}_{15} \mathrm{~Pb}_{4}\right)$. The thermodynamic potentials required for the alloying of $\mathrm{Na}$ is comparatively higher than that of $\mathrm{Li}$ atoms and make it potentially safer. An Sb/C nanocomposite shows a reversible capacity of $397 \mathrm{mAh} \mathrm{g}^{-1}$ for the initial 30 cycles. Afterward, the capacity fades rapidly to $100 \mathrm{mAh} \mathrm{g}^{-1}$, while the $\mathrm{Sn} / \mathrm{C}$ nanocomposite electrode shows poor recyclability and the initial capacity suddenly decreased to $80 \%$ after 13 cycles. The capacity decay in a single metal electrode is due to the expansion of volume during mechanical stress, which mainly occurred in the electrodes of Li alloys. The size of Li-Sn and Li-Sb alloys is less than the size of $\mathrm{Na}-\mathrm{Sn}$ and $\mathrm{Na}-\mathrm{Sb}$ alloys and this difference is further increased during the alloying process $^{[155]}$. The binary alloys of $\mathrm{SnSb}$ are more stable compared to the single metals, which may be due to the occurrence of an electrochemical reaction at a wide potential range of (0.0-0.9 V) and distinctive structural confinement through the charge/discharge process. Therefore, it is expected that the pristine $\mathrm{Sb}$ and $\mathrm{Sn}$ phases produced through the in situ charge/discharge process sustain the conductivity and integrity of the electrode material and fabricate a self-supporting network ${ }^{[258]}$.

\section{CURRENT CHALLENGES FACING LIBS}

The next generation of LIBs will be more capable, stable, durable, environmentally friendly and less expensive. However, we continue to confront some challenges. These challenges are as follows.

\section{Overcharge and overdischarge}

The major causes of safety incidents with LIBs are heat evolvement and storage inside the batteries. Gas production is generally accompanied by heat generation and both are regulated by battery voltage and temperature. One of the most common reasons of heat evolvement is overcharging. As a result, adopting precautions to avoid spontaneous overcharging within the battery will complement the exterior overcharge prevention methods. Thermal runaway occurs when a battery short circuit occurs due to separator breakdown and the heat generated locally cannot be dissipated efficiently. The development of temperature- 
sensitive materials for limiting local temperature rises in the battery is a pivotal approach to avoid thermal runaway. Another possible technique for heat dissipation is to create an internal fast heat diffusion path (for example, by adding materials with high thermal conductivity). Finally, careful selection of active electrode materials and electrolytes is necessary to minimize heat and gas production, while also protecting the electrode interface ${ }^{[259]}$. Furthermore, LIBs should not be charged at temperatures below $32^{\circ} \mathrm{F}$. Lithium coating results in the accumulation of $\mathrm{Li}$ atoms along the anode surface when charging at this temperature and the battery is more susceptible to harm, such as high-speed charging, which can lead to short circuit. Excessive discharge and overcharging of LIB packs must be avoided by those who use them. LIBs chemistry must have a voltage of at least $2 \mathrm{~V}$. This problem might arise if the battery has been kept for an extended period of time or has been drained excessively. Both the cathode and the anode begin to break down when the voltage is less than $2 \mathrm{~V}$. The anode collector will disintegrate when copper dissolves in the electrolyte. $\mathrm{Cu}$ ions begin to precipitate into metal $\mathrm{Cu}$ when the battery is charged over $2 \mathrm{~V}$, resulting in a short circuit. Simultaneously, the cathode begins to release oxygen and the battery begins to lose capacity permanently after a few cycles.

\section{Thermal runaway}

The temperature difference between high-temperature operation and the battery will result in battery accelerated aging, out-of-control heating and other safety issues, posing a serious threat to vehicle safety. The breakdown of electrolyte and metal oxide cathode is caused by the pace at which the heat and pressure rise. The safety vent does not discharge the gas from the battery pack quickly enough and gas begins to build in the battery pack. Nothing can prevent this effect before the battery ignites or explodes and once one battery in the battery pack experiences thermal runaway, the next battery in the battery pack will begin to experience thermal runaway as well. Since it allows the system temperature to be managed, the welldesigned built-in cooling system is a key component of LIB safety. A cooling system may be necessary if heat is created too late in the cycle to disperse. A cooling system is also necessary to manually regulate the overall temperature in the event of unequal temperature distribution. The operating temperature range for LIBs is $15-35^{\circ} \mathrm{C}^{[260]}$. As a result, an optimum cooling control system capable of maintaining this range is critical for safely extending battery life and lowering costs. The electrolyte is the most dangerous part of a LIB and the core is flammable. The exothermic reaction rate inside the battery increases when the battery temperature goes over $80^{\circ} \mathrm{C}$. These processes eventually cause LIBs to thermally runaway, causing the battery to burst and explode. The cause for this is that the high-temperature flammable gas in the battery interacts with the surrounding oxygen ${ }^{[261]}$.

\section{Dendrite formation}

One of the main causes of thermal runaway is the growth of Li dendrites, which can be mitigated by four different methods: (1) capping with additive molecules or ions; (2) redirecting dendrite growth away from the separator with Li friendly/hydrophobic coatings; (3) using a compartment/structured collector; and (4) inhibition using a solid electrolyte. Currently, the composite of a ceramic or glass electrolyte and polymer hybrid, as well as the insertion of an artificial interface stabilizing layer between Li and electrolyte, are the most prevalent and promising techniques among the aforementioned tactics. The dendrite development process in SES needs to be investigated and understood better in the future, so that a more practical and scalable method may be used to provide a new path to solve the dendrite problem ${ }^{[262]}$. To assess dendritic inhibition, it is advised to utilize standard CE characterization, more powerful in situ characterization technology, restricted Li, early detection of "soft short circuit" and thinner electrolytes.

\section{Safety issues caused by undesirable chemical reactions}

Only $\mathrm{Li}^{+}$shuttle occurs in the electrolyte during the insertion/extraction cycle of the cathode and anode in the typical voltage and temperature range. Electrochemical reactions grow more complicated at high 
temperatures and pressures, with the breakdown of the SEI membrane, oxygen release on the cathode side and extra electrolyte/electrode side reactions occur ${ }^{[263]}$. The temperature rises as a result of SEI membrane breakdown occurring, which increases the danger of oxygen leakage from active cathode materials. These processes eventually cause LIBs to thermally runaway, as described above ${ }^{[261]}$.

\section{Short circuit}

A separator is an important part of a LIB. Its purpose is to keep the positive and negative electrodes of the battery from making physical contact, to prevent internal short circuits, and to act as an electrolyte reservoir for ion transfer. The ideal separator should have a large electrolyte absorption capacity to lower the internal resistance, as well as an extremely thin thickness, high mechanical strength, electrochemical and structural stability, a highly porous structure and a large curvature to prevent tree-branched lithium dendrite formation. Industry and scientific research will require high-performance battery separators in the future as demand for high charge discharge efficiency and high energy density LIB growth. Experiments are now used to do research on separator materials and characteristics. Simultaneously, DFT simulations are a costeffective and efficient method to design separators and battery systems. In order to provide safer and more powerful separators, it is very important to develop new LIBs or battery systems and optimize the manufacturing process. The following DFT research and development models are recommended for the future: (1) a novel thermal runaway model for LIB systems, which can combine a variety of battery separator materials with different mechanical and physical properties; and (2) a coupling multiscale simulation model to study all internal/external coupling phenomena.

\section{FUTURE PROSPECTS OF LIBS}

LIBs have come a long way since their introduction in 1991, with their specific energy content nearly tripling. Despite the necessity for complex control systems and battery energy reserves, LIBs have more than quadrupled their life, allowing them to fulfill most automotive calendar and cycle life requirements. While attaining significant performance gains, the cost of LIBs has been lowered by roughly two orders of magnitude and has been steadily declining in recent years. These LIB technological advancements have been made while retaining the high level of safety demanded by automotive goods.

1. The next generation of LIBs will be greater in capacity, have longer service lives, more environmentally friendly and less expensive, necessitating possible lightweight collectors with higher electrochemical stability and conductivity. Furthermore, in the future, a collector with a flexible construction will be required for the use of wearable devices.

2. A number of successful techniques are discovered based on an understanding of LIB structures and operating principles. The safety and performance stability of LIBs may be substantially enhanced by carefully selecting electrode materials, separators and electrolytes, as well as improving battery architecture. External methods, such as cooling and battery balance, can also significantly improve LIB safety performance under typical circumstances.

3. As the size of the real battery pack has grown in recent years, a new vehicle quick charging objective has emerged, resulting in a constant increase in the charging rate of the battery system. LIBs will be able to reach a total energy of $350 \mathrm{Wh} / \mathrm{kg}$ at the start of their life, based on current development and materials chemistry research results. Unfortunately, this energy content is insufficient to satisfy the vehicle energy objective if this performance is moved to the accessible end-of-life value of component ${ }^{[264]}$. About a decade ago, numerous research initiatives beyond lithium ion were launched in response to this impending problem. The Li metal system has been the most advanced beyond lithium ion technology in the last 
decade. The American Advanced Battery Alliance recently issued an automobile LIB objective that highlights the advancement and potential effect of LIBs.

4. New liquid electrolytes compatible with Li metal have recently made significant progress by enhancing the design of existing $\operatorname{LIBs}^{[265]}$. The possibility of a Li metal solid-state battery has also been revised thanks to the discovery of many recently found solid Li superionic conductors (LMSSBs) ${ }^{[266]}$. Traditional LIB cathodes and battery design characteristics are also used in most proposed LMSSB systems. Long-term LIBs development will need a deeper knowledge of $\mathrm{Li}$ mechanics ${ }^{[267]}$ and Li-electrolyte interactions, whether liquid or solid ${ }^{[268]}$. Regardless of whether solid or liquid electrolyte systems are utilized, the basic architecture of these Li metal batteries will inherit the vast majority of the LIB system's technical and materials chemistry advancements.

5. The scientific community must still satisfy its standards in order for solid-state batteries to be commercialized in the future. The area specific resistance (ASR) of the interface between the solid-state ceramic electrolyte and the electrode (containing anode and cathode) is less than $25 \Omega \mathrm{cm}^{-2}$ (the total battery resistance of commercial LIBs is $22 \Omega \mathrm{cm}^{-2}$, which is utilized for liquid batteries). The ASR range of most solid ceramic electrolytes' ceramic Li metal interface is $37-20,000 \Omega \mathrm{cm}^{-2}$. The cathode is more powerful. Hitz et al. ${ }^{[269]}$ investigated the construction of a three-layer Li garnet electrolyte, which had a low interface impedance of $7 \Omega \mathrm{cm}^{-2}$ and a high current density of $10 \mathrm{~mA} / \mathrm{cm}^{2}$. However, the production cost must be weighed against the existing technological level.

6. Environmental atmosphere is required for the stability of a sulfide-based Li-ion conductor ceramic electrolyte. The next class of most promising superionic Li-ion conductors $\left(\geq 10^{-4} \mathrm{~S} / \mathrm{cm}\right)$ will be accurately identified using a combination of a computational prediction models of material selection and a density functional theory molecular dynamics calculation ${ }^{[270]}$. Many potential possibilities have been found using machine learning calculation approaches, including $\mathrm{Li}_{5} \mathrm{~B}_{7} \mathrm{~S}_{13}, \mathrm{Li}_{2} \mathrm{~B}_{2} \mathrm{~S}_{5}, \mathrm{Li} 3 \mathrm{ErCl}_{6}, \mathrm{LiSO}_{3} \mathrm{~F}, \mathrm{Li}_{3} \mathrm{InCl}_{6}, \mathrm{Li}_{2} \mathrm{HIO}$, $\mathrm{LiMgB}_{3}\left(\mathrm{H}_{9} \mathrm{~N}\right)_{2}$ and $\mathrm{CsLi}_{2} \mathrm{BS}_{3}$. The Li-ion conductivity $(74 \mathrm{mS} / \mathrm{cm})$ of $\mathrm{Li}_{5} \mathrm{~B}_{7} \mathrm{~S}_{13}$ is expected to be several times that of the fastest Li-ion conductor known today ${ }^{[271]}$.

7. To assess dendritic inhibition, it is advised to utilize standard CE characterization, restricted Li amount, early detection of "soft short circuit", more powerful in situ characterization technology and thinner electrolytes.

8. Coin cell batteries have been used to test the majority of existing Li-metal protection techniques. Testing the stability of Li metal in larger batteries is quite practical (such as pouch batteries). The artificial interface layer between SE and Li metal must be stable and functional.

9. Simulation is becoming increasingly essential in identifying novel electrolyte possibilities and assisting experimenters in gaining a better understanding and predicting performance. We have a fundamental knowledge of the design and interfacial stability of Li-metal anodes on different scales, notably the interface layer can guide Li-metal anode development and stabilization eventually commercialization of Li-metal anodes in ASLBs.

\section{CONCLUSIONS}

Emerging electrochemical energy storage devices will play a vital role in the future energy systems of the world. The innovation of electrode materials is a decisive factor for the improvement of new electrochemical energy storage devices. Nanotechnology opens up new properties and uses the advantage of 
the best chemical properties of elements to bring them to a useful plane. The in-depth knowledge of elemental chemistry has been fully utilized, providing new applications for nanomaterials. The periodic table of elements is helpful to understand the chemical diversity of elements. It also helps us to find out the effective combination of elements to produce novel nanoenergy storage materials and assists us in making additional progress and innovation in the field of nanoscience and nanotechnology. The combination of periodic table knowledge with theoretical calculations and experimental procedures will pave the way for the development of novel materials with excellent electrochemical properties. The specific capacity, rate performance, energy density, cycling performance, long-term cycling stability and their mechanisms for LIBs of s-, p-, d- and f-block elements, transition and inner transition metals and hybrid materials (MXene, graphene oxide and alloys) were studied in detail, which provided appropriate treatment methods and creative remedial measures for the better performance of energy storage devices. We have also highlighted the challenges facing LIBs and their future prospects for the next generation.

\section{DECLARATIONS}

\section{Authors' contributions}

Conceptualization, methodology, writing -original draft: Bashir T

Writing - review and editing: Ismail SA

Literature survey - revision: Song Y, Zhou S

Literature survey - figures set up: Irfan RM

Validation, formal analysis; literature survey - revision: Yang S

Supervision, writing - review and editing: Zhao J, Gao L

\section{Availability of data and materials}

Not applicable.

\section{Financial support and sponsorship}

This work was supported by the National Natural Science Foundation of China (grant numbers 21703147 and U1401248); One of the authors (Bashir T) also acknowledges the support of China Scholarship Council (grant number 2018SLJ022487).

\section{Conflicts of interest}

All authors declared that there are no conflicts of interest.

\section{Ethical approval and consent to participate}

Not applicable.

\section{Consent for publication}

Not applicable.

\section{Copyright}

(c) The Author(s) 2021.

\section{REFERENCES}

1. Tomalia DA, Khanna SN. A systematic framework and nanoperiodic concept for unifying nanoscience: hard/soft nanoelements, superatoms, meta-atoms, new emerging properties, periodic property patterns, and predictive mendeleev-like nanoperiodic tables. Chem Rev 2016;116:2705-74. DOI PubMed

2. Marcano DC, Kosynkin DV, Berlin JM, et al. Improved synthesis of graphene oxide. ACS Nano 2010;4:4806-14. DOI PubMed

3. Naguib M, Gogotsi Y. Synthesis of two-dimensional materials by selective extraction. Acc Chem Res 2015;48:128-35. DOI PubMed

4. Naguib M, Mochalin VN, Barsoum MW, Gogotsi Y. 25th anniversary article: MXenes: a new family of two-dimensional materials. Adv Mater 2014;26:992-1005. DOI PubMed

5. Naguib M, Mashtalir O, Carle J, et al. Two-dimensional transition metal carbides. ACS Nano 2012;6:1322-31. DOI PubMed 
6. Ong WJ, Tan LL, Ng YH, Yong ST, Chai SP. Graphitic carbon nitride (g-C3N4)-based photocatalysts for artificial photosynthesis and environmental remediation: are we a step closer to achieving sustainability? Chem Rev 2016;116:7159-329. DOI PubMed

7. $\mathrm{Li} \mathrm{W}$, Bashir T, Wang J, et al. Enhanced sodium-ion storage performance of a $2 \mathrm{D} \mathrm{MoS}_{2}$ anode material coated on carbon nanotubes. ChemElectroChem 2021;8:903-10. DOI

8. Yao L, Xi Y, Han H, Li W, Wang C, Feng Y. $\mathrm{LiMn}_{2} \mathrm{O}_{4}$ prepared from waste lithium ion batteries through sol-gel process. $J$ Alloys Compd 2021;868:159222. DOI

9. Ozawa K. Lithium-ion rechargeable batteries with $\mathrm{LiCoO}_{2}$ and carbon electrodes: the $\mathrm{LiCoO}_{2} / \mathrm{C}$ system. Solid State Ionics 1994;69:212-21. DOI

10. Li L, Zhao R, Xu T, et al. Stabilizing a high-voltage $\mathrm{LiNi}_{0.5} \mathrm{Mn}_{1.5} \mathrm{O}_{4}$ cathode towards all solid state batteries: a Li-Al-Ti-P-O solid electrolyte nano-shell with a host material. Nanoscale 2019;11:8967-77. DOI PubMed

11. Yang $\mathrm{S}$, Yao J, Hu H, et al. Sonication-induced electrostatic assembly of an $\mathrm{FeCO}_{3} @ \mathrm{Ti}_{3} \mathrm{C}_{2}$ nanocomposite for robust lithium storage. J Mater Chem A 2020;8:23498-510. DOI

12. Gao X, Yang H. Multi-electron reaction materials for high energy density batteries. Energy Environ Sci 2010;3:174-89. DOI PubMed PMC

13. Chung SY, Bloking JT, Chiang YM. Electronically conductive phospho-olivines as lithium storage electrodes. Nat Mater 2002;1:123-8. DOI PubMed

14. Kim D, Kim J. Synthesis of $\mathrm{LiFePO}_{4}$ nanoparticles in polyol medium and their electrochemical properties. Electrochem Solid-State Lett 2006;9:A439. DOI

15. Doeff MM, Ma Y, Visco SJ, De Jonghe LC. Electrochemical insertion of sodium into carbon. J Electrochem Soc 1993;140:L169-70. DOI

16. Alcántara R, Lavela P, Tirado JL, Stoyanova R, Kuzmanova E, Zhecheva E. Lithium-nickel citrate precursors for the preparation of $\mathrm{LiNiO}_{2}$ insertion electrodes. Chem Mater 1997;9:2145-55. DOI

17. Wenzel S, Hara T, Janek J, Adelhelm P. Room-temperature sodium-ion batteries: improving the rate capability of carbon anode materials by templating strategies. Energy Environ Sci 2011;4:3342. DOI

18. Stevens DA, Dahn JR. High capacity anode materials for rechargeable sodium-ion batteries. J Electrochem Soc 2000;147:1271. DOI

19. Dominko R, Gaberscek M, Bele M, Mihailovic D, Jamnik J. Carbon nanocoatings on active materials for Li-ion batteries. $J$ Eur Ceram Soc 2007;27:909-13. DOI

20. Gaberscek M, Dominko R, Bele M, Remskar M, Jamnik J. Mass and charge transport in hierarchically organized storage materials. Example: porous active materials with nanocoated walls of pores. Solid State Ionics 2006;177:3015-22. DOI

21. Kharbachi A, Zavorotynska O, Latroche M, Cuevas F, Yartys V, Fichtner M. Exploits, advances and challenges benefiting beyond Li-ion battery technologies. $J$ Alloys Compd 2020;817:153261. DOI

22. Gogotsi Y, Simon P. Materials science. True performance metrics in electrochemical energy storage. Science 2011;334:917-8. DOI PubMed

23. Deng Z, Liu T, Chen T, et al. Enhanced electrochemical performances of $\mathrm{Bi}_{2} \mathrm{O}_{3} / \mathrm{rGO}$ nanocomposite via chemical bonding as anode materials for lithium ion batteries. ACS Appl Mater Interfaces 2017;9:12469-77. DOI PubMed

24. Ghodbane O, Pascal J, Favier F. Microstructural effects on charge storage properties in $\mathrm{MnO}_{2}$ based electrochemical supercapacitors. ECS Trans 2009;16:235-41. DOI PubMed

25. Lukatskaya MR, Mashtalir O, Ren CE, et al. Cation intercalation and high volumetric capacitance of two-dimensional titanium carbide. Science 2013;341:1502-5. DOI PubMed

26. Ali T, Wang X, Tang K, et al. $\mathrm{SnS}_{2}$ quantum dots growth on $\mathrm{MoS}_{2}$ : atomic-level heterostructure for electrocatalytic hydrogen evolution. Electrochim Acta 2019;300:45-52. DOI

27. Pomerantseva E, Bonaccorso F, Feng X, Cui Y, Gogotsi Y. Energy storage: the future enabled by nanomaterials. Science 2019;366:eaan8285. DOI PubMed

28. Er D, Li J, Naguib M, Gogotsi Y, Shenoy VB. $\mathrm{Ti}_{3} \mathrm{C}_{2}$ MXene as a high capacity electrode material for metal ( $\left.\mathrm{Li}, \mathrm{Na}, \mathrm{K}, \mathrm{Ca}\right)$ ion batteries. ACS Appl Mater Interfaces 2014;6:11173-9. DOI

29. Mills G, Jónsson H, Schenter GK. Reversible work transition state theory: application to dissociative adsorption of hydrogen. Surf Sci 1995;324:305-37. DOI

30. Tang Q, Zhou Z, Shen P. Are MXenes promising anode materials for Li ion batteries? J Am Chem Soc 2012;134:16909-16. DOI PubMed

31. Manthiram A, Fu Y, Chung SH, Zu C, Su YS. Rechargeable lithium-sulfur batteries. Chem Rev 2014;114:11751-87. DOI PubMed

32. Bruce PG, Freunberger SA, Hardwick LJ, Tarascon JM. Li-O2 and Li-S batteries with high energy storage. Nat Mater 2011;11:19-29. DOI PubMed

33. Ye H, Li M, Liu T, Li Y, Lu J. Activating $\mathrm{Li}_{2} \mathrm{~S}$ as the lithium-containing cathode in lithium-sulfur Batteries. ACS Energy Lett 2020;5:2234-45. DOI

34. Liang X, Hart C, Pang Q, Garsuch A, Weiss T, Nazar LF. A highly efficient polysulfide mediator for lithium-sulfur batteries. Nat Commun 2015;6:5682. DOI PubMed

35. He X, Ren J, Wang L, Pu W, Jiang C, Wan C. Expansion and shrinkage of the sulfur composite electrode in rechargeable lithium batteries. J Power Sources 2009;190:154-6. DOI

36. Rauh R, Shuker F, Marston J, Brummer S. Formation of lithium polysulfides in aprotic media. Journal of Inorganic and Nuclear Chemistry 1977;39:1761-6. DOI

37. Yamin H, Gorenshtein A, Penciner J, Sternberg Y, Peled E. Lithium sulfur battery: oxidation/reduction mechanisms of polysulfides 
in THF dolutions. J Electrochem Soc 1988;135:1045-8. DOI

38. Xiong S, Xie K, Diao Y, Hong X. Characterization of the solid electrolyte interphase on lithium anode for preventing the shuttle mechanism in lithium-sulfur batteries. J Power Sources 2014;246:840-5. DOI

39. Cañas NA, Fronczek DN, Wagner N, Latz A, Friedrich KA. Experimental and theoretical analysis of products and reaction intermediates of lithium-sulfur batteries. J Phys Chem C 2014;118:12106-14. DOI

40. Ali T, Yan C. 2 D Materials for inhibiting the shuttle effect in advanced lithium-sulfur batteries. ChemSusChem 2020;13:1447-79. DOI PubMed

41. Luo C, Zhu H, Luo W, et al. Atomic-layer-deposition functionalized carbonized mesoporous wood fiber for high sulfur loading lithium sulfur batteries. ACS Appl Mater Interfaces 2017;9:14801-7. DOI PubMed

42. Abraham KM, Jiang Z. A polymer electrolyte-based rechargeable lithium/oxygen battery. J Electrochem Soc 1996;143:1-5. DOI

43. Ogasawara T, Débart A, Holzapfel M, Novák P, Bruce PG. Rechargeable $\mathrm{LI}_{2} \mathrm{O}_{2}$ electrode for lithium batteries. J Am Chem Soc 2006;128:1390-3. DOI PubMed

44. Peng Z, Freunberger SA, Chen Y, Bruce PG. A reversible and higher-rate Li-O 2 battery. Science 2012;337:563-6. DOI PubMed

45. Shao Y, Park S, Xiao J, Zhang J, Wang Y, Liu J. Electrocatalysts for nonaqueous lithium-air batteries: status, challenges, and perspective. ACS Catal 2012;2:844-57. DOI

46. Zhao G, Xu Z, Sun K. Hierarchical porous $\mathrm{Co}_{3} \mathrm{O}_{4}$ films as cathode catalysts of rechargeable Li- $\mathrm{O}_{2}$ batteries. $J$ Mater Chem A 2013;1:12862. DOI

47. Mourad E, Coustan L, Lannelongue P, et al. Biredox ionic liquids with solid-like redox density in the liquid state for high-energy supercapacitors. Nat Mater 2017;16:446-53. DOI PubMed

48. Mahne N, Fontaine O, Thotiyl MO, Wilkening M, Freunberger SA. Mechanism and performance of lithium-oxygen batteries - a perspective. Chem Sci 2017;8:6716-29. DOI PubMed PMC

49. Zhang T, Yang J, Zhu J, et al. A lithium-ion oxygen battery with a Si anode lithiated in situ by a $\mathrm{Li}_{3} \mathrm{~N}$-containing cathode. Chem Commun (Camb) 2018;54:1069-72. DOI PubMed

50. Freunberger SA, Chen Y, Drewett NE, Hardwick LJ, Bardé F, Bruce PG. The lithium-oxygen battery with ether-based electrolytes. Angew Chem Int Ed Engl 2011;50:8609-13. DOI PubMed

51. Mirzaeian M, Hall PJ. Characterizing capacity loss of lithium oxygen batteries by impedance spectroscopy. J Power Sources 2010;195:6817-24. DOI

52. Burke CM, Pande V, Khetan A, Viswanathan V, McCloskey BD. Enhancing electrochemical intermediate solvation through electrolyte anion selection to increase nonaqueous Li-O2 battery capacity. Proc Natl Acad Sci U S A 2015;112:9293-8. DOI PubMed PMC

53. Lee $\mathrm{S}$, Kwon $\mathrm{G}, \mathrm{Ku} \mathrm{K}$, et al. Recent progress in organic electrodes for Li and Na rechargeable batteries. Adv Mater 2018;30:e1704682. DOI PubMed

54. Liang Y, Tao Z, Chen J. Organic electrode materials for rechargeable lithium batteries. Adv Energy Mater 2012;2:742-69. DOI

55. Luo C, Ji X, Hou S, et al. Azo compounds derived from electrochemical reduction of nitro compounds for high performance Li-ion batteries. Adv Mater 2018;30:e1706498. DOI PubMed

56. Alt H, Binder H, Köhling A, Sandstede G. Investigation into the use of quinone compounds-for battery cathodes. Electrochim Acta 1972;17:873-87. DOI

57. Kim T, Song W, Son D, Ono LK, Qi Y. Lithium-ion batteries: outlook on present, future, and hybridized technologies. J Mater Chem A 2019;7:2942-64. DOI

58. Luo C, Huang R, Kevorkyants R, Pavanello M, He H, Wang C. Self-assembled organic nanowires for high power density lithium ion batteries. Nano Lett 2014;14:1596-602. DOI PubMed

59. Cariello M, Johnston B, Bhosale M, et al. Benzo-dipteridine derivatives as organic cathodes for Li- and Na-ion batteries. ACS Appl Energy Mater 2020;3:8302-8. DOI PubMed PMC

60. Lakraychi AE, Deunf E, Fahsi K, et al. An air-stable lithiated cathode material based on a 1,4-benzenedisulfonate backbone for organic Li-ion batteries. J Mater Chem A 2018;6:19182-9. DOI

61. Shea JJ, Luo C. Organic electrode materials for metal ion batteries. ACS Appl Mater Interfaces 2020;12:5361-80. DOI PubMed

62. Luo C, Borodin O, Ji X, et al. Azo compounds as a family of organic electrode materials for alkali-ion batteries. Proc Natl Acad Sci US A 2018;115:2004-9. DOI PubMed PMC

63. Peng C, Ning G, Su J, et al. Reversible multi-electron redox chemistry of $\pi$-conjugated N-containing heteroaromatic molecule-based organic cathodes. Nat Energy 2017;2:17074. DOI

64. Lei Z, Chen X, Sun W, Zhang Y, Wang Y. Exfoliated triazine-based covalent organic nanosheets with multielectron redox for highperformance lithium organic batteries. Adv Energy Mater 2019;9:1801010. DOI

65. Thangadurai $\mathrm{V}$, Kaack $\mathrm{H}$, Weppner WJF. Novel fast lithium ion conduction in garnet-type $\mathrm{Li}_{5} \mathrm{La}_{3} \mathrm{M}_{2} \mathrm{O}_{12}(\mathrm{M}=\mathrm{Nb}, \mathrm{Ta}) . J$ Am Ceram Soc 2003; $86: 437-40$. DOI

66. Manthiram A, Yu X, Wang S. Lithium battery chemistries enabled by solid-state electrolytes. Nat Rev Mater 2017;2:16103. DOI

67. Zhang M, Takahashi K, Imanishi N, et al. Preparation and electrochemical properties of $\mathrm{Li}_{1+\mathrm{x}} \mathrm{Al}_{\mathrm{x}} \mathrm{Ge}_{2-\mathrm{x}}\left(\mathrm{PO}_{4}\right)_{3}$ synthesized by a sol-gel method. J Electrochem Soc 2012;159:A1114-9. DOI

68. Inaguma Y, Liquan C, Itoh M, et al. High ionic conductivity in lithium lanthanum titanate. Solid State Commun 1993;86:689-93. DOI

69. Chen R, Qu W, Guo X, Li L, Wu F. The pursuit of solid-state electrolytes for lithium batteries: from comprehensive insight to emerging horizons. Mater Horiz 2016;3:487-516. DOI 
70. Sun C, Liu J, Gong Y, Wilkinson DP, Zhang J. Recent advances in all-solid-state rechargeable lithium batteries. Nano Energy 2017;33:363-86. DOI

71. Appetecchi G, Croce F, Scrosati B. Kinetics and stability of the lithium electrode in poly(methylmethacrylate)-based gel electrolytes. Electrochim Acta 1995;40:991-7. DOI

72. Macglashan GS, Andreev YG, Bruce PG. Structure of the polymer electrolyte poly(ethylene oxide)6:LiAsF6. Nature 1999;398:7924. DOI

73. Abraham KM, Alamgir M. $\mathrm{Li}^{+}$-conductive solid polymer electrolytes with liquid-like conductivity. J Electrochem Soc 1990;137:1657-8. DOI

74. Choe H, Giaccai J, Alamgir M, Abraham K. Preparation and characterization of poly(vinyl sulfone)- and poly(vinylidene fluoride)based electrolytes. Electrochim Acta 1995;40:2289-93. DOI

75. Kanehori K, Matsumoto K, Miyauchi K, Kudo T. Thin film solid electrolyte and its application to secondary lithium cell. Solid State Ionics 1983;9-10:1445-8. DOI

76. Chhowalla M, Teo KBK, Ducati C, et al. Growth process conditions of vertically aligned carbon nanotubes using plasma enhanced chemical vapor deposition. J Appl Phys 2001;90:5308-17. DOI

77. Bates J, Dudney N, Gruzalski G, et al. Fabrication and characterization of amorphous lithium electrolyte thin films and rechargeable thin-film batteries. J Power Sources 1993;43:103-10. DOI

78. Tabata $\mathrm{H}$, Tanaka H, Kawai T. Formation of artificial $\mathrm{BaTiO}_{3} / \mathrm{SrTiO}_{3}$ superlattices using pulsed laser deposition and their dielectric properties. Appl Phys Lett 1994;65:1970-2. DOI

79. Han X, Gong Y, Fu KK, et al. Negating interfacial impedance in garnet-based solid-state Li metal batteries. Nat Mater 2017;16:5729. DOI PubMed

80. Bates J. Electrical properties of amorphous lithium electrolyte thin films. Solid State Ionics 1992;53-56:647-54. DOI

81. Yu X, Bates JB, Jellison GE, Hart FX. A stable thin-film lithium electrolyte: lithium phosphorus oxynitride. $J$ Electrochem Soc 1997; 144:524-32. DOI

82. Larson RW, Day DE. Preparation and characterization of lithium phosphorus oxynitride glass. J Non Cryst Solids 1986;88:97-113. DOI

83. Li J, Ma C, Chi M, Liang C, Dudney NJ. Solid electrolyte: the key for high-voltage lithium batteries. Adv Energy Mater 2015;5:1401408. DOI

84. Haruyama J, Sodeyama K, Han L, Takada K, Tateyama Y. Space-charge layer effect at interface between oxide cathode and sulfide electrolyte in all-solid-state lithium-ion battery. Chem Mater 2014;26:4248-55. DOI

85. Ohta N, Takada K, Zhang L, Ma R, Osada M, Sasaki T. Enhancement of the high-rate capability of solid-state lithium batteries by nanoscale interfacial modification. Adv Mater 2006;18:2226-9. DOI

86. Yamaguchi Y, Takeuchi T, Sakaebe H, et al. Ab initio simulations of Li/pyrite- $\mathrm{MS}_{2}(\mathrm{M}=\mathrm{Fe}, \mathrm{Ni})$ battery cells. $J$ Electrochem Soc 2010;157:A630. DOI

87. Zhou W, Wang S, Li Y, Xin S, Manthiram A, Goodenough JB. Plating a dendrite-free lithium anode with a polymer/ceramic/polymer sandwich electrolyte. J Am Chem Soc 2016;138:9385-8. DOI PubMed

88. Wang L, Zhang X, Wang T, et al. Ameliorating the interfacial problems of cathode and solid-state electrolytes by interface modification of functional polymers. Adv Energy Mater 2018;8:1801528. DOI

89. Mehrer H. Diffusion in solids: fundamentals, methods, materials, diffusion-controlled processes. Springer Science \& Business Media; 2007. p. 209-36.

90. Takechi K, Shiga T, Asaoka T. A Li- $\mathrm{O}_{2} / \mathrm{CO}_{2}$ battery. Chem Commun (Camb) 2011;47:3463-5. DOI PubMed

91. Lim HK, Lim HD, Park KY, et al. Toward a lithium-“air" battery: the effect of $\mathrm{CO}_{2}$ on the chemistry of a lithium-oxygen cell. $J \mathrm{Am}$ Chem Soc 2013;135:9733-42. DOI PubMed

92. Xu S, Das SK, Archer LA. The Li-CO $\mathrm{CO}_{2}$ battery: a novel method for $\mathrm{CO}_{2}$ capture and utilization. RSC Adv 2013;3:6656. DOI

93. Liu Y, Wang R, Lyu Y, Li H, Chen L. Rechargeable Li/ $\mathrm{CO}_{2}-\mathrm{O}_{2}(2: 1)$ battery and Li/ $/ \mathrm{CO}_{2}$ battery. Energy Environ Sci $2014 ; 7: 677$. DOI

94. Hou Y, Wang J, Liu L, et al. $\mathrm{Mo}_{2} \mathrm{C} / \mathrm{CNT}$ : an efficient catalyst for rechargeable $\mathrm{Li}_{-} \mathrm{CO}_{2}$ batteries. Adv Funct Mater 2017;27:1700564. DOI

95. Németh K, Srajer G. $\mathrm{CO}_{2}$ /oxalate cathodes as safe and efficient alternatives in high energy density metal-air type rechargeable batteries. RSC Adv 2014;4:1879-85. DOI

96. Németh K, Srajer G. $\mathrm{CO}_{2}$ /oxalate cathodes as safe and efficient alternatives in high energy density metal-air type rechargeable batteries. RSC Adv 2014;4:1879-85. DOI

97. Ehteshami SMM, Chan S. The role of hydrogen and fuel cells to store renewable energy in the future energy network - potentials and challenges. Energy Policy 2014;73:103-9. DOI

98. Armand M, Tarascon JM. Building better batteries. Nature 2008;451:652-7. DOI PubMed

99. Dahn JR, Zheng T, Liu Y, Xue JS. Mechanisms for lithium insertion in carbonaceous materials. Science 1995;270:590-3. DOI

100. Claye AS, Fischer JE, Huffman CB, Rinzler AG, Smalley RE. Solid-state electrochemistry of the Li single wall carbon nanotube system. J Electrochem Soc 2000;147:2845. DOI

101. Xu M, Liang T, Shi M, Chen H. Graphene-like two-dimensional materials. Chem Rev 2013;113:3766-98. DOI PubMed

102. Liu M, Kutana A, Liu Y, Yakobson BI. First-principles studies of Li nucleation on graphene. J Phys Chem Lett 2014;5:1225-9. DOI PubMed

103. Seo MH, Choi SM, Lim EJ, et al. Toward new fuel cell support materials: a theoretical and experimental study of nitrogen-doped 
graphene. ChemSusChem 2014;7:2609-20. DOI PubMed

104. Kim D, Liu X, Yu B, et al. Amine-functionalized boron nitride nanosheets: a new functional additive for robust, flexible ion gel electrolyte with high lithium-ion transference number. Adv Funct Mater 2020;30:1910813. DOI

105. Xiong J, Zhu W, Li H, et al. Few-layered graphene-like boron nitride induced a remarkable adsorption capacity for dibenzothiophene in fuels. Green Chem 2015;17:1647-56. DOI

106. Wang X, Zeng Z, Ahn H, Wang G. First-principles study on the enhancement of lithium storage capacity in boron doped graphene. Appl Phys Lett 2009;95:183103. DOI

107. Chou S, Wang J, Choucair M, Liu H, Stride JA, Dou S. Enhanced reversible lithium storage in a nanosize silicon/graphene composite. Electrochem commun 2010;12:303-6. DOI

108. Zhao N, Yang L, Zhang $\mathrm{P}$, et al. Polycrystalline $\mathrm{SnO}_{2}$ nanowires coated with amorphous carbon nanotube as anode material for lithium ion batteries. Mater Lett 2010;64:972-5. DOI

109. Winter M, Besenhard JO. Electrochemical lithiation of tin and tin-based intermetallics and composites. Electrochim Acta 1999;45:3150. DOI

110. Julien C, Mauger A, Zaghib K, Groult H. Comparative issues of cathode materials for Li-ion batteries. Inorganics 2014;2:132-54. DOI

111. Ge M, Cao C, Biesold GM, et al. Recent advances in silicon-based electrodes: from fundamental research toward practical applications. Adv Mater 2021;33:e2004577. DOI PubMed

112. Yang C, Zhang Y, Zhou J, et al. Hollow $\mathrm{Si} / \mathrm{SiO}_{\mathrm{x}}$ nanosphere/nitrogen-doped carbon superstructure with a double shell and void for high-rate and long-life lithium-ion storage. J Mater Chem A 2018;6:8039-46. DOI

113. Zhou Y, Guo H, Wang Z, Li X, Zhou R, Peng W. Improved electrochemical performance of Si/C material based on the interface stability. J Alloys Compd 2017;725:1304-12. DOI

114. Wang Z, Zhou L, Lou XW. Metal oxide hollow nanostructures for lithium-ion batteries. Adv Mater 2012;24:1903-11. DOI PubMed

115. Adams BD, Radtke C, Black R, Trudeau ML, Zaghib K, Nazar LF. Current density dependence of peroxide formation in the Li- $\mathrm{O}_{2}$ battery and its effect on charge. Energy Environ Sci 2013;6:1772. DOI

116. Seh ZW, Yu JH, Li W, et al. Two-dimensional layered transition metal disulphides for effective encapsulation of high-capacity lithium sulphide cathodes. Nat Commun 2014;5:5017. DOI PubMed

117. Feng X, Ouyang M, Liu X, Lu L, Xia Y, He X. Thermal runaway mechanism of lithium ion battery for electric vehicles: a review. Energy Stor Mater 2018;10:246-67. DOI

118. May GJ, Davidson A, Monahov B. Lead batteries for utility energy storage: a review. J Energy Storage 2018;15:145-57. DOI

119. Neuville S. Differentiated carbon material for energy storage and conversion. Mater Today Proc 2018;5:13837-45. DOI

120. Ullah S, Denis PA, Sato F. Beryllium doped graphene as an efficient anode material for lithium-ion batteries with significantly huge capacity: a DFT study. Appl Mater Today 2017;9:333-40. DOI

121. Pei F, Fu A, Ye W, et al. Robust lithium metal anodes realized by lithiophilic 3D porous current collectors for constructing highenergy lithium-sulfur batteries. ACS Nano 2019;13:8337-46. DOI PubMed

122. Zhou L, Hou ZF, Gao B, Frauenheim T. Doped graphenes as anodes with large capacity for lithium-ion batteries. J Mater Chem A 2016;4:13407-13. DOI

123. Wu H, Chang S, Liu X, et al. Sr-doped $\mathrm{Li}_{4} \mathrm{Ti}_{5} \mathrm{O}_{12}$ as the anode material for lithium-ion batteries. Solid State Ionics 2013;232:13-8. DOI

124. Walz KA, Suyama AN, Suyama WE, et al. Characterization and performance of high power iron(VI) ferrate batteries. J Power Sources 2004;134:318-23. DOI

125. Kao W, Haberichter SL, Patel P. Barium metaplumbate for lead/acid batteries. J Electrochem Soc 1994;141:3300-5. DOI

126. Hertzberg B, Sviridov L, Stach EA, Gupta T, Steingart D. A manganese-doped barium carbonate cathode for alkaline batteries. $J$ Electrochem Soc 2014;161:A835-40. DOI

127. Tanaka U, Sogabe T, Sakagoshi H, Ito M, Tojo T. Anode property of boron-doped graphite materials for rechargeable lithium-ion batteries. Carbon 2001;39:931-6. DOI

128. Wang Y, Ai X, Cao Y, Yang H. Exceptional electrochemical activities of amorphous Fe-B and Co-B alloy powders used as high capacity anode materials. Electrochem commun 2004;6:780-4. DOI

129. Walter M, Kovalenko MV, Kravchyk KV. Challenges and benefits of post-lithium-ion batteries. New J Chem 2020;44:1677-83. DOI

130. Shehzad K, Xu Y, Gao C, Duan X. Three-dimensional macro-structures of two-dimensional nanomaterials. Chem Soc Rev 2016;45:5541-88. DOI PubMed

131. Qie L, Chen WM, Wang ZH, et al. Nitrogen-doped porous carbon nanofiber webs as anodes for lithium ion batteries with a superhigh capacity and rate capability. Adv Mater 2012;24:2047-50. DOI PubMed

132. Dreyer DR, Park S, Bielawski CW, Ruoff RS. The chemistry of graphene oxide. Chem Soc Rev 2010;39:228-40. DOI PubMed

133. Dong Y, Wu Z, Ren W, Cheng H, Bao X. Graphene: a promising 2D material for electrochemical energy storage. Sci Bull 2017;62:724-40. DOI

134. Béguin F, Chevallier F, Vix-guterl C, et al. Correlation of the irreversible lithium capacity with the active surface area of modified carbons. Carbon 2005;43:2160-7. DOI

135. Chen JS, Wang Z, Dong XC, Chen P, Lou XW. Graphene-wrapped $\mathrm{TiO}_{2}$ hollow structures with enhanced lithium storage capabilities. Nanoscale 2011;3:2158-61. DOI PubMed

136. Pumera M. Graphene-based nanomaterials for energy storage. Energy Environ Sci 2011;4:668-74. DOI

137. Uthaisar C, Barone V, Peralta JE. Lithium adsorption on zigzag graphene nanoribbons. J Appl Phys 2009;106:113715. DOI 
138. Liu Y, Wang X, Dong Y, Wang Z, Zhao Z, Qiu J. Nitrogen-doped graphene nanoribbons for high-performance lithium ion batteries. J Mater Chem A 2014;2:16832-5. DOI

139. Chan CK, Peng H, Liu G, et al. High-performance lithium battery anodes using silicon nanowires. Nat Nanotechnol 2008;3:31-5. DOI PubMed

140. Boukamp BA, Lesh GC, Huggins RA. All-solid lithium electrodes with mixed-conductor matrix. J Electrochem Soc 1981;128:725-9. DOI

141. Thakur M, Isaacson M, Sinsabaugh SL, Wong MS, Biswal SL. Gold-coated porous silicon films as anodes for lithium ion batteries. $J$ Power Sources 2012;205:426-32. DOI

142. Obrovac MN, Christensen L, Le DB, Dahn JR. Alloy design for lithium-ion battery anodes. J Electrochem Soc 2007;154:A849. DOI

143. Lee S, Nam K, Jung H, Park C. Si-based composite interconnected by multiple matrices for high-performance Li-ion battery anodes. Chem Eng J 2020;381:122619. DOI

144. Xu H, Shi L, Wang Z, et al. Fluorine-doped tin oxide nanocrystal/reduced graphene oxide composites as lithium ion battery anode material with high capacity and cycling stability. ACS Appl Mater Interfaces 2015;7:27486-93. DOI PubMed

145. Share K, Cohn AP, Carter R, Rogers B, Pint CL. Role of nitrogen-doped graphene for improved high-capacity potassium ion battery anodes. ACS Nano 2016;10:9738-44. DOI PubMed

146. Ma Y, Yin G, Zuo P, Tan X, Gao Y, Shi P. A phosphorous additive for lithium-ion batteries. Electrochem Solid-State Lett 2008;11:A129. DOI

147. Chung K, Kim W, Choi Y. Lithium phosphorous oxynitride as a passive layer for anodes in lithium secondary batteries. $J$. Electroanal Chem 2004;566:263-7. DOI

148. Zhao C, Chen H, Liu H, et al. Quantifying the reaction mechanisms of a high-capacity $\mathrm{CuP}_{2} / \mathrm{C}$ composite anode for potassium ion batteries. J Mater Chem A 2021;9:6274-83. DOI

149. Li W, Chou SL, Wang JZ, Kim JH, Liu HK, Dou SX. $\mathrm{Sn}_{4+\mathrm{x}} \mathrm{P}_{3} @$ amorphous Sn-P composites as anodes for sodium-ion batteries with low cost, high capacity, long life, and superior rate capability. Adv Mater 2014;26:4037-42. DOI PubMed

150. Lim YR, Shojaei F, Park K, et al. Arsenic for high-capacity lithium- and sodium-ion batteries. Nanoscale 2018;10:7047-57. DOI PubMed

151. Darwiche A, Marino C, Sougrati MT, Fraisse B, Stievano L, Monconduit L. Better cycling performances of bulk Sb in Na-ion batteries compared to Li-ion systems: an unexpected electrochemical mechanism. J Am Chem Soc 2012;134:20805-11. DOI PubMed

152. Baggetto L, Allcorn E, Unocic RR, Manthiram A, Veith GM. $\mathrm{Mo}_{3} \mathrm{Sb}_{7}$ as a very fast anode material for lithium-ion and sodium-ion batteries. J Mater Chem A 2013;1:11163. DOI

153. Xiao L, Cao Y, Xiao J, et al. High capacity, reversible alloying reactions in $\mathrm{SnSb} / \mathrm{C}$ nanocomposites for Na-ion battery applications. Chem Commun (Camb) 2012;48:3321-3. DOI PubMed

154. Yu DY, Prikhodchenko PV, Mason CW, et al. High-capacity antimony sulphide nanoparticle-decorated graphene composite as anode for sodium-ion batteries. Nat Commun 2013;4:2922. DOI PubMed

155. Zhang K, Wang Y, Liu P, Li W. Chemical fabrication and electrochemical performance of $\mathrm{Bi}_{2} \mathrm{~S}_{3}$-nanorods charged reduced graphene oxide. Mater Lett 2015;161:774-7. DOI

156. Yang W, Wang H, Liu T, Gao L. A Bi $\mathrm{S}_{3} @$ CNT nanocomposite as anode material for sodium ion batteries. Mater Lett 2016;167:102-5. DOI

157. Li Y, Trujillo MA, Fu E, et al. Bismuth oxide: a new lithium-ion battery anode. J Mater Chem A Mater 2013:1. DOI PubMed PMC

158. Lu Y, Gasteiger HA, Parent MC, Chiloyan V, Shao-horn Y. The influence of catalysts on discharge and charge voltages of rechargeable Li-oxygen batteries. Electrochem Solid-State Lett 2010;13:A69. DOI

159. Chen JJ, Jia x, She QJ, et al. The preparation of nano-sulfur/MWCNTs and its electrochemical performance. Electrochim Acta 2010;55:8062-6. DOI

160. Ji X, Lee KT, Nazar LF. A highly ordered nanostructured carbon-sulphur cathode for lithium-sulphur batteries. Nat Mater 2009;8:500-6. DOI PubMed

161. Xiao J, Wang X, Yang X, et al. Electrochemically induced high capacity displacement reaction of $\mathrm{PEO} / \mathrm{MoS}_{2} / \mathrm{graphene}$ nanocomposites with lithium. Adv Funct Mater 2011;21:2840-6. DOI

162. Fang X, Guo X, Mao Y, et al. Mechanism of lithium storage in $\mathrm{MoS}_{2}$ and the feasibility of using $\mathrm{Li}_{2} \mathrm{~S} / \mathrm{Mo}$ nanocomposites as cathode materials for lithium-sulfur batteries. Chem Asian J 2012;7:1013-7. DOI PubMed

163. Lu ZW, Wang YH, Dai Z, et al. One-pot sulfur-containing ion assisted microwave synthesis of reduced graphene oxide@nano-sulfur fibrous hybrids for high-performance lithium-sulfur batteries. Electrochim Acta 2019;325:134920. DOI

164. Cui Y, Abouimrane A, Sun CJ, Ren Y, Amine K. Li-Se battery: absence of lithium polyselenides in carbonate based electrolyte. Chem Commun (Camb) 2014;50:5576-9. DOI PubMed

165. Yang CP, Xin S, Yin YX, Ye H, Zhang J, Guo YG. An advanced selenium-carbon cathode for rechargeable lithium-selenium batteries. Angew Chem Int Ed Engl 2013;52:8363-7. DOI PubMed

166. Zeng L, Zeng W, Jiang Y, et al. A flexible porous carbon nanofibers-selenium cathode with superior electrochemical performance for both Li-Se and Na-Se batteries. Adv Energy Mater 2015;5:1401377. DOI

167. Eftekhari A. The rise of lithium-selenium batteries. Sustain Energy Fuels 2017;1:14-29. DOI

168. Liu Y, Wang J, Xu Y, Zhu Y, Bigio D, Wang C. Lithium-tellurium batteries based on tellurium/porous carbon composite. J Mater Chem A 2014;2:12201-7. DOI

169. He J, Chen Y, Lv W, et al. Three-dimensional hierarchical reduced graphene oxide/tellurium nanowires: a high-performance 
freestanding cathode for Li-Te batteries. ACS Nano 2016;10:8837-42. DOI PubMed

170. Nakajima T. Fluorine compounds as energy conversion materials. J Fluor Chem 2013;149:104-11. DOI

171. Cui D, Zheng Z, Peng X, Li T, Sun T, Yuan L. Fluorine-doped $\mathrm{SnO}_{2}$ nanoparticles anchored on reduced graphene oxide as a highperformance lithium ion battery anode. J Power Sources 2017;362:20-6. DOI

172. Zhang S, Zhang L, Wang W, Xue W. A Novel cathode material based on polyaniline used for lithium/sulfur secondary battery. Synth Met 2010;160:2041-4. DOI

173. Niessen RH, Notten PL. Hydrogen storage in thin film magnesium-scandium alloys. J Alloys Compd 2005;404-406:457-60. DOI

174. Amatucci G, Safari A, Shokoohi F, Wilkens B. Lithium scandium phosphate-based electrolytes for solid state lithium rechargeable microbatteries. Solid State Ionics 1993;60:357-65. DOI

175. Zheng P, Liu T, Su Y, Zhang L, Guo S. $\mathrm{TiO}_{2}$ nanotubes wrapped with reduced graphene oxide as a high-performance anode material for lithium-ion batteries. Sci Rep 2016;6:36580. DOI PubMed PMC

176. Tao B, He J, Miao F. A hybrid sandwich structure of $\mathrm{TiO}_{2} / \mathrm{N}$-graphene/Ag supported by ordered silicon nanowires and its application as lithium-ion battery electrodes. Mater Lett 2020;262:127046. DOI

177. Ihsan M, Meng Q, Li L, et al. $\mathrm{V}_{2} \mathrm{O}_{5} /$ mesoporous carbon composite as a cathode material for lithium-ion batteries. Electrochim Acta 2015;173:172-7. DOI

178. Poullikkas A. A comparative overview of large-scale battery systems for electricity storage. Renew Sustain Energy Rev 2013;27:77888. DOI

179. Wang C, Chen S, Xie H, Wei S, Wu C, Song L. Atomic $\mathrm{Sn}^{4+}$ decorated into vanadium carbide MXene interlayers for superior lithium storage. Adv Energy Mater 2019;9:1802977. DOI

180. Yang F, Zhu Y, Xia Y, et al. Fast $\mathrm{Zn}^{2+}$ kinetics of vanadium oxide nanotubes in high-performance rechargeable zinc-ion batteries. $J$ Power Sources 2020;451:227767. DOI

181. Zeng Y, Zhao T, An L, Zhou X, Wei L. A comparative study of all-vanadium and iron-chromium redox flow batteries for large-scale energy storage. J Power Sources 2015;300:438-43. DOI

182. Cao Y, Xiao L, Wang W, et al. Reversible sodium ion insertion in single crystalline manganese oxide nanowires with long cycle life. Adv Mater 2011;23:3155-60. DOI PubMed

183. Yensen N, Allen PB. Open source all-iron battery for renewable energy storage. HardwareX 2019;6:e00072. DOI

184. Wang Z, Liu C. Preparation and application of iron oxide/graphene based composites for electrochemical energy storage and energy conversion devices: Current status and perspective. Nano Energy 2015;11:277-93. DOI

185. Lv L, Peng M, Wu L, et al. Progress in iron oxides based nanostructures for applications in energy storage. Nanoscale Res Lett 2021;16:138. DOI PubMed PMC

186. Zhang L, Wu HB, Lou XWD. Iron-oxide-based advanced anode materials for lithium-ion batteries. Adv Energy Mater 2014;4:1300958. DOI

187. Jiang T, Bu F, Feng X, Shakir I, Hao G, Xu Y. Porous $\mathrm{Fe}_{2} \mathrm{O}_{3}$ nanoframeworks encapsulated within three-dimensional graphene as high-performance flexible anode for lithium-ion battery. ACS Nano 2017;11:5140-7. DOI PubMed

188. Zheng M, Qiu D, Zhao B, et al. Mesoporous iron oxide directly anchored on a graphene matrix for lithium-ion battery anodes with enhanced strain accommodation. RSC Adv 2013;3:699-703. DOI

189. Ma R, He L, Lu Z, Yang S, Xi L, Chung JCY. Large-scale fabrication of hierarchical $\alpha-\mathrm{Fe}_{2} \mathrm{O}_{3}$ assemblies as high performance anode materials for lithium-ion batteries. CrystEngComm 2012;14:7882. DOI

190. Zhu S, Fan L, Lu Y. Highly uniform $\mathrm{Fe}_{3} \mathrm{O}_{4}$ nanoparticle-rGO composites as anode materials for high performance lithium-ion batteries. RSC Adv 2017;7:54939-46. DOI

191. Atar N, Eren T, Yola ML, Gerengi H, Wang S. Fe@Ag nanoparticles decorated reduced graphene oxide as ultrahigh capacity anode material for lithium-ion battery. Ionics 2015;21:3185-92. DOI

192. Qi S, Wu D, Dong Y, et al. Cobalt-based electrode materials for sodium-ion batteries. Chem Eng J 2019;370:185-207. DOI

193. Schipper F, Erickson EM, Erk C, Shin J, Chesneau FF, Aurbach D. Review - recent advances and remaining challenges for lithium ion battery cathodes: I. nickel-rich, $\mathrm{LiNi}_{\mathrm{x}} \mathrm{Co}_{\mathrm{y}} \mathrm{Mn}_{\mathrm{z}} \mathrm{O}_{2}$. J Electrochem Soc 2017;164:A6220-8. DOI

194. Chang H, Bai Y, Song X, et al. Hydrothermal synthesis, structural elucidation and electrochemical properties of three nickel and cobalt based phosphonates as anode materials for lithium ion batteries. Electrochim Acta 2019;321:134647. DOI

195. Asif M, Ali Z, Qiu H, Rashad M, Hou Y. Confined polysulfide shuttle by nickel disulfide nanoparticles encapsulated in graphene nanoshells synthesized by cooking oil. ACS Appl Energy Mater 2020;3:3541-52. DOI

196. Sethuraman VA, Kowolik K, Srinivasan V. Increased cycling efficiency and rate capability of copper-coated silicon anodes in lithium-ion batteries. J Power Sources 2011;196:393-8. DOI

197. Kumar R, Nithya C, Gopukumar S, Anbu Kulandainathan M. Diamondoid-structured Cu-dicarboxylate-based metal-organic frameworks as high-capacity anodes for lithium-ion storage. Energy Technol 2014;2:921-7. DOI

198. Fan M, Chen Y, Xie Y, et al. Half-cell and full-cell applications of highly stable and binder-free sodium ion batteries based on $\mathrm{Cu}_{3} \mathrm{P}$ nanowire anodes. Adv Funct Mater 2016;26:5019-27. DOI

199. Li N, An R, Su Y, et al. The role of yttrium content in improving electrochemical performance of layered lithium-rich cathode materials for Li-ion batteries. J Mater Chem A 2013;1:9760. DOI

200. Aziz MA, Shanmugam S. Zirconium oxide nanotube-Nafion composite as high performance membrane for all vanadium redox flow battery. J Power Sources 2017;337:36-44. DOI

201. Li B, Wang Q, Zhang Y, Song Z, Yang D. Nickel-modified and zirconium-modified $\mathrm{Li}_{2} \mathrm{MnO}_{3}$ and applications in lithium-ion battery. Int J Electrochem Sci 2013;8:5396-406. DOI 
202. Lubimtsev AA, Kent PRC, Sumpter BG, Ganesh P. Understanding the origin of high-rate intercalation pseudocapacitance in $\mathrm{Nb}_{2} \mathrm{O}_{5}$ crystals. J Mater Chem A 2013;1:14951. DOI

203. Zhang C, Beidaghi M, Naguib M, et al. Synthesis and charge storage properties of hierarchical niobium pentoxide/carbon/niobium carbide (MXene) hybrid materials. Chem Mater 2016;28:3937-43. DOI

204. Tolosa A, Krüner B, Fleischmann S, et al. Niobium carbide nanofibers as a versatile precursor for high power supercapacitor and high energy battery electrodes. J Mater Chem A 2016;4:16003-16. DOI

205. Chang K, Chen W. L-cysteine-assisted synthesis of layered $\mathrm{MoS}_{2}$ /graphene composites with excellent electrochemical performances for lithium ion batteries. ACS Nano 2011;5:4720-8. DOI

206. Wang H, Lan X, Jiang D, et al. Sodium storage and transport properties in pyrolysis synthesized MoSe ${ }_{2}$ nanoplates for high performance sodium-ion batteries. J Power Sources 2015;283:187-94. DOI

207. Morales J. Electrochemical studies of lithium and sodium intercalation in MoSe ${ }_{2}$. Solid State Ionics 1996;83:57-64. DOI

208. Luo Y, Zhang Y, Zhao Y, et al. Aligned carbon nanotube/molybdenum disulfide hybrids for effective fibrous supercapacitors and lithium ion batteries. J Mater Chem A 2015;3:17553-7. DOI

209. Xiao Y, Zhang W. Adsorption mechanisms of $\mathrm{Mo}_{2} \mathrm{CrC}_{2}$ MXenes as potential anode materials for metal-ion batteries: a first-principles investigation. Appl Surf Sci 2020;513:145883. DOI

210. He B, Dong B, Li H. Preparation and electrochemical properties of Ag-modified TiO2 nanotube anode material for lithium-ion battery. Electrochem commun 2007;9:425-30. DOI

211. Zou G, Zhang Z, Guo J, et al. Synthesis of MXene/Ag composites for extraordinary long cycle lifetime lithium storage at high rates. ACS Appl Mater Interfaces 2016;8:22280-6. DOI PubMed

212. Nam SH, Shim H, Kim Y, Dar MA, Kim JG, Kim WB. Ag or Au nanoparticle-embedded one-dimensional composite $\mathrm{TiO}_{2}$ nanofibers prepared via electrospinning for use in lithium-ion batteries. ACS Appl Mater Interfaces 2010;2:2046-52. DOI

213. Hwang H, Oh S, Kim H, Cho W, Cho B, Lee D. Characterization of Ag-doped vanadium oxide $\left(\mathrm{Ag}_{\mathrm{x}} \mathrm{V}_{2} \mathrm{O}_{5}\right)$ thin film for cathode of thin film battery. Electrochim Acta 2004;50:485-9. DOI

214. Liu Z, Zhang N, Wang Z, Sun K. Highly dispersed Ag nanoparticles ( $<10 \mathrm{~nm}$ ) deposited on nanocrystalline $\mathrm{Li}_{4} \mathrm{Ti}_{5} \mathrm{O}_{12}$ demonstrating high-rate charge/discharge capability for lithium-ion battery. J Power Sources 2012;205:479-82. DOI

215. Kumagai N, Kumagai N, Tanno K. Electrochemical and structural characteristics of tungstic acids as cathode materials for lithium batteries. Appl Phys A 1989;49:83-9. DOI

216. Sasidharan M, Gunawardhana N, Yoshio M, Nakashima $\mathrm{K}$. $\mathrm{WO}_{3}$ hollow nanospheres for high-lithium storage capacity and good cyclability. Nano Energy 2012;1:503-8. DOI

217. Gao J, Li L, Tan J, et al. Vertically oriented arrays of $\mathrm{ReS}_{2}$ nanosheets for electrochemical energy storage and electrocatalysis. Nano Lett 2016;16:3780-7. DOI PubMed

218. Zhu J, Xu Z, Lu B. Ultrafine Au nanoparticles decorated $\mathrm{NiCo}_{2} \mathrm{O}_{4}$ nanotubes as anode material for high-performance supercapacitor and lithium-ion battery applications. Nano Energy 2014;7:114-23. DOI

219. Lee M, Luo Y, Do J. Using PANI-PPDA/Au composite films as cathode of lithium secondary battery. J Power Sources 2005;146:340-4. DOI

220. Zhao J, Yu K, Hu Y, et al. Discharge behavior of Mg- $4 \mathrm{wt} \% \mathrm{Ga}-2 \mathrm{wt} \% \mathrm{Hg}$ alloy as anode for seawater activated battery. Electrochim Acta 2011;56:8224-31. DOI

221. Eftekhari A, Moghaddam AB, Solati-hashjin M. Electrochemical properties of $\mathrm{LiMn}_{2} \mathrm{O}_{4}$ cathode material doped with an actinide. $J$ Alloys Compd 2006;424:225-30. DOI

222. Rauda IE, Augustyn V, Dunn B, Tolbert SH. Enhancing pseudocapacitive charge storage in polymer templated mesoporous materials. Acc Chem Res 2013;46:1113-24. DOI PubMed

223. Pramudita JC, Aughterson R, Dose WM, Donne SW, Brand HEA, Sharma N. Using in situ synchrotron x-ray diffraction to study lithium- and sodium-ion batteries: A case study with an unconventional battery electrode $\left(\mathrm{Gd}_{2} \mathrm{TiO}_{5}\right)$. J Mater Res 2015;30:381-9. DOI

224. Wu H, Zheng G, Liu N, Carney TJ, Yang Y, Cui Y. Engineering empty space between Si nanoparticles for lithium-ion battery anodes. Nano Lett 2012;12:904-9. DOI PubMed

225. Xia J, Zhao H, Pang WK, et al. Lanthanide doping induced electrochemical enhancement of $\mathrm{Na}_{2} \mathrm{Ti}_{3} \mathrm{O}_{7}$ anodes for sodium-ion batteries. Chem Sci 2018;9:3421-5. DOI PubMed PMC

226. El-metwaly F, Abou-sekkina M, Saad F, Khedr A. Synthesis, effect of $\gamma$-ray and electrical conductivity of uranium doped nano LiMn2O4 spinels for applications as positive electrodes in Li-ion rechargeable batteries. Mater Sci-Poland 2014;32:571-7. DOI

227. Gogotsi Y. What nano can do for energy storage. ACS Nano 2014;8:5369-71. DOI PubMed

228. Augustyn V, Come J, Lowe MA, et al. High-rate electrochemical energy storage through Li+ intercalation pseudocapacitance. Nat Mater 2013;12:518-22. DOI PubMed

229. Xie Y, Dall'Agnese Y, Naguib M, et al. Prediction and characterization of MXene nanosheet anodes for non-lithium-ion batteries. ACS Nano 2014;8:9606-15. DOI PubMed

230. Chen J, Song W, Hou H, et al. $\mathrm{Ti}^{3+}$ self-doped dark rutile $\mathrm{TiO}_{2}$ ultrafine nanorods with durable high-rate capability for lithium-ion batteries. Adv Funct Mater 2015;25:6793-801. DOI

231. Seh ZW, Yu JH, Li W, et al. Two-dimensional layered transition metal disulphides for effective encapsulation of high-capacity lithium sulphide cathodes. Nat Commun 2014;5:5017. DOI PubMed

232. Chhowalla M, Shin HS, Eda G, Li LJ, Loh KP, Zhang H. The chemistry of two-dimensional layered transition metal dichalcogenide nanosheets. Nat Chem 2013;5:263-75. DOI PubMed 
233. Coleman JN, Lotya M, O’Neill A, et al. Two-dimensional nanosheets produced by liquid exfoliation of layered materials. Science 2011;331:568-71. DOI PubMed

234. Naguib M, Kurtoglu M, Presser V, et al. Two-dimensional nanocrystals produced by exfoliation of Ti3 AlC2. Adv Mater 2011:23:4248-53. DOI PubMed

235. Shein IR, Ivanovskii AL. Graphene-like nanocarbides and nanonitrides of d metals (MXenes): synthesis, properties and simulation. Micro Nano Lett 2013;8:59-62. DOI

236. Tang H, Hu Q, Zheng M, et al. MXene-2D layered electrode materials for energy storage. Prog Nat Sci 2018;28:133-47. DOI

237. Li J, Guo C, Li CM. Recent advances of two-dimensional (2D) MXenes and phosphorene for high-performance rechargeable batteries. ChemSusChem 2020;13:1047-70. DOI

238. Kurtoglu M, Naguib M, Gogotsi Y, Barsoum MW. First principles study of two-dimensional early transition metal carbides. MRS Commun 2012;2:133-7. DOI

239. Zhou J, Zha X, Chen FY, et al. A two-dimensional zirconium carbide by selective etching of $\mathrm{Al}_{3} \mathrm{C}_{3}$ from nanolaminated $\mathrm{Zr}_{3} \mathrm{Al}_{3} \mathrm{C}_{5}$. Angew Chem Int Ed Engl 2016;55:5008-13. DOI PubMed

240. Li N, Jiang Y, Zhou C, et al. High-performance humidity sensor based on urchin-like composite of $\mathrm{Ti}_{3} \mathrm{C}_{2} \mathrm{MXene}_{\mathrm{C}}-\mathrm{derived} \mathrm{TiO}_{2}$ nanowires. ACS Appl Mater Interfaces 2019;11:38116-25. DOI PubMed

241. Mashtalir O, Naguib M, Mochalin VN, et al. Intercalation and delamination of layered carbides and carbonitrides. Nat Commun 2013;4:1716. DOI PubMed

242. Zhou J, Zha X, Zhou X, et al. Synthesis and electrochemical properties of two-dimensional hafnium carbide. ACS Nano 2017;11:3841-50. DOI PubMed

243. Ahmed B, Anjum DH, Gogotsi Y, Alshareef HN. Atomic layer deposition of $\mathrm{SnO}_{2}$ on MXene for Li-ion battery anodes. Nano Energy 2017;34:249-56. DOI

244. Zhang Z, Guo H, Li W, Liu G, Zhang Y, Wang Y. Sandwich-like $\mathrm{Co}_{3} \mathrm{O}_{4} /$ MXene composites as high capacity electrodes for lithiumion batteries. New J Chem 2020;44:5913-20. DOI

245. Lin Z, Sun D, Huang Q, Yang J, Barsoum MW, Yan X. Carbon nanofiber bridged two-dimensional titanium carbide as a superior anode for lithium-ion batteries. J Mater Chem A 2015;3:14096-100. DOI

246. Mashtalir O, Lukatskaya MR, Zhao MQ, Barsoum MW, Gogotsi Y. Amine-assisted delamination of $\mathrm{Nb}_{2} \mathrm{C}$ MXene for Li-ion energy storage devices. Adv Mater 2015;27:3501-6. DOI PubMed

247. Ren CE, Zhao M, Makaryan T, et al. Porous two-dimensional transition metal carbide (MXene) flakes for high-performance Li-ion storage. ChemElectroChem 2016;3:689-93. DOI

248. Wu X, Wang Z, Yu M, Xiu L, Qiu J. Stabilizing the MXenes by carbon nanoplating for developing hierarchical nanohybrids with efficient lithium storage and hydrogen evolution capability. Adv Mater 2017;29:1607017. DOI PubMed

249. Rakhi RB, Ahmed B, Anjum D, Alshareef HN. Direct chemical synthesis of $\mathrm{MnO}_{2}$ nanowhiskers on transition-metal carbide surfaces for supercapacitor applications. ACS Appl Mater Interfaces 2016;8:18806-14. DOI PubMed

250. Huang H, Cui J, Liu G, Bi R, Zhang L. Carbon-coated $\mathrm{MoSe}_{2} /$ MXene hybrid nanosheets for superior potassium storage. ACS Nano 2019;13:3448-56. DOI PubMed

251. Schedy A, Quarthal D, Oetken M. Graphene - exciting insights into the synthesis and chemistry of the miracle material of the $21^{\text {st }}$ century and its implementation in chemistry lessons for the first time. WJCE 2018;6:43-53. DOI

252. Brodie BC. On the atomic weight of graphite. Phil Trans R Soc 1859;149:249-59. DOI PubMed

253. Andre Mkhoyan K, Contryman AW, Silcox J, et al. Atomic and electronic structure of graphene-oxide. Nano Lett 2009;9:1058-63. DOI PubMed

254. Yoo E, Kim J, Hosono E, Zhou HS, Kudo T, Honma I. Large reversible Li storage of graphene nanosheet families for use in rechargeable lithium ion batteries. Nano Lett 2008;8:2277-82. DOI PubMed

255. Li B, Cao H, Shao J, Li G, Qu M, Yin G. $\mathrm{Co}_{3} \mathrm{O}_{4} @$ graphene composites as anode materials for high-performance lithium ion batteries. Inorg Chem 2011;50:1628-32. DOI PubMed

256. Su D, Ahn HJ, Wang G. $\mathrm{SnO}_{2} @$ graphene nanocomposites as anode materials for Na-ion batteries with superior electrochemical performance. Chem Commun (Camb) 2013;49:3131-3. DOI PubMed

257. Berchmans S, Bandodkar AJ, Jia W, Ramírez J, Meng YS, Wang J. An epidermal alkaline rechargeable Ag-Zn printable tattoo battery for wearable electronics. J Mater Chem A 2014;2:15788-95. DOI

258. Xia X, Obrovac MN, Dahn JR. Comparison of the reactivity of NaxC6 and LixC6 with non-aqueous solvents and electrolytes. Electrochem Solid-State Lett 2011;14:A130. DOI

259. Chen Y, Kang Y, Zhao Y, et al. A review of lithium-ion battery safety concerns: The issues, strategies, and testing standards. $J$ Energy Chem 2021;59:83-99. DOI

260. Wu W, Wang S, Wu W, Chen K, Hong S, Lai Y. A critical review of battery thermal performance and liquid based battery thermal management. Energy Convers Manag 2019;182:262-81. DOI

261. Finegan DP, Darst J, Walker W, et al. Modelling and experiments to identify high-risk failure scenarios for testing the safety of lithium-ion cells. J Power Sources 2019;417:29-41. DOI

262. Cao D, Sun X, Li Q, Natan A, Xiang P, Zhu H. Lithium dendrite in all-solid-state batteries: growth mechanisms, suppression strategies, and characterizations. Matter 2020;3:57-94. DOI

263. Maleki H, Deng G, Anani A, Howard J. Thermal stability studies of Li-ion cells and components. J Electrochem Soc 1999;146:32249. DOI

264. Masias A, Marcicki J, Paxton WA. Opportunities and challenges of lithium ion batteries in automotive applications. ACS Energy Lett 
2021;6:621-30. DOI

265. Weber R, Genovese M, Louli AJ, et al. Long cycle life and dendrite-free lithium morphology in anode-free lithium pouch cells enabled by a dual-salt liquid electrolyte. Nat Energy 2019;4:683-9. DOI

266. Kamaya N, Homma K, Yamakawa Y, et al. A lithium superionic conductor. Nat Mater 2011;10:682-6. DOI PubMed

267. Masias A, Felten N, Sakamoto J. Characterizing the mechanical behavior of lithium in compression. J Mater Res 2021;36:729-39. DOI

268. Hatzell KB, Chen XC, Cobb CL, et al. Challenges in lithium metal anodes for solid-state batteries. ACS Energy Lett 2020;5:922-34. DOI

269. Hitz GT, Mcowen DW, Zhang L, et al. High-rate lithium cycling in a scalable trilayer Li-garnet-electrolyte architecture. Mater Today 2019;22:50-7. DOI

270. Ely T, Kamzabek D, Chakraborty D. Batteries safety: recent progress and current challenges. Front Energy Res 2019;7:71. DOI

271. Sendek AD, Cubuk ED, Antoniuk ER, Cheon G, Cui Y, Reed EJ. Machine learning-assisted discovery of solid Li-ion conducting materials. Chem Mater 2019;31:342-52. DOI 